\title{
Coupled, Physics-Based Modeling Reveals Earthquake Displacements are Critical to the 2018 Palu, Sulawesi Tsunami
}

\author{
T. Ulrich, ${ }^{1}$ (D) S. Vater, ${ }^{2}$ E. H. Madden, ${ }^{1,3}$ J. Behrens, ${ }^{4}$ Y. van Dinther,${ }^{5}$ I. van Zelst, ${ }^{6}$ E. J. Fielding, ${ }^{7}$ \\ C. LiAng, ${ }^{8}$ and A.-A. GABriel ${ }^{1}$
}

\begin{abstract}
The September 2018, $M_{w} 7.5$ Sulawesi earthquake occurring on the Palu-Koro strike-slip fault system was followed by an unexpected localized tsunami. We show that direct earthquakeinduced uplift and subsidence could have sourced the observed tsunami within Palu Bay. To this end, we use a physics-based, coupled earthquake-tsunami modeling framework tightly constrained by observations. The model combines rupture dynamics, seismic wave propagation, tsunami propagation and inundation. The earthquake scenario, featuring sustained supershear rupture propagation, matches key observed earthquake characteristics, including the moment magnitude, rupture duration, fault plane solution, teleseismic waveforms and inferred horizontal ground displacements. The remote stress regime reflecting regional transtension applied in the model produces a combination of up to $6 \mathrm{~m}$ left-lateral slip and up to $2 \mathrm{~m}$ normal slip on the straight fault segment dipping $65^{\circ}$ East beneath Palu Bay. The time-dependent, 3D seafloor displacements are translated into bathymetry perturbations with a mean vertical offset of $1.5 \mathrm{~m}$ across the submarine fault segment. This sources a tsunami with wave amplitudes and periods that match those measured at the Pantoloan wave gauge and inundation that reproduces observations from field surveys. We conclude that a source related to earthquake displacements is probable and that landsliding may not have been the primary source of the tsunami. These results have important implications for submarine strike-slip fault systems worldwide. Physics-based modeling offers rapid response specifically in tectonic settings that
\end{abstract}

1 Department of Earth and Environmental Sciences, LudwigMaximilians-Universität München, Munich, Germany. E-mail: ulrich@geophysik.uni-muenchen.de

2 Institute of Mathematics, Freie Universität Berlin, Berlin, Germany.

3 Observatório Sismológico, Instituto de Geociências, Universidade de Brasília, Brasilia, Brazil.

4 Numerical Methods in Geosciences, Department of Mathematics, Universität Hamburg, Hamburg, Germany.

5 Department of Earth Sciences, Utrecht University, Utrecht, The Netherlands.

6 Seismology and Wave Physics, Department of Earth Sciences, Institute of Geophysics, ETH Zürich, Zürich, Switzerland.

7 Jet Propulsion Laboratory, California Institute of Technology, Pasadena, CA, USA.

8 Seismological Laboratory, California Institute of Technology, Pasadena, CA, USA. are currently underrepresented in operational tsunami hazard assessment.

Key words: Sulawesi, tsunami, earthquake dynamics, coupled model, physics-based modeling, strike slip.

\section{Introduction}

Tsunamis occur due to abrupt perturbations to the water column, usually caused by the seafloor deforming during earthquakes or submarine landslides. Devastating tsunamis associated with submarine strike-slip earthquakes are rare. While such events may trigger landslides that in turn trigger tsunamis, the associated ground displacements are predominantly horizontal, not vertical, which does not favor tsunami genesis.

However, strike-slip fault systems in complex tectonic regions, such as the Palu-Koro fault zone cutting across the island of Sulawesi, may host vertical deformation. For example, a transtensional tectonic regime can favour strike-slip faulting overall, while also inducing normal faulting. Strike-slip systems may also include complicated fault geometries, such as non-vertical faults, bends or en echelon stepover structures. These can host complex rupture dynamics and produce a variety of displacement patterns when ruptured, which may promote tsunami generation (Legg and Borrero 2001; Borrero et al. 2004).

To mitigate the commonly under-represented hazard of strike-slip induced tsunamis, it is crucial to fundamentally understand the direct effect of coseismic displacements on tsunami genesis. Globally, geological settings similar to that governing the 
Sulawesi earthquake-tsunami sequence are not unique. Large strike-slip faults crossing off-shore and running through narrow gulfs include the elongated Bodega and Tomales bays in northern California, USA, hosting major segments of the right-lateral strike-slip San Andreas fault system, and the leftlateral Anatolian fault system in Turkey, extending beneath the Marmara Sea just south of Istanbul. Indeed, historical data do record local tsunamis generated from earthquakes along these and other strike-slip fault systems, such as in the 1906 San Francisco (California), 1994 Mindoro (Philippines), and 1999 Izmit (Turkey) earthquakes (Legg et al. 2003) and, more recently, the 2016 Kaikoura, New Zealand earthquake (Ulrich et al. 2019; Power et al. 2017). Large magnitude strike-slip earthquakes can also produce tsunamigenic aftershocks (e.g., Geist and Parsons 2005).

In most tsunami modelling approaches, the tsunami source is computed according to the approach of Mansinha and Smylie (1971) and subsequently parameterized by the Okada model (Okada 1985), which translates finite fault models into seafloor displacements. Okada's model allows for the analytical computation of static ground displacements generated by a uniform dislocation over a finite rectangular fault assuming a homogeneous elastic half space. Heterogeneous slip can be captured by linking several dislocations in space, and time-dependence is approximated by allowing these dislocations to move in sequence (e.g., Tanioka et al. 2006). While seafloor and coastal topography are ignored, the contribution of horizontal displacements may be additionally accounted for by a filtering approach suggested by Tanioka and Satake (1996), which includes the gradient of local bathymetry. Applying a traditional Okada source to study tsunami genesis is specifically limited for near-field tsunami observations and localized events due to its underlying, simplifying assumptions.

Realistic modeling of earthquakes and tsunamis benefits from physics-based approaches. Kinematic models of earthquake slip are the result of solving data-driven inverse problems. Such models aim to closely fit observations with a large number of free parameters. In contrast, dynamic rupture models aim at reproducing the physical processes that govern the way the fault yields and slides, and are therefore often referred to as 'physics-based'. Finite fault models are affected by inherent non-uniqueness, which may spread via the ground displacement fields to the modeled tsunami genesis. Constraining the kinematics of multi-fault rupture is especially challenging, since initial assumptions on fault geometry strongly affect the slip inversion results. Mechanically viable earthquake source descriptions are provided by dynamic rupture modeling combining spontaneous frictional failure and seismic wave propagation. Dynamic rupture simulations fully coupled to the time-dependent response of an overlying water layer have been performed by Lotto et al. (2017a, b, 2018). These have been instrumental in determining the influence of different earthquake parameters and material properties on coupled systems, but are restricted to 2D. Maeda and Furumura (2013) showcase a fully-coupled 3D modeling framework capable of simultaneously modeling seismic and tsunami waves, but not earthquake rupture dynamics. Ryan et al. (2015) couple a 3D dynamic earthquake rupture model to a tsunami model, but these are restricted to using a static snapshot of the seafloor displacement field as the tsunami source.

In order to capture the physics of the interaction between the Palu earthquake and the subsequent tsunami, we utilize a physics-based, coupled earthquake-tsunami model. While the feasibility of formal dynamic rupture inversion approaches has been demonstrated (e.g. Peyrat et al. 2001; Gallovič et al. 2019a, b), these are limited by the computational cost of each forward dynamic rupture model and therefore rely on model simplifications. In this study, we do not perform a formal dynamic rupture inversion, but constrain the earthquake model by static considerations and few trial dynamic simulations. The forward model of the dynamic earthquake rupture incorporates 3D spatial variation in subsurface material properties, spontaneously developing slip on a complex, non-planar system of 3D faults, off-fault plastic deformation, and the non-linear interaction of frictional failure with seismic waves. The coseismic deformation of the crust generates time-dependent seafloor displacements, which we translate into bathymetry perturbations to source the tsunami. The 
tsunami model solves for non-linear wave propagation and inundation at the coast.

Using this coupled approach, we evaluate the influence of coseismic deformation during the strikeslip Sulawesi earthquake on generating the observed tsunami waves. The physics-based model reveals that the rupture of a fault crossing Palu Bay with a moderate, but wide-spread, component of normal fault slip produces vertical deformation, which can explain the observed tsunami wave amplitudes and inundation elevations.

\section{The 2018 Palu, Sulawesi Earthquake and Tsunami}

\subsection{Tectonic Setting}

The Indonesian island of Sulawesi is located at the triple junction between the Sunda plate, the Australian plate and the Philippine Sea plate (Bellier et al. 2006; Socquet et al. 2006, 2019) (Fig. 1a). Convergence of the Philippine and Australian plates toward the Sunda plate is accommodated by subduction and rotation of the Molucca Sea, Banda Sea and Timor plates, leading to complicated patterns of faulting.

In central Sulawesi, the NNW-striking Palu-Koro fault (PKF) and the WNW-striking Matano faults (MF) (Fig. 1a) comprise the Central Sulawesi Fault System. The Palu-Koro fault runs off-shore to the north of Sulawesi through the narrow Palu Bay and is the fault that hosted the earthquake that occurred on 28 September 2018 . With a relatively high slip rate inferred from recent geodetic measurements $(40 \mathrm{~mm} /$ year, Socquet et al. 2006; Walpersdorf et al. 1998) and from geomorphology (upper limit $58 \mathrm{~mm} /$ year, Daryono 2018) and clear evidence for Quaternary activity (Watkinson and Hall 2017), the Palu-Koro fault was presumed to pose a threat to the region (Watkinson and Hall 2017). In addition, four tsunamis associated with earthquakes on the PaluKoro fault have struck the northwest coast of Sulawesi in the past century (1927, 1938, 1968 and 1996) (Pelinovsky et al. 1997; Prasetya et al. 2001).

The complex regional tectonics subject northwestern Sulawesi to transtensional strain (Socquet et al. 2006). Transtension promotes some component of dip-slip faulting on the predominantly strikeslipping Palu-Koro fault (Bellier et al. 2006; Watkinson and Hall 2017) and leads to more complicated surface deformation than is expected from slip along a fault hosting purely strike-slip motion.

\subsection{The 2018 Palu, Sulawesi Earthquake}

The $M_{w} 7.5$ Sulawesi earthquake that occurred on September 28, 2018 ruptured a $180 \mathrm{~km}$ long section of the Palu-Koro fault (Socquet et al. 2019). It nucleated $70 \mathrm{~km}$ north of the city of Palu at shallow depths, with inferred hypocentral depths varying between 10 and $22 \mathrm{~km}$ (Valkaniotis et al. 2018). The rupture propagated predominantly southward, passing under Palu Bay and the city of Palu. It arrested after a total rupture time of 30-40 s (Socquet et al. 2019; Okuwaki et al. 2018; Bao et al. 2019). The earthquake was well-captured by satellite data and inversions of these data by Socquet et al. (2019) return several locations of dip-slip offset along the rupture, including within Palu Bay. Similarly, Song et al. (2019) reveal predominantly left-lateral, strikeslip faulting on relatively straight, connected fault segments with a component of dip-slip offset. Song et al. (2019) also suggest possible rupture on a secondary normal fault north of Palu Bay.

The earthquake appears to have propagated at a supershear rupture speed, i.e., faster than the shear waves produced by the earthquake are able to travel through the surrounding rock (e.g., Socquet et al. 2019; Bao et al. 2019; Mai 2019). Socquet et al. (2019) note that the characteristics of the relatively straight, clear rupture trace south of the Bay, with few aftershocks, match those for which supershear rupture speeds have been inferred in other earthquakes. Using back-projection analysis, which maps the location and timing of earthquake energy from the waves recorded on distant seismic arrays, Bao et al. (2019) do not resolve any portion of the rupture as traveling at sub-Rayleigh speeds. The authors conclude that this fast rupture velocity began at, or soon after, earthquake nucleation and was sustained for the length of the rupture. Surprisingly, Bao et al. (2019) infer supershear rupture speeds at the lower end of speeds considered theoretically stable, possibly due 
(a)

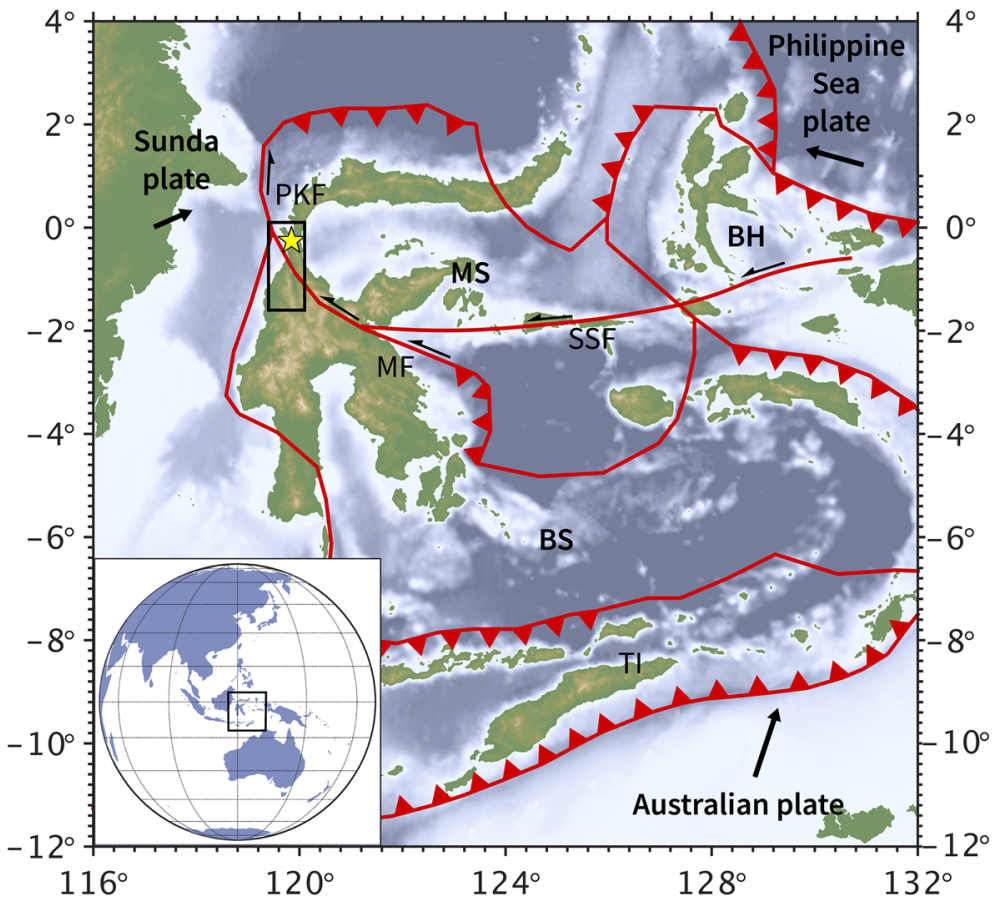

(b) $\begin{array}{ll}119.5^{\circ} & 120.0^{\circ}\end{array}$

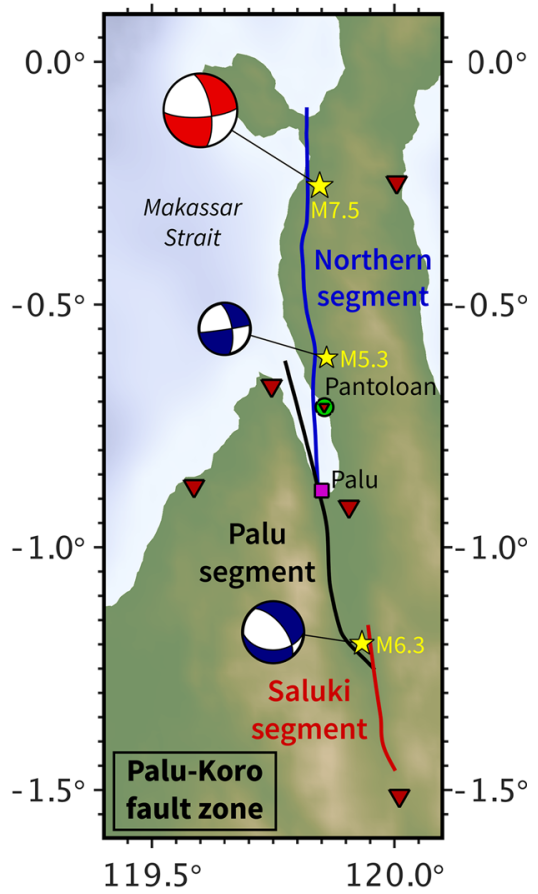

(c) $119.5^{\circ}$

$120.0^{\circ}$

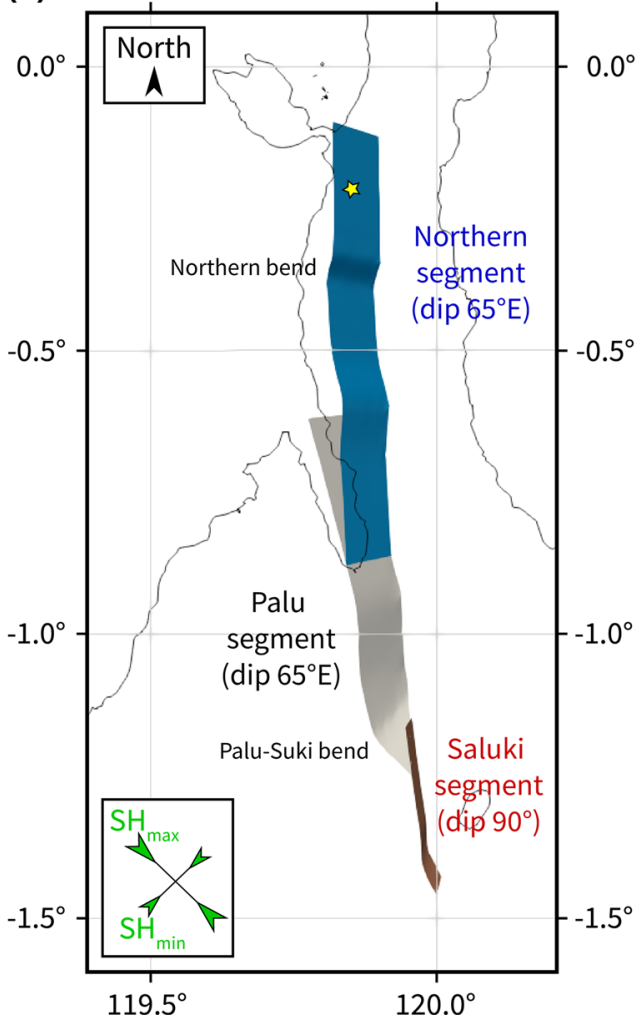

(d)

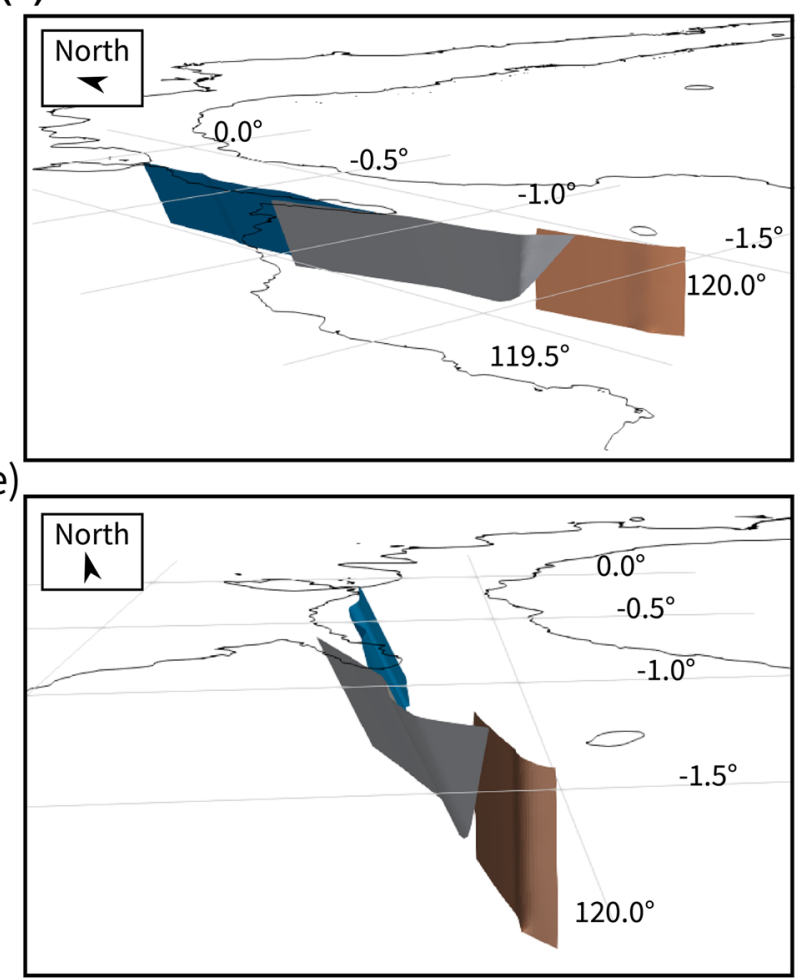


Figure 1

a Tectonic setting of the September 28, $2018 M_{w} 7.5$ Sulawesi earthquake (epicenter indicated by yellow star). Black lines indicate plate boundaries based on Bird (2003); Socquet et al. (2006); Argus et al. (2011). BH Bird's Head plate, $B S$ Banda Sea plate, $M F$ Matano fault zone, $P K F$ Palu-Koro fault zone, $M S$ Molucca Sea plate, SSF Sula-Sorong fault zone, TI Timor plate. Arrows indicate the far-field plate velocities with respect to Eurasia (Socquet et al. 2006). The black box corresponds to the region displayed in b. b A zoom of the region of interest. The site of the harbor tide gauge of Pantoloan is indicated as well as the city of Palu. Locations of the GPS stations at which we provide synthetic ground displacement time series (see Appendix 7.2) are indicated by the red triangles. Focal mechanisms and epicenters of the September 28, 2018 Palu earthquake (USGS (2018a), top), October 1, 2018 Palu aftershock (middle), and January 23, 2005 Sulawesi earthquake (bottom) are shown. These later two events provide constraints on the dip angles of individual segments of the fault network. Individual fault segments of the Palu-Koro fault used in the dynamic rupture model are coloured. c, d, e 3D model of the fault network viewed from top, SW and S

to the influence of widespread, pre-existing damage around the fault. While the exact speed, point of onset, and underlying mechanics of this event's supershear rupture propagation remain to be studied further, it will initiate re-assessment of the hazard associated with supershear rupture on strike-slip faults worldwide, with respect to the potential intensification of shaking.

\subsection{The Induced Tsunami}

The Palu earthquake triggered a local but powerful tsunami that devastated the coastal area of Palu Bay quickly after the earthquake. Inundation depths of over $6 \mathrm{~m}$ and run-up heights of over $9 \mathrm{~m}$ were recorded at specific locations (e.g. Yalciner et al. 2018). At the only tide gauge with available data, located at Pantoloan harbor, a trough-to-peak wave amplitude of almost $4 \mathrm{~m}$ was recorded just $5 \mathrm{~min}$ after the rupture (Muhari et al. 2018). In Ngapa (Wani), on the northeastern shore of Palu Bay, CCTV coverage show the arrival of the tsunami wave after only $3 \mathrm{~min}$.

Coseismic subsidence and uplift, as well as submarine and coastal landsliding, have been suggested as causes of the tsunami in Palu Bay (Heidarzadeh et al. 2018). Both displacements and landsliding are documented on land (Valkaniotis et al. 2018; Løvholt et al. 2018; Sassa and Takagawa 2019), and also at coastal slopes (Yalciner et al. 2018).

Early tsunami models of the Sulawesi event performed using Okada's solution in combination with the USGS finite fault model (USGS 2018b) do not generate tsunami amplitudes large enough to agree with observations (Heidarzadeh et al. 2018; Sepulveda et al. 2018; Liu et al. 2018; van Dongeren et al. 2018). Liu et al. (2018) and Sepulveda et al. (2018) perform Okada-based tsunami modeling with earthquake sources generated by inverting satellite data, but also produce wave amplitudes that are too small. Reasonable tsunami waves are produced by combining tectonic and hypothetical landslide sources (van Dongeren et al. 2018; Liu et al. 2018). However, the predominantly short wavelengths associated with the observed small scale, localized landsliding (Yalciner et al. 2018) appears to be incompatible with the observed long period tsunami waves (Løvholt et al. 2018).

\section{Physical and Computational Models}

\subsection{Earthquake-Tsunami Coupled Modeling}

Since the earthquake and tsunami communities use different vocabulary, we specify the terminology used throughout this manuscript here. We refer to the complete physical setup, including, e.g., the bathymetry data set, fault structure and the governing equations for an earthquake or tsunami, as a 'physical model'. A computer program discretizing the equations and implementing the numerical workflow is termed a 'computational model'. The result of a computation for a specific event achieved with a computational model and according to a specific physical model is called a 'scenario'. We use 'model' where the use of the term as either physical or computational model is unambiguous.

SeisSol, the computational model used to produce the earthquake scenario (e.g., Dumbser and Käser 2006; Pelties et al. 2014; Uphoff et al. 2017), solves the elastodynamic wave equation for spontaneous dynamic rupture and seismic wave propagation. It 
determines the temporal and spatial evolution of slip on predefined frictional interfaces and the stress and velocity fields throughout the modeling domain. With this approach, the earthquake source is not predetermined, but evolves spontaneously as a consequence of the model's initial conditions and of the timedependent, non-linear processes occurring during the earthquake. Initial conditions include the geometry and frictional strength of the fault(s), the tectonic stress state, and the regional lithological structure. Fault slip evolves as frictional shear failure according to an assigned friction law that controls how the fault yields and slides. Model outputs include spatial and temporal evolution of the earthquake rupture front(s), off-fault plastic strain, surface displacements, and the ground shaking caused by the radiated seismic waves.

SeisSol uses the Arbitrary high-order accurate DERivative Discontinuous Galerkin method (ADERDG). It employs fully non-uniform, unstructured tetrahedral meshes to combine geometrically complex 3D geological structures, nonlinear rheologies, and high-order accurate propagation of seismic waves. Fast time to solution is achieved thanks to end-to-end computational optimization (Breuer et al. 2014; Heinecke et al. 2014; Rettenberger et al. 2016) and an efficient local time-stepping algorithm (Breuer et al. 2016; Uphoff et al. 2017). To this end, dynamic rupture simulations can reach high spatial and temporal resolution of increasingly complex geometrical and physical modelling components (e.g. Bauer et al. 2017; Wollherr et al. 2019). SeisSol is verified with a wide range of community benchmarks, including dipping and branching fault geometries, laboratory derived friction laws, as well as heterogeneous on-fault initial stresses and material properties (de la Puente et al. 2009; Pelties et al. 2012, 2013, 2014; Wollherr et al. 2018) in line with the SCEC/USGS Dynamic Rupture Code Verification exercises (Harris et al. 2011, 2018). SeisSol is freely available (SeisSol website 2019; SeisSol GitHub 2019).

The computational model to generate the tsunami scenario is StormFlash2D, which solves the nonlinear shallow water equations using an explicit RungeKutta discontinuous Galerkin discretization combined with a sophisticated wetting and drying treatment for the inundation at the coast (Vater and
Behrens 2014; Vater et al. 2015, 2017). A tsunami is triggered by a (possibly time-dependent) perturbation of the discrete bathymetry. The shallow water approximation does not account for complex 3D effects such as dispersion and non-hydrostatic effects (e.g., compressive waves). Nevertheless, StormFlash2D allows for stable and accurate simulation of large-scale wave propagation in deep sea, as well as small-scale wave shoaling and inundation at the shore, thanks to a multi-resolution adaptive mesh refinement approach based on a triangular refinement strategy (Behrens et al. 2005; Behrens and Bader 2009). Bottom friction is parameterized through Manning friction by a split-implicit discretization (Liang and Marche 2009). The model's applicability for tsunami events has been validated by a number of test cases (Vater et al. 2019), which are standard for the evaluation of operational tsunami codes (Synolakis et al. 2007).

Coupling between the earthquake and tsunami models is realized through the time-dependent coseismic 3D seafloor displacement field computed in the dynamic earthquake rupture scenario, which is translated into 2D bathymetry perturbations of the tsunami model using the ASCETE framework (Advanced Simulation of Coupled Earthquake and Tsunami Events, Gabriel et al. 2018).

\subsection{Earthquake Model}

The 3D dynamic rupture model of the Sulawesi earthquake requires initial assumptions related to the structure of the Earth, the structure of the fault system, the stress state, and the frictional strength of the faults. These input parameters are constrained by a variety of independent near-source and far-field data sets. Most importantly, we aim to ensure mechanical viability by a systematic approach integrating the observed regional stress state and frictional parameters and including state-of-the-art earthquake physics and fracture mechanics concepts in the model (Ulrich et al. 2019).

\subsubsection{Earth Structure}

The earthquake model incorporates topography and bathymetry data and state-of-the-art information 
about the subsurface structure in the Palu region. Local topography and bathymetry are honored at a resolution of approximately $900 \mathrm{~m}$ (GEBCO 2015; Weatherall et al. 2015). 3D heterogeneous media are included by combining two subsurface velocity data sets at depth (see also Sect. 7.7). A local model by Awaliah et al. (2018), which is built from ambient noise tomography, covers the model domain down to $40 \mathrm{~km}$ depth. In this region, we assume a Poisson medium. The Collaborative Seismic Earth Model (Fichtner et al. 2018) is used for the rest of the model domain down to $150 \mathrm{~km}$.

\subsubsection{Fault Structure}

For this model, we construct a network of non-planar, intersecting crustal faults involved in this earthquake. This includes three major fault segments: the Northern segment, a previously unmapped fault on which the earthquake nucleated, and the Palu and the Saluki segments of the Palu-Koro fault (cf. Fig. 1b-e). We map the fault traces from the horizontal ground displacement field inferred from correlation of Sentinel-2 optical images (De Michele 2019) and from synthetic aperture radar (SAR) data (Bao et al. 2019), which is discussed more below. Differential northsouth offsets clearly delineate the on-land traces of the Palu and Saluki fault segments. The trace of the Northern segment is less well-constrained in both data sets. Nevertheless, we produce a robust map by honoring the clearest features in both data sets and smoothing regions of large variance using QGIS v2.14 (Quantum GIS 2013).

Beneath the Bay, we adopt a relatively simple fault geometry motivated by the on land fault strikes, the homogeneous pattern of horizontal ground deformation east of the Bay (De Michele 2019), which suggests slip on a straight, continuous fault under the Bay, and the absence of direct information available to constrain the rupture's path. We extend the Northern segment southward as a straight line from the point where it enters the Bay to the point where the Palu segment enters the Bay. We extend the Palu segment northward, adopting the same strike that it displays on land to the south of the Bay. This trace deviates a few $\mathrm{km}$ from the mapping reported in Bellier et al (2006, their Fig. 2), both on and off land.
South of the Bay, the modeled segment mostly aligns with the fault as mapped by Watkinson and Hall (2017, their Fig. 5).

We constrain the 3D structure of these faults using focal mechanisms and geodetic data. We assume that the Northern and Palu segments both dip $65^{\circ}$ East, as suggested by the mainshock focal mechanisms $\left(67^{\circ}\right.$, USGS (2018a) and $69^{\circ}$, IPGP (2018), Fig. 1b) and the focal mechanism of the 2018 October 1 st $M_{w} 5.3$ aftershock $\left(67^{\circ}\right.$, BMKG solution, Fig. 1b). This also is consistent with pronounced asymmetric patterns of ground displacement suggesting slip on dipping faults around the city of Palu and the Northern fault segment in both the optical and SAR data. In addition, the eastward dip of the Palu segment on land is consistent with the analysis of Bellier et al. (2006). The southern end of the Palu segment bends towards the Saluki segment and features a dip of $60^{\circ}$ to the northeast, as constrained by the source mechanism of the $2005 M_{w} 6.3$ event (see Fig. 1b). In contrast, we assume that the Saluki segment is vertical. The assigned dip of $90^{\circ}$ is consistent with the inferred ground displacement of comparable amplitude and extent on both sides of this fault segment (De Michele 2019). All faults extend from the surface to a depth of $20 \mathrm{~km}$.

\subsubsection{Stress State}

The fault system is subject to a laterally homogeneous regional stress field with systematic constraints following Ulrich et al. (2019) from seismo-tectonic observations, knowledge of fault fluid pressurization, and the Mohr-Coulomb theory of frictional failure. This is motivated by the fact that the tractions on and strength of natural faults are difficult to quantify. With this approach, only four parameters must be specified to fully describe the state of stress and strength governing the fault system, as further detailed in Appendix 7.3. This systematic approach facilitates rapid dynamic rupture modeling of an earthquake.

Using static considerations and few trial dynamic simulations, we identify an optimal stress configuration for this scenario that simultaneously (i) maximizes the ratio of shear over normal stress across the fault system; (ii) determines shear traction 
orientations that predict surface deformation compatible with the measured ground deformation and focal mechanisms; and (iii) allows dynamic rupture across the fault system's geometric complexities.

The resulting physical model is characterized by a stress regime acknowledging transtensional strain, high fluid pressure, and relatively well oriented, apparently weak faults. The effective confining stress increases with depth by a gradient of $5.5 \mathrm{MPa} / \mathrm{km}$. From 11 to $15 \mathrm{~km}$ depth, we taper the deviatoric stresses to zero, to represent the transition from a brittle to a ductile deformation regime. This depth range is consistent with the $12 \mathrm{~km}$ interseismic locking depth estimated by Vigny et al. (2002).

\subsubsection{Earthquake Nucleation and Fault Friction}

Fault failure is initiated within a highly overstressed circular patch with a radius of $1.5 \mathrm{~km}$ situated at the hypocenter location as inferred by the GFZ $\left(119.86^{\circ} \mathrm{E}, 0.22^{\circ} \mathrm{S}\right.$, at $10 \mathrm{~km}$ depth). This depth is at the shallow end of the range of inferred hypocentral depths (Valkaniotis et al. 2018) and shallower than the modeled brittle-ductile transition, marking the lower limit of the seismogenic zone.

Slip evolves on the fault according to a rapid velocity-weakening friction formulation, which is motivated by laboratory experiments that show strong dynamic weakening at coseismic slip rates (e.g., Di Toro et al. 2011). This formulation reproduces realistic rupture characteristics, such as reactivation and pulse-like behavior, without imposing small-scale heterogeneities (e.g., Dunham et al. 2011; Gabriel et al. 2012). We here use a form of fast-velocity weakening friction proposed in the community benchmark problem TPV104 of the Southern California Earthquake Center (Harris et al. 2018) and as parameterized by Ulrich et al. (2019). Friction drops rapidly from a steady-state, low-velocity friction coefficient, here 0.6 , to a fully weakened friction coefficient, here 0.1 (see Appendix 7.4).

\subsubsection{Model Resolution}

A high resolution computational model is crucial in order to accurately resolve the full dynamic complexity of the earthquake scenario. The required high numerical accuracy is achieved by combining a numerical scheme that is accurate to high-orders and a mesh that is locally refined around the fault network.

The earthquake model domain is discretized into an unstructured computational mesh of 8 million tetrahedral elements. The shortest element edge lengths are $200 \mathrm{~m}$ close to faults. The static mesh resolution is coarsened away from the fault system. Simulating $50 \mathrm{~s}$ of this event using 4th order accuracy in space and time requires about $2.5 \mathrm{~h}$ on 560 Haswell cores of phase 2 of the SuperMUC supercomputer of the Leibniz Supercomputing Centre in Garching, Germany. We point out that running hundreds of such simulations is well within the scope of resources available to typical users of supercomputing centres. All data required to reproduce the earthquake scenario are detailed in Appendix 7.11.

\subsection{Tsunami Model}

The bathymetry and topography for the tsunami model is composed of the high-resolution data set BATNAS (v1.0), provided by the Indonesian Geospatial Data Agency (DEMNAS 2018). This data set has a horizontal resolution of 6 arc seconds (or approximately $190 \mathrm{~m}$ ), and it allows for sufficiently accurate representation of bathymetric features, but is certainly relatively inaccurate with respect to inundation treatment. However, we note that the data set is more accurate than data sets for which the vertical 'rooftop' approach is used, such as typical SRTM data (see, e.g., the accuracy analysis in McAdoo et al. 2007; Kolecka and Kozak 2014).

The coupling between the earthquake and tsunami models is enforced by adding a perturbation, derived from the 3D coseismic seafloor displacements in the dynamic rupture scenario, to the initial 2D bathymetry and topography of the tsunami model. These time-dependent displacement fields are given by the three-dimensional vector $(\Delta x, \Delta y, \Delta z)$. In addition to the vertical displacement $\Delta z$, we incorporate the eastwest and north-south horizontal components, $\Delta x$ and $\Delta y$, into the tsunami source by applying the method proposed by Tanioka and Satake (1996). This is motivated by the potential influence of Palu Bay's steep seafloor slopes (more than 50\%). The ground 


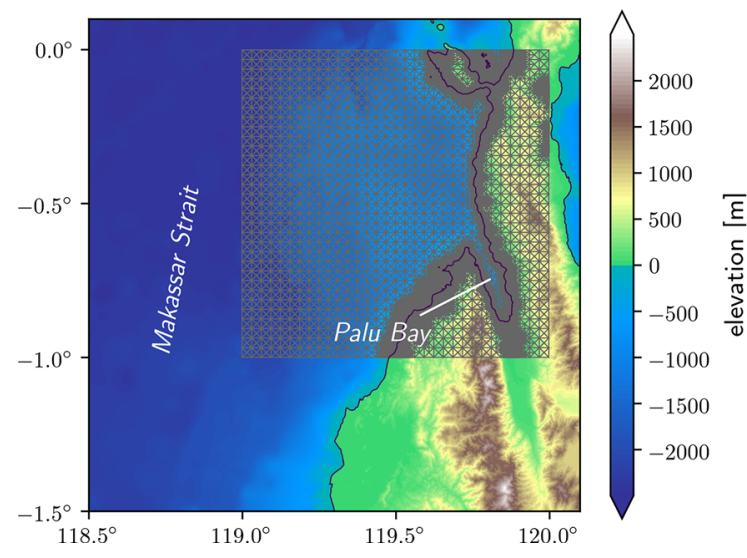

Figure 2

Setup of the tsunami model including high-resolution bathymetry and topography data overlain by the initial adaptive triangular mesh refined near the coast

displacement of the earthquake model is translated into the tsunami generating bathymetry perturbation by

$$
\Delta b=\Delta z-\Delta x \frac{\partial b}{\partial x}-\Delta y \frac{\partial b}{\partial y}
$$

where $b=b(x, y)$ is the bathymetry (increasing in the upward direction). $\Delta b$ is time-dependent, since $\Delta x$, $\Delta y$ and $\Delta z$ are time-dependent. The tsunami is sourced by adding $\Delta b$ to the initial bathymetry and topography of the tsunami model. It should be noted that a comparative scenario using only $\Delta z$ as the bathymetry perturbation (see Appendix 7.5) does not result in large deviations with regards to the preferred model.

The domain of the computational tsunami model (latitudes ranging from $-1^{\circ}$ to $0^{\circ}$, longitudes ranging from $119^{\circ}$ to $120^{\circ}$, see Fig. 2) encompasses Palu Bay and the nearby surroundings in the Makassar Strait, since we here focus on the wave behavior within the Palu Bay. The tsunami model is initialized as an ocean at rest, for which (at $t=0$ ) the initial fluid depth is set in such manner that the sea surface height (ssh, deviation from mean sea level) is equal to zero everywhere in the model domain. Additionally, the fluid velocity is set to zero. This defined initial steady state is then altered by the time-dependent bathymetry perturbation throughout the simulation, which

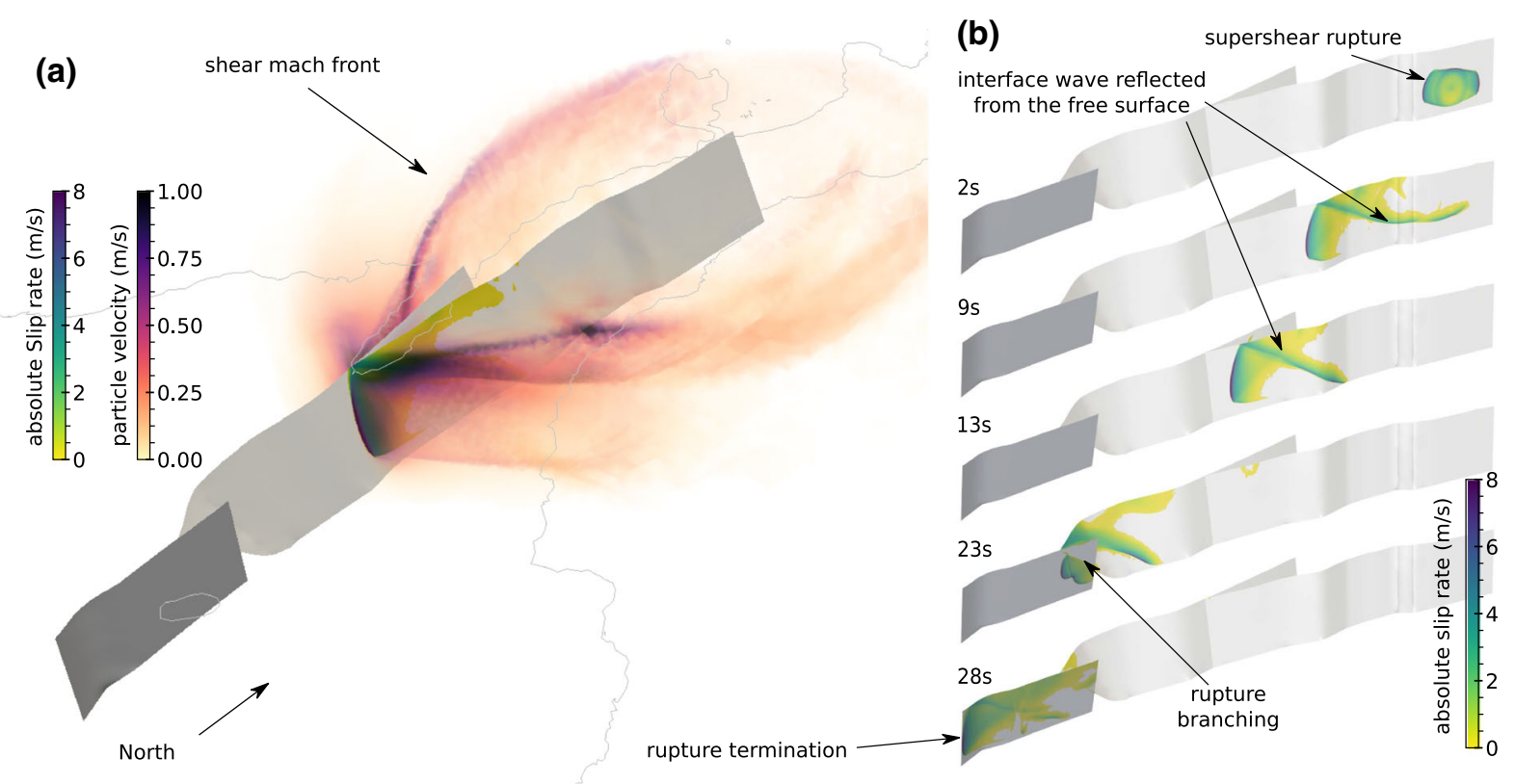

Figure 3

a Snapshot of the wavefield (absolute particle velocity in $\mathrm{m} / \mathrm{s}$ ) and the slip rate (in $\mathrm{m} / \mathrm{s}$ ) across the fault network at a rupture time of $15 \mathrm{~s}$. b Overview of the simulated rupture propagation. Snapshots of the absolute slip rate are shown at a rupture time of 2, 9, 13, 23 and $28 \mathrm{~s}$. Labels indicate noteworthy features of the rupture 
(a)

a)

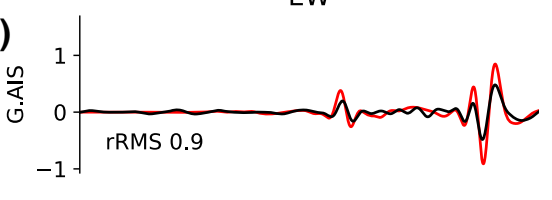

EW

NS

UD
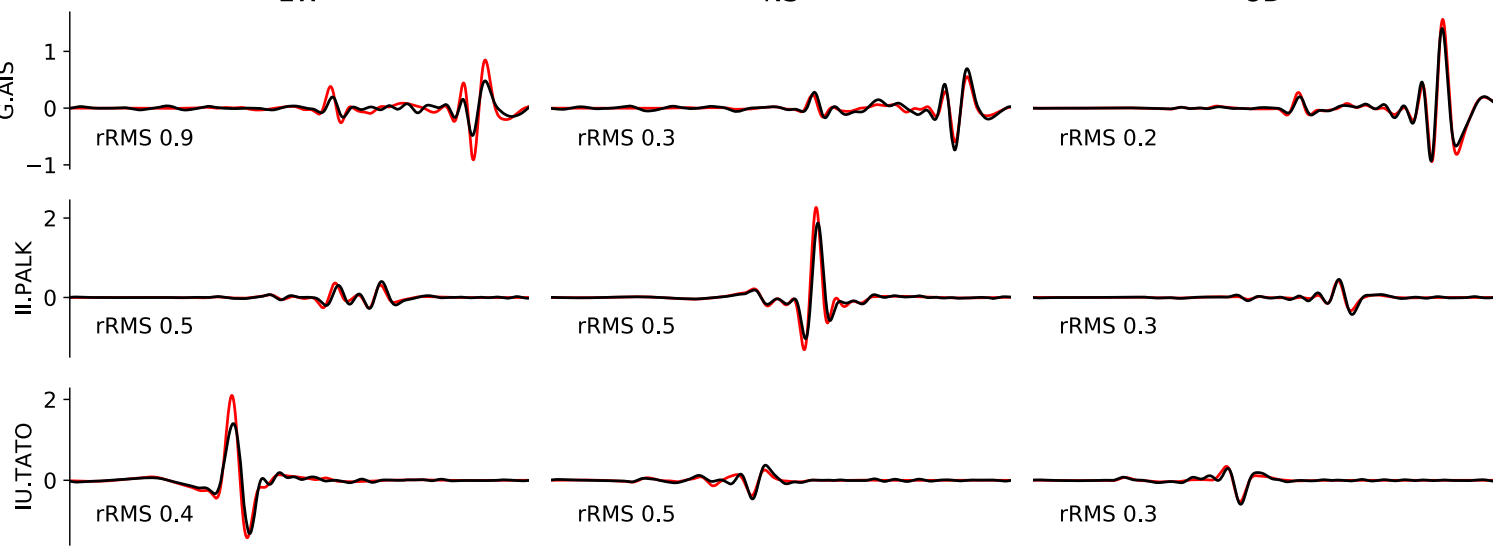

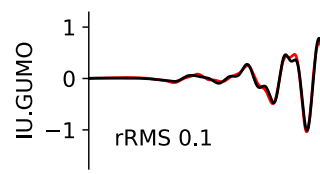
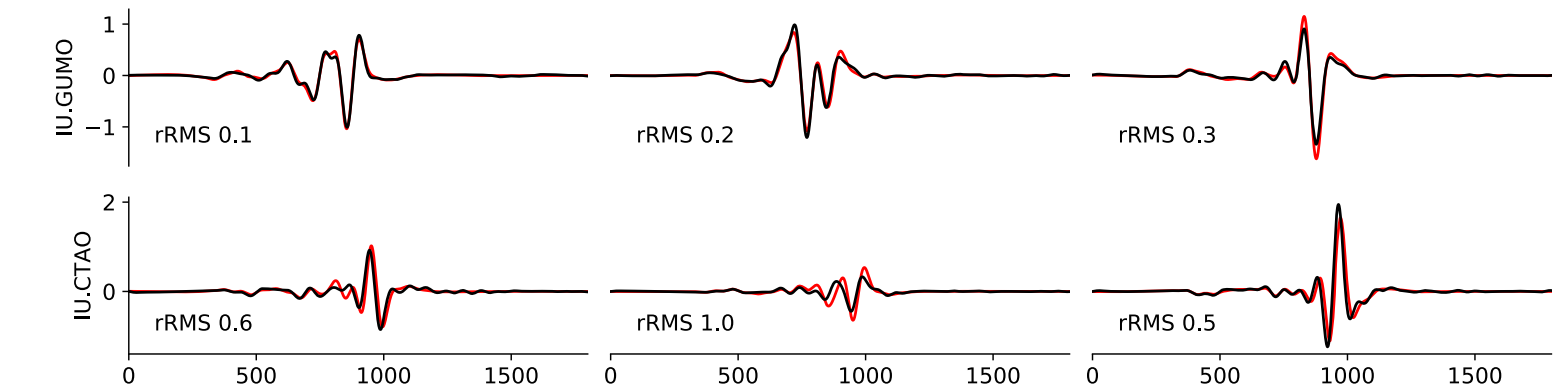

(b)
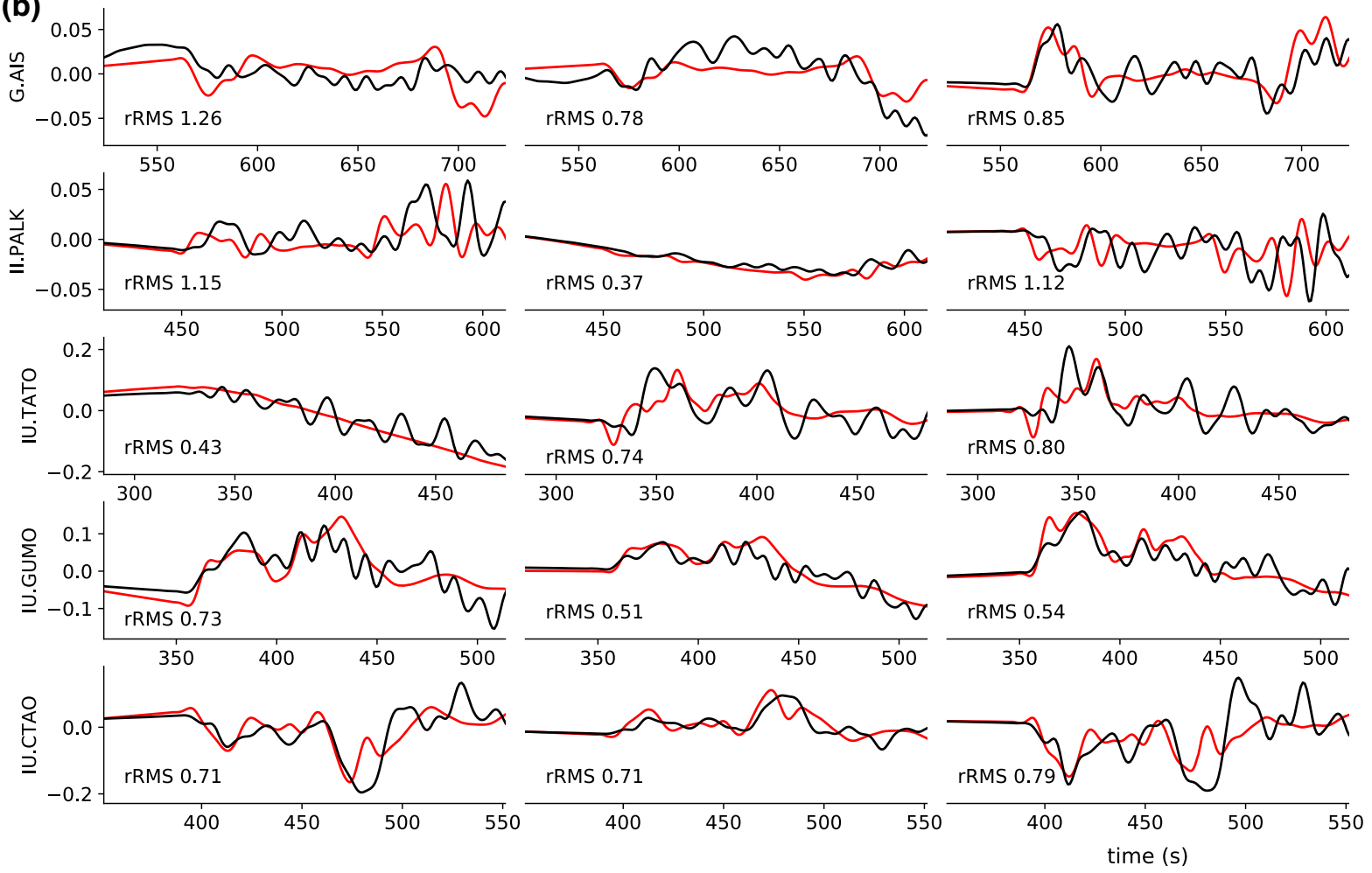
Figure 4

Comparison of modeled (red) and observed (black) teleseismic displacement waveforms. a Full seismograms dominated by surface waves. A 66-450 s band-pass filter is applied to all traces. b Zoom in to body wave arrivals. A $10-450 \mathrm{~s}$ band-pass filter is applied to all traces. Synthetics are generated using Instaseis (Krischer et al. 2017) and the PREM model including anisotropic effects and a maximum period of $2 \mathrm{~s}$. For each panel, a misfit value (rRMS) quantifies the agreement between synthetics and observations. rRMS equal to 0 corresponds to a perfect fit. For more details see Appendix 7.8. Waveforms at 10 additional stations are compared in Figs. 28, 29

triggers the tsunami. The simulation is run for $40 \mathrm{~min}$ (simulation time), which needs 13487 time steps.

The triangle-based computational grid is initially refined near the coast, where the highest resolution within Palu Bay is about 3 arc seconds (or $80 \mathrm{~m}$ ). This results in an initial mesh of 153,346 cells, which expands to more than 300,000 cells during the dynamically adaptive computation. The refinement strategy is based on the gradient in sea surface height.

The parametrization of bottom friction includes the Manning's roughness coefficient $n$. We assume $n=0.03$, which is a typical value for tsunami simulations (Harig et al. 2008).

\section{Results}

In the following, we present the physics-based coupled earthquake and tsunami scenario. We highlight key features and evaluate the model results against seismic and tsunami observations.

\subsection{The Dynamic Earthquake Rupture Scenario: Sustained Supershear Rupture and Normal Slip Component Within Palu Bay}

This earthquake rupture scenario is based on the systematic derivation of initial conditions presented in Sect. 3.2. We evaluate it by comparison of model synthetics with seismological data, geodetic data, and field observations in the near- and far-field.

\subsubsection{Earthquake Rupture}

The dynamic earthquake scenario is characterized by an unilaterally propagating southward rupture (see
Fig. 3 and animations in Appendix 7.10. The rupture nucleates at the northern tip of the Northern segment, then transfers to the Palu segment at the southern end of Palu Bay. Additionally, a shallow portion of the Palu-Koro fault beneath the Bay ruptures from North to South (see inset of Fig. 9a). This segment is dynamically unclamped due to a transient reduction of normal tractions while the rupture passes on the Northern segment. The rupture passes from the Palu segment onto the Saluki segment through a restraining bend at a latitude of $-1.2^{\circ}$. In total, $195 \mathrm{~km}$ of faults are ruptured leading to a $M_{w} 7.6$ earthquake scenario.

\subsubsection{Teleseismic Waves, Focal Mechanism, and Moment Release Rate}

The dynamic rupture scenario satisfactorily reproduces the teleseismic surface waves (Figs. 4a, 28) and body waves (Figs. 4b, 29). Synthetics are generated at 15 teleseismic stations around the event (Fig. 5). Note that the data from these teleseismic stations is not used to build our model, as it is done in classical kinematic models, but to validate the

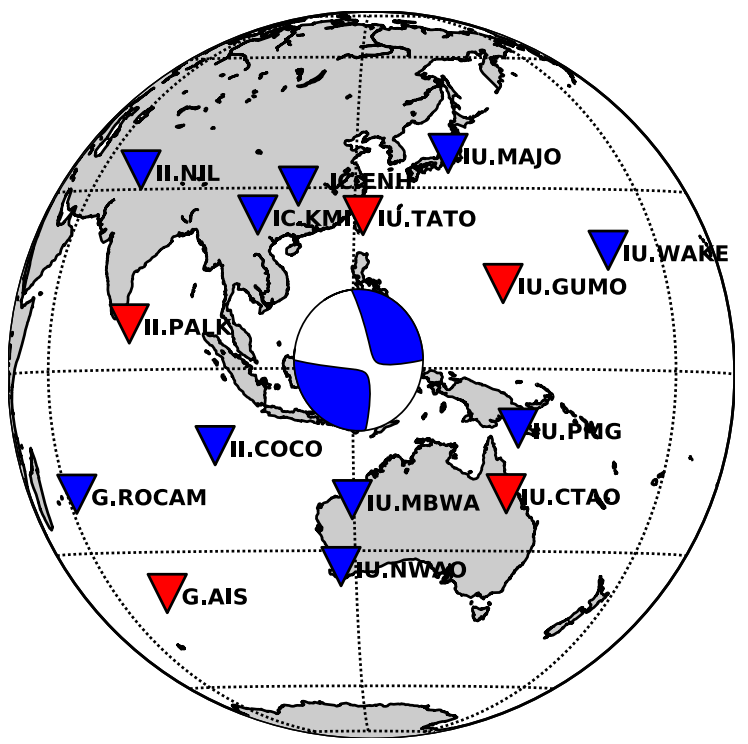

Figure 5

Moment-tensor representation of the dynamic rupture scenario and locations at which synthetic data are compared with observed records (red: stations compared in Fig. 4, blue: stations compared in Figs. 28, 29) 
dynamic rupture scenario a posteriori, by comparing the model results to these measurements. Following Ulrich et al. (2019), we translate the dynamic fault slip time histories of the dynamic rupture scenario into a subset of 40 double couple point sources (20 along strike by 2 along depth). From these sources, broadband seismograms are calculated from a Green's function database using Instaseis (Krischer et al. 2017) and the PREM model (Preliminary Reference Earth Model) for a maximum period of $2 \mathrm{~s}$ and including anisotropic effects. The synthetics agree well with the observed teleseismic signals in terms of both the dominant, long-period surface waves and the body wave signatures.

The focal mechanism of the modeled source is compatible with the one inferred by the USGS (compare in Fig. 1b and Fig. 5). The nodal plane characterizing this model earthquake features strike/ dip/rake angles of $354^{\circ} / 69^{\circ} \%-14^{\circ}$, which are very close to the values of $350^{\circ} / 67^{\circ} /-17^{\circ}$ for the focal plane determined by the USGS.

The dynamically released moment rate is in agreement with source time functions inferred from teleseismic data (Fig 6). The scenario yields a relatively smooth, roughly box-car shaped moment release rate spanning the full rupture duration. This is consistent with the source time function from Okuwaki et al. (2018) and also with the smooth fault slip reported by Socquet et al. (2019). The rupture slows down at the Northern segment restraining bend at $-0.35^{\circ}$ latitude. This resembles the moment rate solutions by the USGS and SCARDEC at $\approx 5 \mathrm{~s}$ rupture time. The transfer of the rupture from the Palu segment to the Saluki segment at $23 \mathrm{~s}$ also produces a transient decrease in the modeled moment release rate, which is discernible in those inferred from observations as well.

\subsubsection{Earthquake Surface Displacements}

We use observations from optical and radar satellites, both sensitive to the horizontal coseismic surface displacements, to validate the outcome of the earthquake scenario (Figs. 7, 8). Along most of the rupture, fault displacements are sharp and linear, highlighting smooth and straight fault orientations with a few bends.

The patterns and magnitudes of the final horizontal surface displacements (black arrows in Fig. 7) are determined from subpixel correlation of coseismic optical images acquired by the Copernicus Sentinel-2 satellites operated by the European Space Agency (ESA) (De Michele 2019). We use both the east-west and north-south components from optical image correlation.

We also infer coseismic surface displacements by incoherent cross correlation of synthetic aperture radar (SAR) images acquired by the Japan Aerospace Exploration Agency (JAXA) Advanced Land Observation Satellite-2 (ALOS-2). SAR can capture

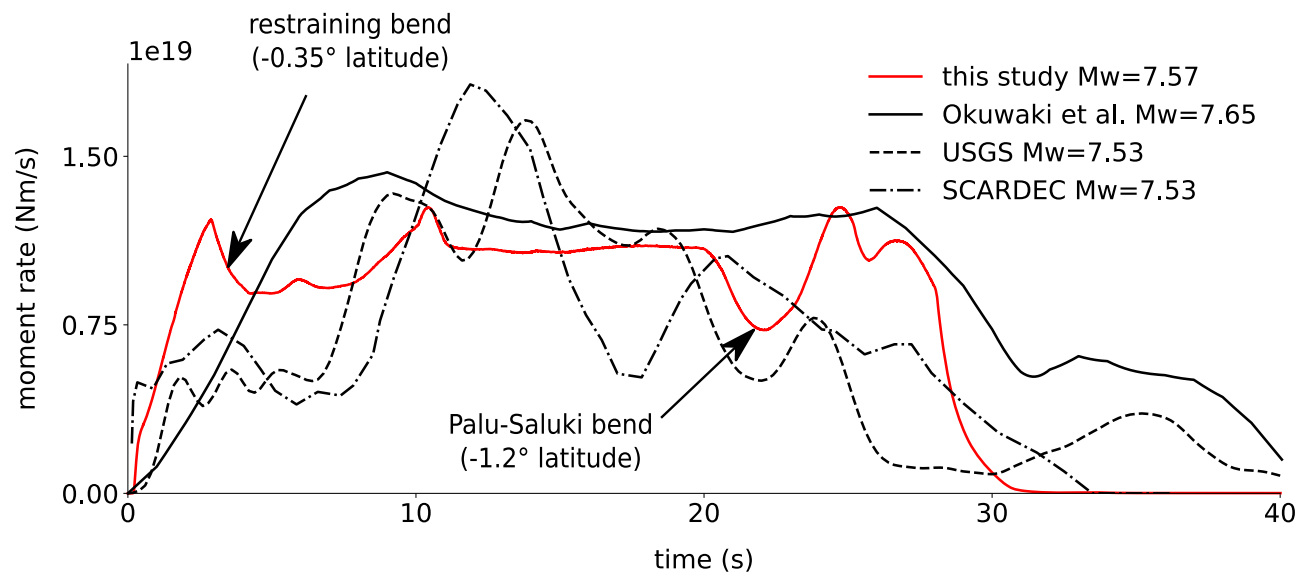

Figure 6

Synthetic moment rate release function compared with those inferred from teleseismic data by Okuwaki et al. (2018), the USGS and the SCARDEC method (optimal solution, Vallée et al. 2011) 


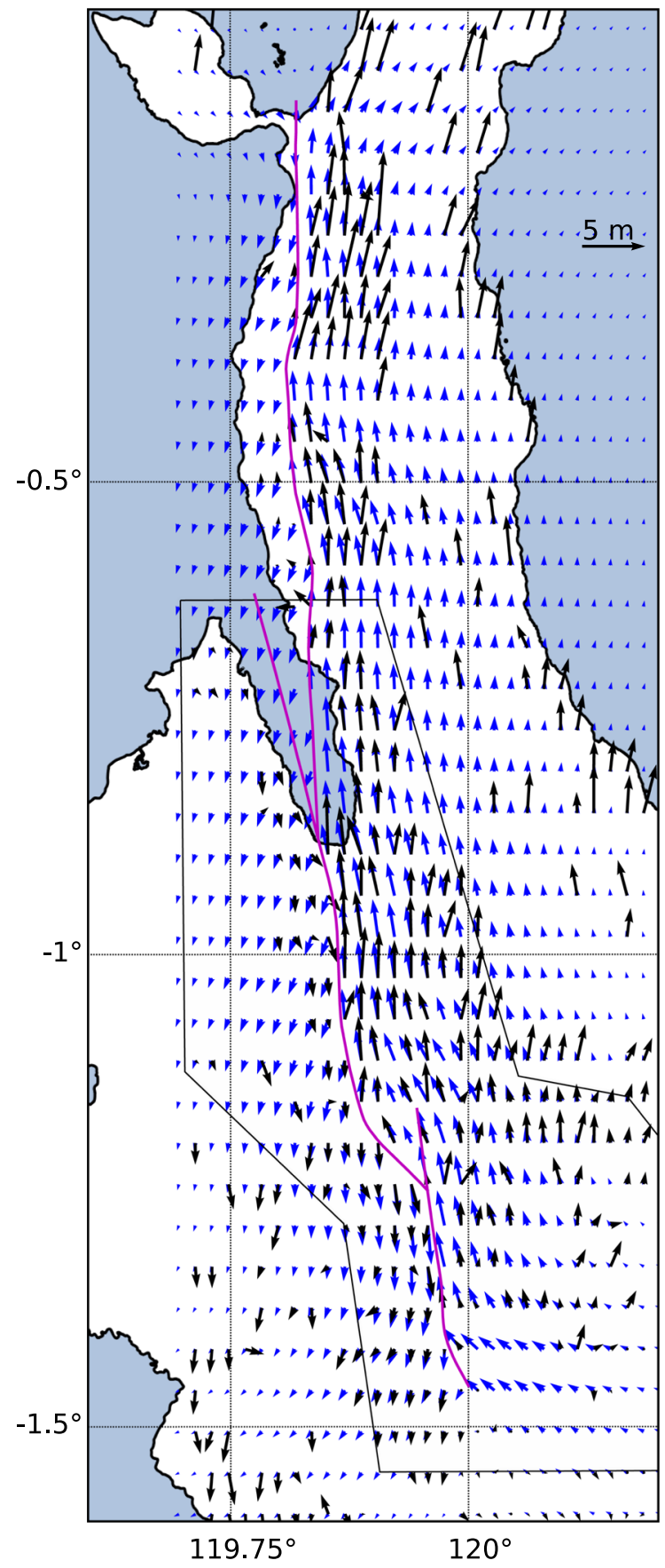

Figure 7

Comparison of the modeled and inferred horizontal surface displacements from subpixel correlation of Sentinel-2 optical images by De Michele (2019). Some parts of large inferred displacements, e.g., north of $-0.5^{\circ}$ latitude, are probably artifacts, because they are not visible in the SAR data (see Fig. 8). The black polygon highlights where an at least first order agreement between SAR and optical data is achieved horizontal surface displacement in the along-track direction and a combination of vertical and horizontal displacement in the slant range direction between the satellite and the ground. Here, we use the along-track horizontal displacements (Fig. 8b), which are nearly parallel to the general strike of the ruptured faults. Further details about the SAR data can be found in Appendix 7.6.

The use of two independent, but partially coinciding, data sets provides insight into data quality. We identify robust features in the imaged surface displacements by projecting the optical data into the along-track direction of the SAR data. The data sets appear to be consistent to first order $( \pm 1 \mathrm{~m})$ in a $30 \mathrm{~km}$ wide area centered on the fault and south of $-0.6^{\circ}$ latitude (region identified in Fig. 7). North of the Bay, we find that the optical displacements are large in magnitude relative to the SAR measurements. Such large displacements continue north of the inferred rupture trace, suggesting a bias in the optical data in this region. These large apparent displacements may be due to partial cloud cover in the optical images or to image misalignment. The east-west component seems unaffected by this problem. Significant differences are also observed near the Palu-Saluki bend. Thus, deviations between model synthetics and observational data in these areas are analyzed with caution.

Overall, the earthquake dynamic rupture scenario matches observed ground displacements well. East of the Palu segment, a good agreement between synthetic displacements and observations is achieved. Horizontal surface displacement vectors predicted by the model are well aligned with and of comparable amplitude to optical observations (Fig. 7). West of the Palu segment, the modeled amplitudes are in good agreement with the SAR (Fig. 8a) and optical data, however the synthetic orientations point to the southwest, whereas the optical data are oriented to the southeast (Fig. 7). While surface displacement orientations around the Saluki segment are reproduced well, amplitudes may be overestimated by about $1 \mathrm{~m}$ on the eastern side of the fault (Fig. 8c). North of the Bay, the modeled amplitudes exceed SAR measurements by about $2 \mathrm{~m}$ (Fig. 8c). Nevertheless, the subtle eastward rotation of the horizontal displacement vectors near the Northern segment bend 

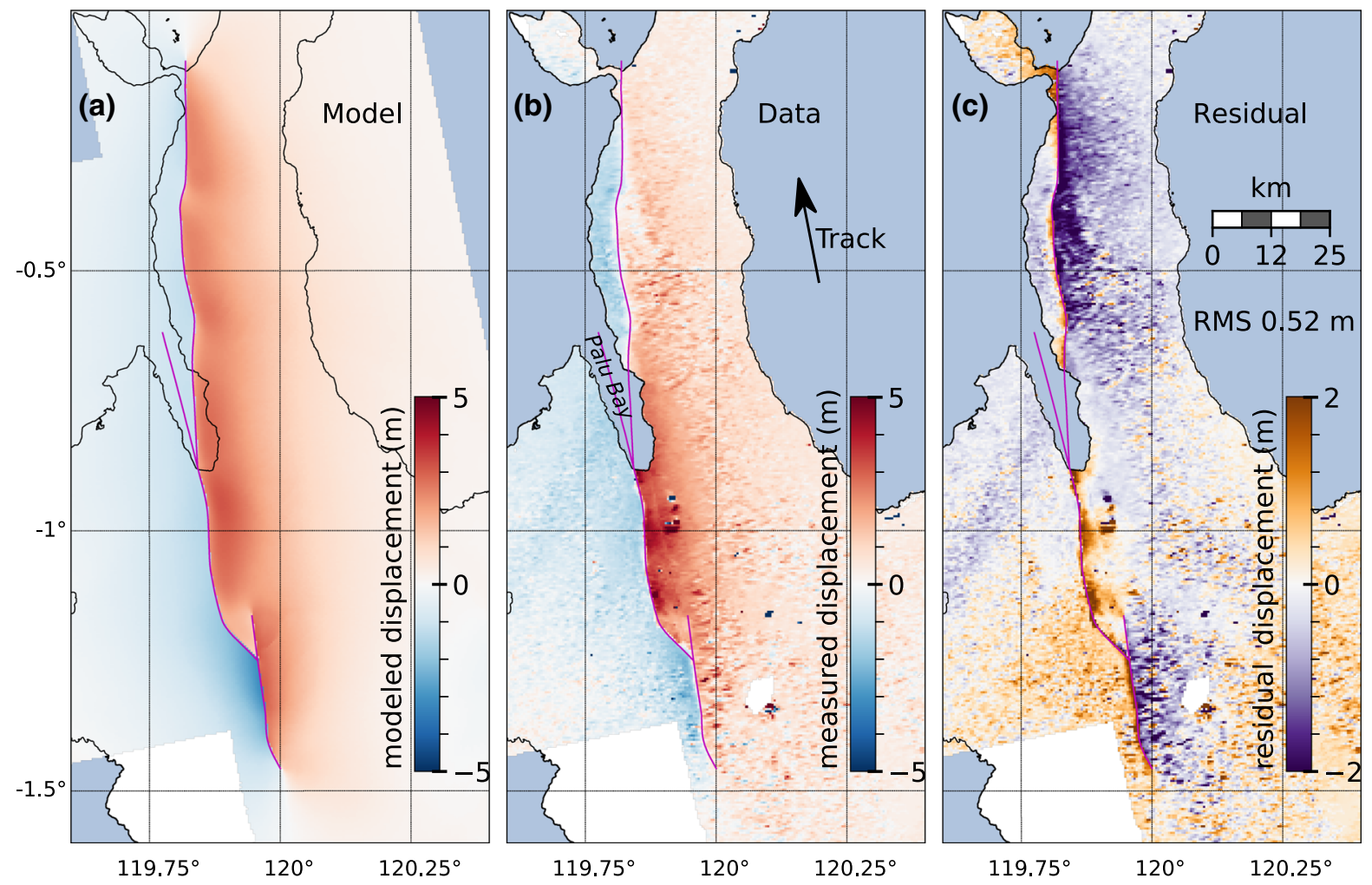

Figure 8

Our a modeled and $\mathbf{b}$ measured ground displacements in the SAR satellite along-track direction (see text). $\mathbf{c}$ Residual $=(\mathbf{b})-(\mathrm{a})$

(at $-0.35^{\circ}$ latitude) is captured well by the scenario (Fig. 7).

\subsubsection{Fault Slip}

The modeled slip distributions and orientations (Fig. 9) are modulated by the geometric complexities of the fault system. On the northern part of the Northern segment, slip is lower than elsewhere along the fault due to a restraining fault bend near $-0.35^{\circ}$ latitude (Fig. 9a). South of this small bend, the slip magnitude increases and remains mostly homogeneous, ranging between 6 and $8 \mathrm{~m}$. Peak slip occurs on the Palu segment.

Over most of the fault network, the faulting mechanism is predominantly strike-slip, but does include a small to moderate normal slip component (Fig. 9b). This dip-slip component varies as a function of fault orientation with respect to the regional stress field. It increases at the junction between the Northern and Palu segment just south of Palu Bay, and at the big bend between the Palu and Saluki fault segments, where dip-slip reaches a maximum of approx. $4 \mathrm{~m}$. Pure strike-slip faulting is modeled on the southern part of the vertical Saluki segment (Fig. 9b). The dip-slip component along the rupture shown in Fig. $9 \mathrm{~b}$ produces subsidence above the hanging wall (east of the fault traces) and uplift above the foot wall (west of the fault traces). The resulting seafloor displacements are further discussed in Sect. 4.2.

\subsubsection{Earthquake Rupture Speed}

The earthquake scenario features an early and persistent supershear rupture velocity (Fig. 9d). This means that the rupture speed exceeds the seismic shear wave velocity $\left(V_{s}\right)$ of $2.5-3.1 \mathrm{~km} / \mathrm{s}$ in the vicinity of the fault network from the onset of the event. This agrees with the inferences for supershear rupture by Bao et al. (2019) from back-projection analyses and by Socquet et al. (2019) from satellite 


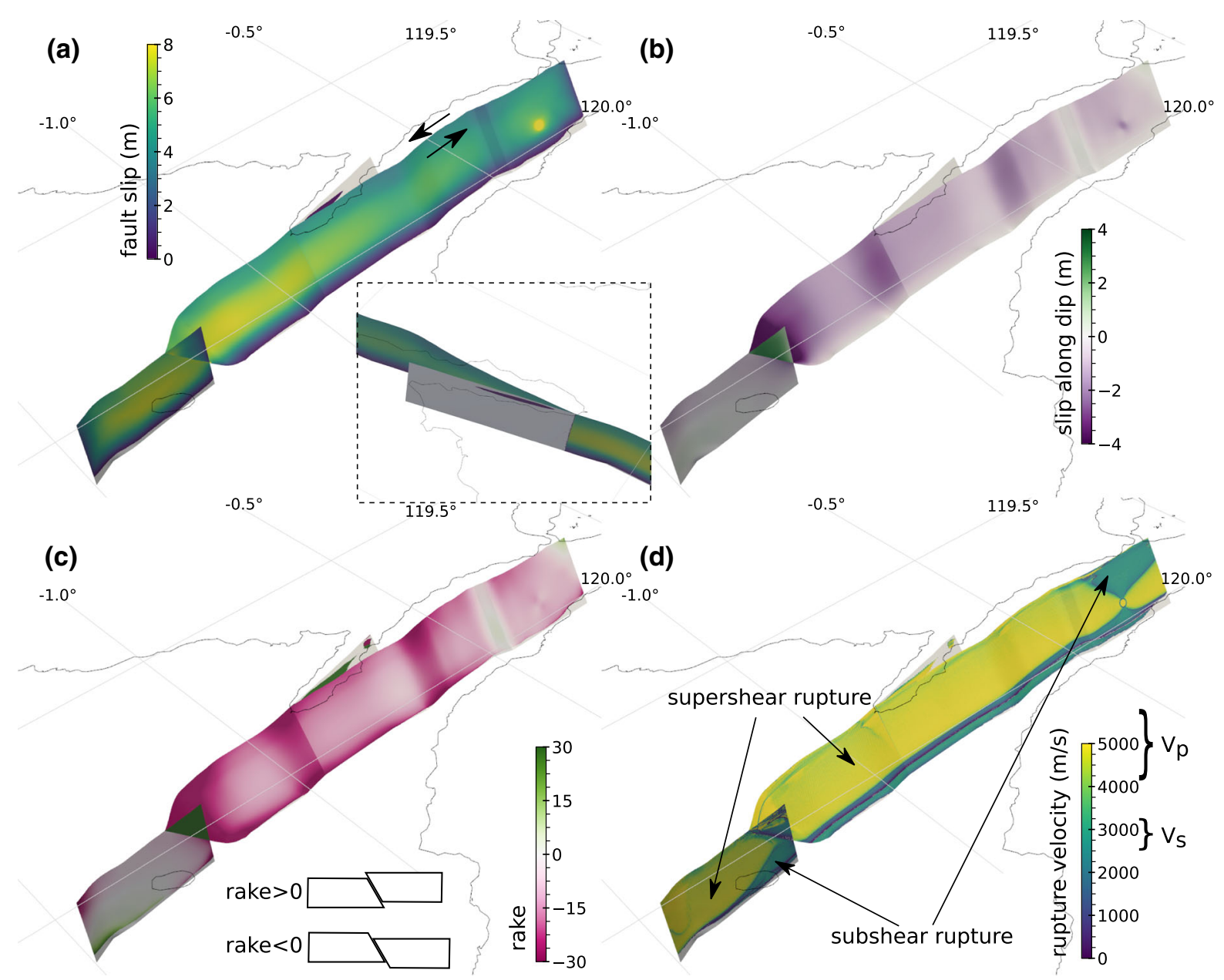

Figure 9

Source properties of the dynamic rupture scenario. a Final slip magnitude. The inset shows the slip magnitude on the main Palu-Koro fault within the Bay. b Dip-slip component. $\mathbf{c}$ Final rake angle. b, $\mathbf{c}$ both illustrate a moderate normal slip component. d Maximum rupture velocity indicating pervasive supershear rupture

data analyses. However, we here infer supershear propagation faster than Eshelby speed $\left(\sqrt{2} V_{s}\right)$, thus faster than Bao et al. (2019) and well within the stable supershear rupture regime (Burridge 1973).

\subsection{Tsunami Propagation and Inundation: An Earthquake-Induced Tsunami}

The surface displacements induced by the earthquake result in a bathymetry perturbation $\Delta b$ (as defined in Eq. (1)), which is visualized after $50 \mathrm{~s}$ simulation time (20 s after rupture arrest, which is when seismic waves have left Palu Bay) in Fig. 10a.
In general, the bathymetry perturbation shows subsidence east of the faults and uplift west of the faults. The additional bathymetry effect incorporated through the approach of Tanioka and Satake (1996) locally modulates the smooth displacement fields from the earthquake rupture scenario (see Appendix 7.5, Figs. 22, 23). Four cross-sections of the final perturbation in the west-east direction are shown in Fig. 10b. These capture the area of Palu Bay and clearly show the step induced by the normal component of fault slip. The step varies between 0.8 and $2.8 \mathrm{~m}$, with an average of $1.5 \mathrm{~m}$. Note that this step is defined as fault throw in structural geology. However, 
(a)

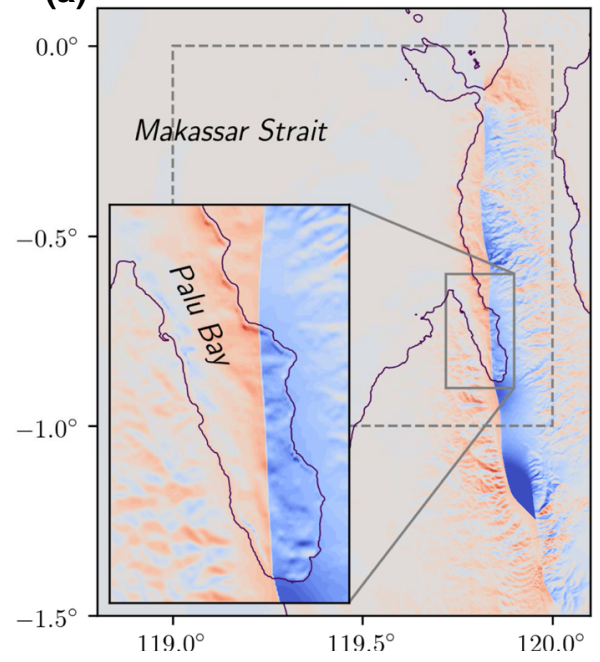

(b)
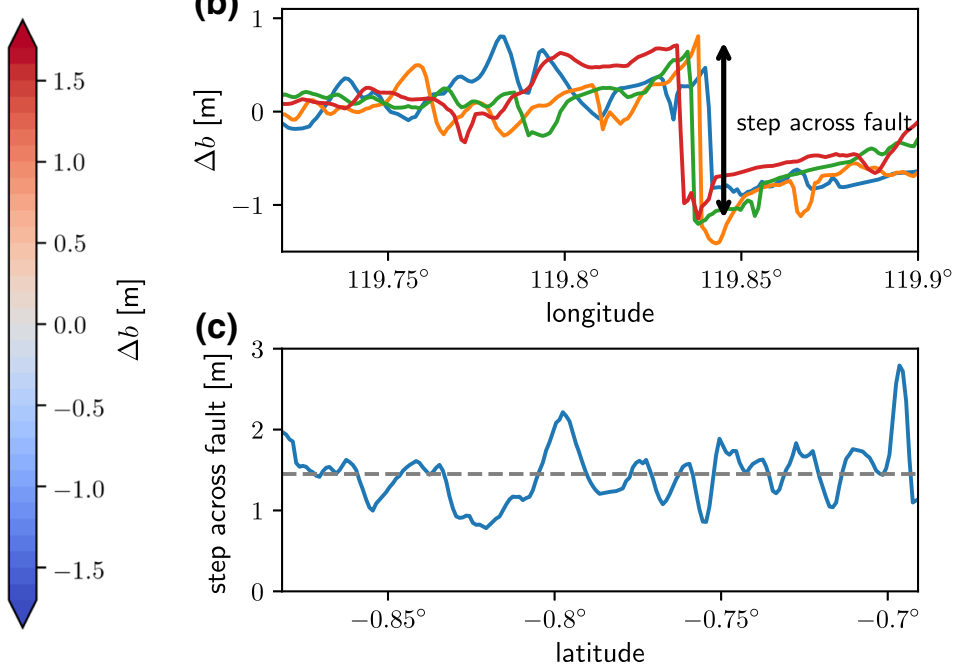

Figure 10

a Snapshot of the computed bathymetry perturbation $\Delta b$ used as input for the tsunami model. The snapshot corresponds to a $50 \mathrm{~s}$ simulation time at the end of the earthquake scenario. b West-east cross-sections of the bathymetry perturbation at $-0.85^{\circ}$ (blue), $-0.8^{\circ}$ (orange), $-0.75^{\circ}$ (green), $-0.7^{\circ}$ (red) latitude showing the induced step in bathymetry perturbation across the fault. c Step in bathymetry perturbation (as indicated in b) as function of latitude. Grey dashed line shows the average

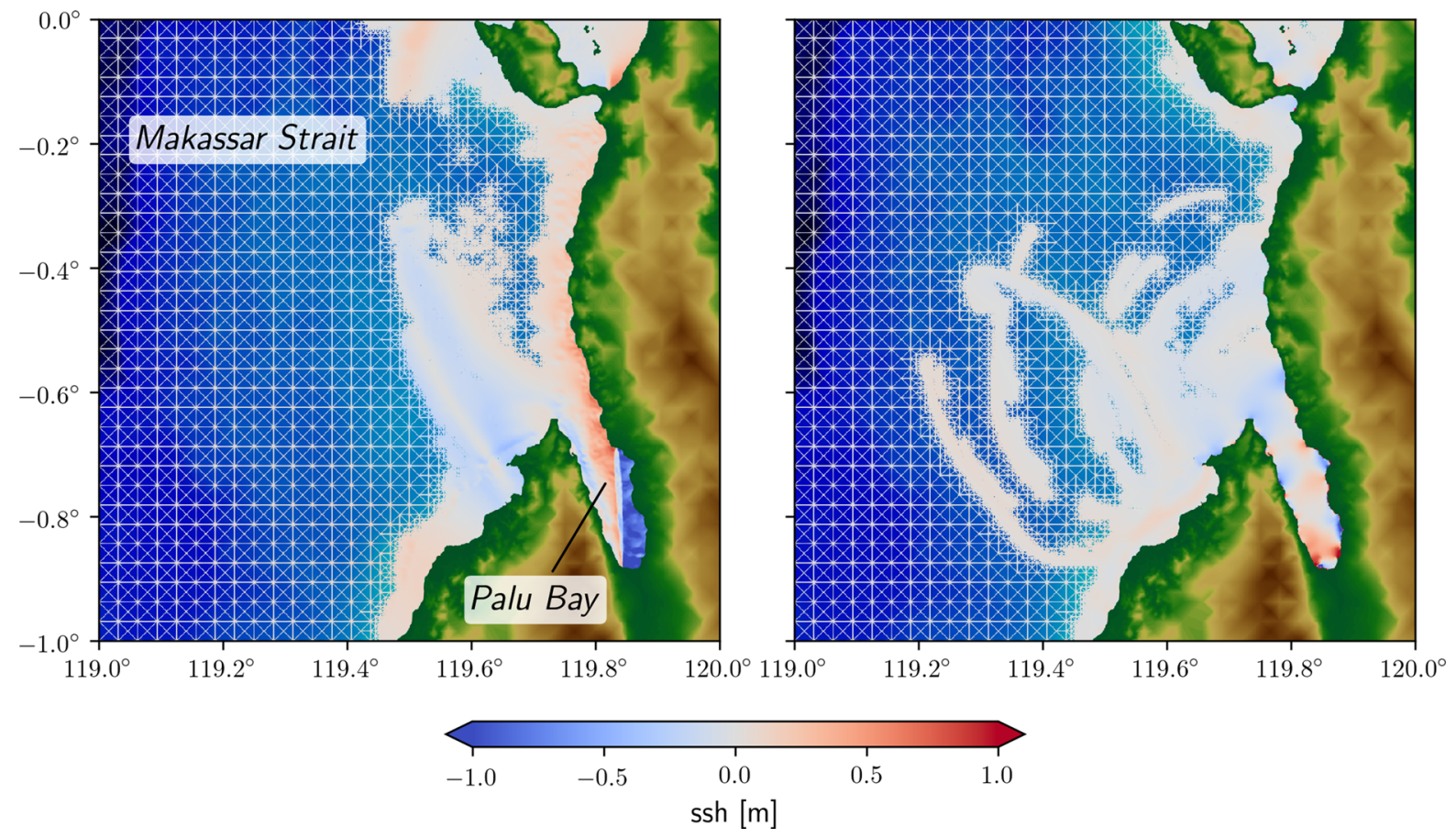

Figure 11

Snapshots of the tsunami scenario at $20 \mathrm{~s}$ (left) and $600 \mathrm{~s}$ (right), showing the dynamic mesh adaptivity of the model 
here we explicitly incorporate effects of bathymetry and thus 'step' here refers to the total seafloor perturbation. Variation in the step magnitude along the fault is displayed in Fig. 10c.

The tsunami generated in this scenario is mostly localized in Palu Bay, which is illustrated in snapshots of the dynamically adaptive tsunami simulation after $20 \mathrm{~s}$ and $600 \mathrm{~s}$ simulation time in Fig. 11. This is expected as the modeled fault system is offshore only within the Bay. At $20 \mathrm{~s}$, the seafloor displacement due to the earthquake is clearly visible in the sea surface height (ssh) within Palu Bay. Additionally, the effect of a small uplift is visible along the coast north of the Bay. The local behavior within Palu Bay is displayed in Fig. 12 at 20 s, $180 \mathrm{~s}$ and $300 \mathrm{~s}$ (see also the tsunami animation in Appendix 7.10). The local extrema along the coast reveal the complex wave reflections and refractions within the Bay caused by complex, shallow bathymetry as well as funnel effects.

We compare the synthetic time series of the Pantoloan harbor tide gauge at $\left(119.856155^{\circ} \mathrm{E}\right.$, $0.71114^{\circ} \mathrm{S}$ ) to the observational gauge data. Additionally, a wealth of post-event field surveys characterize the inundation of the Palu tsunami (e.g. Widiyanto et al. 2019; Muhari et al. 2018; Omira et al. 2019; Yalciner et al. 2018; Pribadi et al. 2018). We compare the tsunami modeling results with observational data from a comprehensive overview of run-up data, inundation data, and arrival times of tsunami waves around the shores of the Palu Bay compiled by Yalciner et al. (2018) and Pribadi et al. (2018).

The Pantoloan tide gauge is the only tide gauge with available data in Palu Bay. The instrument is installed on a pier in Pantoloan harbor and thus records the change of water height with respect to a pier moving synchronously with the land. It has a 1-min sampling rate and the observational time series was detided by a low-pass filter eliminating wave periods above $2 \mathrm{~h}$. The tsunami arrived $5 \mathrm{~min}$ after the earthquake onset time with a leading trough (Fig. 13). The first and highest wave arrived approximately $8 \mathrm{~min}$ after the earthquake rupture time. The

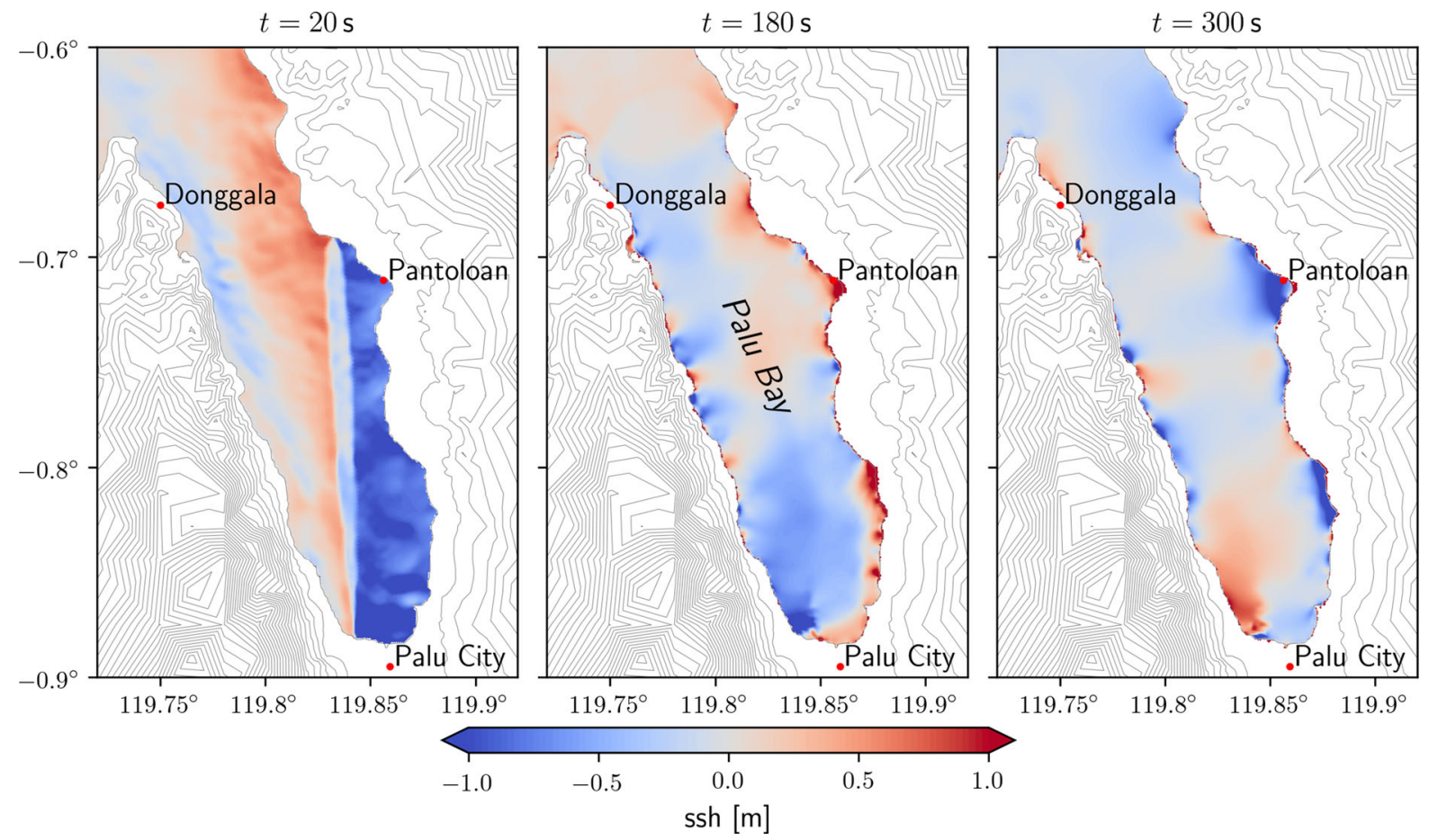

Figure 12

Snapshots of the tsunami scenario at $20 \mathrm{~s}, 180 \mathrm{~s}$ and $300 \mathrm{~s}$ (left to right), showing only the area of Palu Bay. Colors depict the sea surface height (ssh), which is the deviation from mean sea level 


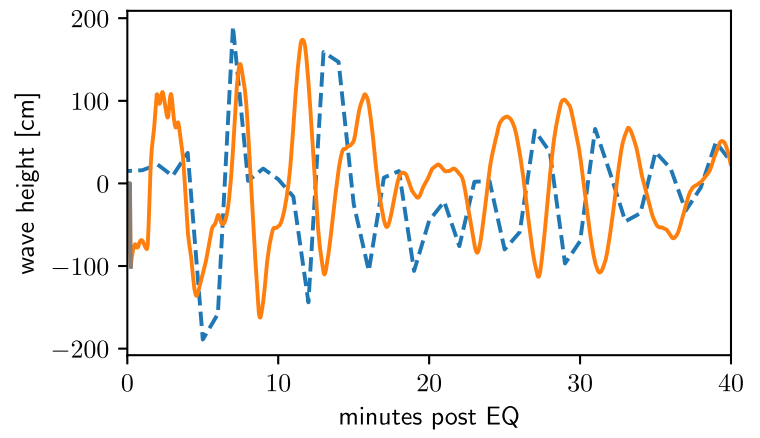

Figure 13

Time series from the wave gauge at Pantoloan port. Blue dashed: measurements, orange: output from the model scenario

difference between trough and cusp amounts to almost $4 \mathrm{~m}$. A second wave arrived after approximately 13 min with a preceding trough at $12 \mathrm{~min}$.

The corresponding synthetic time series derived from the tsunami scenario is also shown in Fig. 13. Although a leading wave trough is not present in the scenario results, the magnitude of the wave is well captured. Note that coseismic subsidence produces a negative shift of approx. $80 \mathrm{~cm}$ within the first minute of the scenario. This effect is not captured by the tide gauge due to the way the instrument is designed. We detail this issue in Appendix 5.3. It cannot be easily filtered out, due to re-adjustments throughout the computation to the background mean sea level. After 5 min of simulated time, the model mareogram resembles the measured wave behavior, characterized by a dominant wave period of about $4 \mathrm{~min}$. The scenario exposes a clear resonating wave behavior due to the narrow geometry of the Bay. We note that these wave amplitudes are produced due to displacements resulting from the earthquake, without any contribution from landsliding.

We conduct a macro-scale comparison between the scenario and the inundation data, rather than point-wise comparison, in view of the relatively low resolution topography data available. We adopt the following terminology, which is commonly used in the tsunami community and in the field surveys we reference (Yalciner et al. 2018; Pribadi et al. 2018): inundation elevation at a given point above ground is measured by adding the inundation depth to the ground elevation. In distinction, run-up elevation is

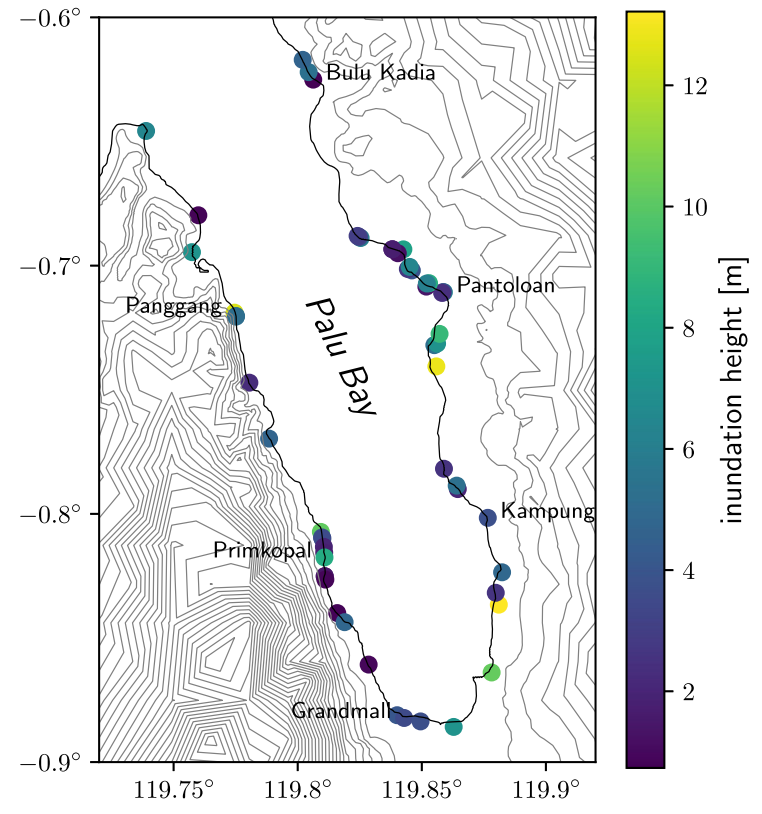

Figure 14

Simulated inundation elevations at different locations around Palu Bay, where observations have been recorded

the inundation elevation measured at the inundation point that is the farthest inland. We consistently report synthetic inundation elevations from the model.

In Figs. 14 and 15, we compare model results to run-up elevations that are reported in the field surveys. For practical reasons, we compare the observed run-up elevations to synthetic inundation elevations at the exact measurement locations. In doing so, we consider only those points on land that are reached by water in the tsunami scenario. While inundation and run-up elevations are different observations, observed run-up and simulated inundation elevations can be compared if the run-up site is precisely georeferenced, which is here the case. Fig. 14 illustrates the distribution of the modeled maximum inundation elevations around the Bay. A quantitative view comparing these same results with observations is shown in Fig. 15. Because of the limited model resolution, the validity of the scenario cannot be analysed site by site, and we only discuss the overall agreement of the simulated inundation elevations with observations. It is remarkable that the model yields similar inundation elevations as 


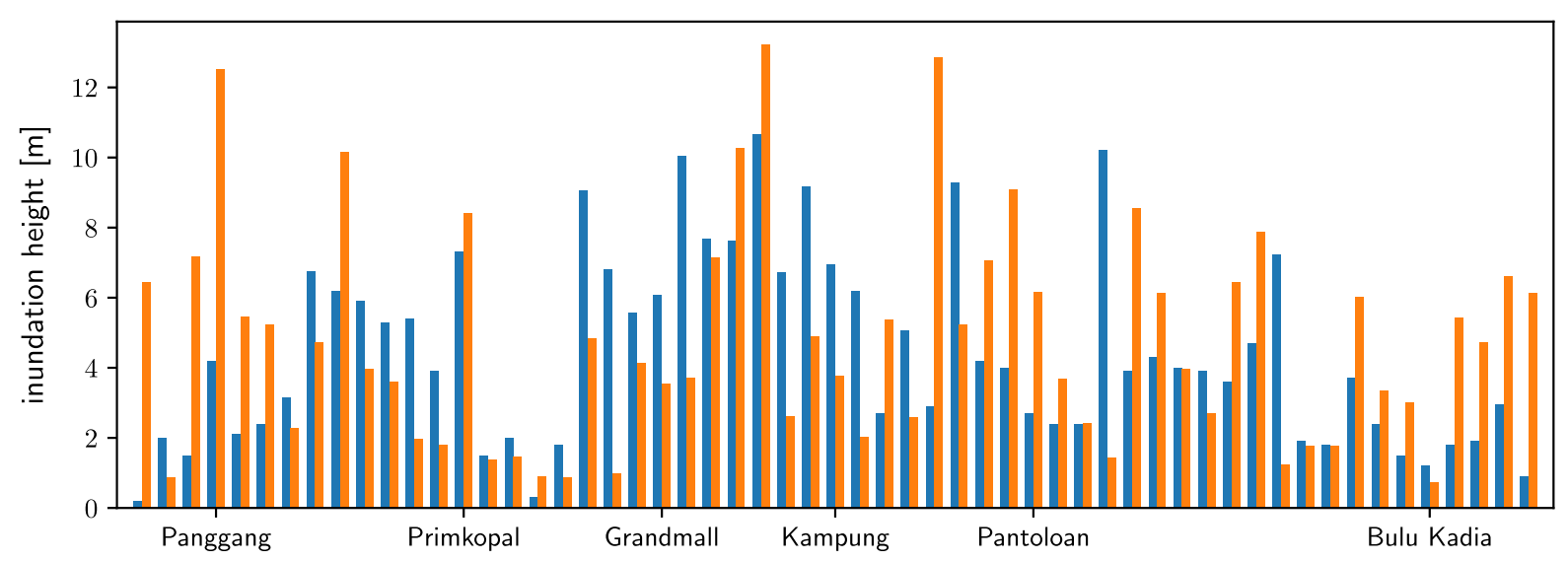

Figure 15

Inundation elevations from observation (blue) and simulation (orange) at different locations around Palu Bay (left to right: around the Bay from the northwest to the south to the northeast, see Fig. 14 for locations)

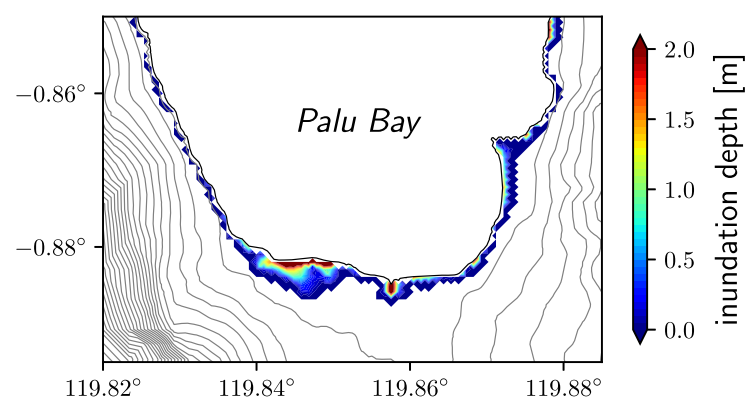

Figure 16

Maximum inundation depth near Palu City computed from the tsunami scenario

observed, with some overestimation at the northern margins of the bay and some slight underestimation in the southern part near Grandmall Palu City. What we can conclude is that large misfit in the inundation elevations are more or less randomly distributed, suggesting it comes from local amplification effects that cannot be captured in the scenario due to insufficient bathymetry/topography resolution. Fig. 16 shows maximum inundation depths computed from the tsunami scenario near Palu City. Qualitatively, the results from the scenario agree quite well with observations, as the largest inundation depths are close to the Grandmall area, where vast damage due to the tsunami is reported.

In summary, the tsunami scenario sourced by coseismic displacements from the dynamic earthquake rupture scenario yields results that are qualitatively comparable to available observations. Wave amplitudes match well, as do the inundation elevations given the limited quality of the available topography data.

\section{Discussion}

The Palu, Sulawesi tsunami was as unexpected as it was devastating. While the Palu-Koro fault system was known as a very active strike-slip plate boundary, tsunamis from strike-slip events are generally not anticipated. Fears arise that other regions, currently not expected to sustain tsunami-triggering ruptures, are at risk. This physics-based, coupled earthquaketsunami model shows that a submarine strike-slip fault can produce a tsunami, if a component of dipslip faulting occurs.

In the following, we discuss advantages and limitations of physics-based models of tsunamigenesis, as well as of the individual earthquake and tsunami models. We then focus on the broader implications of rapid coupled scenarios for seismic hazard mitigation and response. Finally, we look ahead to improving the here-presented coupled model in light of newly available information and data. 


\subsection{Success and Limitation of the Physics-Based Tsunami Source}

We constrain the initial conditions for the coupled model according to the available earthquake data and physical constraints provided by previous studies, including those reporting regional transtensional strain (Walpersdorf et al. 1998; Socquet et al. 2006; Bellier et al. 2006). A stress field characterized by transtension induces a normal component of slip on the dipping faults in the earthquake scenario. The degree of transtension assumed here translates into a fault slip rake of about $15^{\circ}$ on the $65^{\circ}$ dipping modeled faults (Fig. 9c), which is consistent with the earthquake focal mechanism (USGS 2018a).

This normal slip component results in widespread uplift and subsidence. The surface rupture generates a throw across the fault of $1.5 \mathrm{~m}$ on average in Palu Bay, which translates into a step of a similar magnitude in the bathymetry perturbation used to source the tsunami (Fig. 10c). This is sufficient for triggering a realistic tsunami that reproduces the observational data quite well. In particular it is enough to obtain the observed wave amplitude at the Pantoloan harbor wave gauge and the recorded inundation elevations.

However, we point out that transtension is not an necessary condition to generate oblique faulting on such a fault network. From static considerations, we show that specific alternative stress orientations can induce a considerable dip-slip component, particularly near fault bends, in biaxial stress regimes reflecting pure-shear (Appendix 7.3, Fig. 20).

The coupled earthquake-tsunami model performs well at reproducing observations from a macroscopic perspective and suggests that additional tsunami sources are not needed to explain the main tsunami. However, it does not constrain the small-scale features of the tsunami source and thus does not completely rule out other, potentially additional, sources, such as those suggested by Carvajal et al. (2018) based on local tsunami waves captured on video.

For example, despite the overall consistency of the earthquake scenario results with data, the fault slip scenario has viable alternatives. The fault within Palu Bay may have hosted a different or more complicated slip profile than this scenario produces. Also, the fault geometry underneath the Bay is not known. We choose a simple geometry that honors the information at hand (see Sect. 3.2.2). However, complex faulting may also exist within Palu Bay, as is observed south of the Bay where slip was partitioned between minor dip-slip fault strands and the primary strike-slip rupture (Socquet et al. 2019). Such complexity would change the seafloor displacements and therefore the tsunami results. Furthermore, a less smooth fault geometry in the Northern region, closely fitting inferred fault traces, could reduce fault slip locally, and therefore produce better fitting ground displacement observations in the North. However, the influence on seafloor displacements within Palu Bay is likely to be small. In contrast, a different slip scenario along the Palu-Koro fault within Palu Bay could have a large influence on the seafloor displacements and modeled tsunami. The earthquake model shows a decrease in normal stress (unclamping) here as the model rupture front passes. Though slip is limited in the current scenario, alternative fault geometry or a lower assigned static coefficient of friction on the Palu-Koro fault could lead to more triggered slip and alternative earthquake and tsunami scenarios.

Finally, incorporating the effect of landslides is likely necessary to capture local features of the tsunami wave and inundation patterns. Constraining these sources is very difficult without pre- and postevent high-resolution bathymetric charts. This study suggests that these sources play a secondary role in explaining the overall tsunami magnitude and wave patterns, since these can be generated by strike-slip faulting with a normal slip component.

\subsection{The Sulawesi Earthquake Scenario}

We review and discuss the dynamic earthquake scenario here and note avenues for additional modeling. For example, the speed of this earthquake is of utmost interest, although it does not provide an important contribution to the tsunami generation in this scenario. The initial stress state and lithology included in the physical earthquake model are areas that could be improved with more in-depth study and better available data.

The dynamic earthquake model requires supershear rupture velocities to produce results that agree 
with the teleseismic data and moment rate function. This scenario also provides new perspectives on the possible timing and mechanism of this supershear rupture. Bao et al. (2019) infer an average rupture velocity of about $4 \mathrm{~km} / \mathrm{s}$ from back-projection. This speed corresponds to a barely stable mechanical regime, which is interpreted as being promoted by a damage zone around the mature Palu-Koro fault that formed during previous earthquakes.

In contrast, the earthquake scenario features an early and persistent rupture velocity of $5 \mathrm{~km} / \mathrm{s}$ on average, close to P-wave speed. Supershear rupture speed is enabled in the model by a relatively low fault strength and triggered immediately at rupture onset by a highly overstressed nucleation patch. Supershear transition is enabled and enhanced by high background stresses (or more generally, low ratios of strength excess over stress drop) (Andrews 1976). The transition distance, the rupture propagation distance at which supershear rupture starts to occur, also depends on nucleation energy (Dunham 2007; Gabriel et al. 2012, 2013). Observational support for the existence of a highly stressed nucleation region arises from the series of foreshocks that occurred nearby in the days before the mainshock, including a $M_{w} 6.1$ on the same day of the mainshock.

We conducted numerical experiments reducing the level of overstress within the nucleation patch, reaching a critical overstress level at which supershear is no longer triggered immediately at rupture onset. These alternative models initiate at subshear rupture speeds and never transition to supershear. Importantly, these slower earthquake scenarios do not match the observational constraints, specifically the teleseismic waveforms and moment release rate.

Stress and/or strength variations due to, for example, variations in tectonic loading, stress changes from previous earthquakes, or local material heterogeneities, are expected, but poorly constrained, and therefore not included in this dynamic rupture model. Accounting for such features in relation to long term deformation can distinctly influence the stress field and lithological contrasts (e.g., van Dinther et al. 2013; Dal Zilio et al. 2018, 2019; Preuss et al. 2019; D’Acquisto et al. 2018; van Zelst et al. 2019). Realistic initial conditions in terms of stress and lithology are shown to significantly influence the dynamics of individual ruptures (Lotto et al. 2017a; van Zelst et al. 2019). Specifically, different fault stress states for the Palu and the Northern fault segments are possible, since the PaluKoro fault acts as the regional plate-bounding fault that likely experiences increased tectonic loading (Fig. 1a). The introduction of self-consistent, physics-based stress and strength states could be obtained by coupling this earthquake-tsunami framework to geodynamic seismic cycle models (e.g., van Dinther et al. 2013, 2014; van Zelst et al. 2019), as done in Gabriel et al. (2018). However, in light of an absence of data or models justifying the introduction of complexity, we here use the simplest option with a laterally homogeneous stress field that honors the regional scale transtension.

We also note that the earthquake scenario is dependent on the subsurface structural model (e.g., Lotto et al. 2017a; van Zelst et al. 2019). The local velocity model of Awaliah et al. (2018) is of limited resolution within the Palu area, since only one of the stations used illuminates this region. Despite the strong effects of data regularization, this is, to our knowledge, the most detailed data set characterizing the subsurface in the area of study.

\subsection{The Sulawesi Tsunami Scenario}

Overall, the tsunami model shows good agreement with available key observations. Wave amplitudes and periods at the only available tide gauge station in Palu Bay match well. Inundation data from the model show satisfactory agreement with the observations by international survey teams (Yalciner et al. 2018).

Apart from the earthquake model limitations discussed in Sect. 5.1 that may influence the tsunami characteristics, the following items may cause deviations between the tsunami model results and observations: (a) insufficiently accurate bathymetry/topography data; (b) approximation by hydrostatic shallow water wave theory; (c) simplified coupling between earthquake rupture and tsunami scenarios. In the following we will briefly discuss these topics.

The limited resolution of the bathymetry and topography data sets may prevent us from properly capturing local effects, which in turn may affect site- 
specific tsunami and inundation observations. This is discussed further and quantified in Appendix 7.9. While the adaptively refined computational mesh, which refines down to $80 \mathrm{~m}$ near the shore, allows inundation to be resolved numerically, interpolating the bathymetry data does not increase its resolution. Therefore, in Sect. 4.2, we focus on the overall agreement between model and observation in the distribution of simulated inundation elevations around Palu Bay. This is a relevant result, since it confirms that the modeled tsunami wave behavior is reasonable overall.

The accuracy of the tsunami model may also be affected by the simplifications underlying the shallow water equations. In particular, a near-field tsunami within a narrow bay may be affected by large bathymetry gradients. In the shallow-water framework, all three spatial components of the ground displacements generated by the earthquake model cannot be properly accounted for. In fact, a direct application of a horizontal displacement to the hydrostatic (single layer) shallow water model would lead to unrealistic momentum in the whole water column. Additionally, all bottom movements are immediately and directly transferred to the entire water column, since we model the water wave by (essentially 2D) shallow water theory. In reality, an adjustment process takes place. The large bathymetry gradients may also lead to non-hydrostatic effects in the water column, which cannot be neglected. Whilst fully 3D simulations of tsunami genesis and propagation have been undertaken (e.g. Saito and Furumura 2009), less compute-intensive alternatives are underway (e.g., Jeschke et al. 2017), and should be tested to quantify the influence of such effects in realistic situations such as the Sulawesi event.

We account for the effect of the horizontal seafloor displacements by applying the method proposed by Tanioka and Satake (1996). We observe only minor differences in the modeled water waves when including the effect of the horizontal ground displacements (see Figs. 12, 16, 25, 26). We thus conclude that vertical ground displacements are the primary cause of the tsunami.

Directly after the earthquake, about $80 \mathrm{~cm}$ of ground subsidence is imprinted on the synthetic mareogram at Pantaloan wave gauge, but is not visible in the observed signal (cf. Figs. 10, 13, 18).
The tide gauge at Pantaloan is indeed not sensitive to ground vertical displacements, since the instrument and the water surface are displaced jointly during ground subsidence, and therefore their distance remains fixed. Note that we also cannot remove this shift from the synthetic time series, since the tsunami model includes a background mean sea level, to which it re-adjusts throughout the computation.

The tsunami model produces inundation elevations of more than $10 \mathrm{~m}$ at several locations in Palu Bay. Similarly large values are also reported in field surveys (e.g. Yalciner et al. 2018). We note that offshore tsunami heights ranging between 0 and $2 \mathrm{~m}$ are not inconsistent with large run-up elevations. A moderate tsunami wave can generate significant runup elevation if it reaches the shoreline with significant inertia (velocity). Amplification factors of 5-10 from wave height to local run-up height are not uncommon (see e.g. Okal et al. 2010), and result from shoaling due to local bathymetry features.

\subsection{Advantages and Outcome of a Physics-Based Coupled Model}

A physics-based earthquake and coupled tsunami model is well-posed to shed light on the mechanisms and competing hypotheses governing earthquaketsunami sequences as puzzling as the Sulawesi event. By capturing dynamic slip evolution that is consistent with the fault geometry and the regional stress field, the dynamic rupture model produces mechanically consistent ground deformation, even in submarine areas where space borne imaging techniques are blind. These seafloor displacement time-histories, which include the influence of seismic waves, in nature contribute to source the tsunami and are utilized as such in this coupled framework. However, the earthquake-tsunami coupling is not physically seamless. For example, as noted above, seismic waves cannot be captured using the shallow water approach, but rather require a non-hydrostatic water body (e.g. Lotto et al. 2018). The coupled system nevertheless remains mechanically consistent to the order of the typical spatiotemporal scales governing tsunami modeling.

The use of a dynamic rupture earthquake source has distinct contributions relative to the standard finitefault inversion source approach, which is typically 
used in tsunami models. The latter enables close fitting of observations through the use of a large number of free parameters. Despite recent advances (e.g., Shimizu et al. 2019), kinematic models typically need to pre-define fault geometries. Naive first-order finitefault sources are automatically determined after an earthquake and this can be done quickly (e.g. by the USGS or GFZ German Research Centre for Geoscience), which is a great advantage. Models can be improved later on by including new data and more complexity. However, kinematic models are characterized by inherent non-uniqueness and do not ensure mechanical consistency of the source (e.g., Mai et al. 2016). The physics-based model also suffers from nonuniqueness, but this is reduced, since it excludes scenarios that are not mechanically viable.

These advantages and the demonstrated progress potentially make physics-based, coupled earthquaketsunami modeling an important tool for seismic hazard mitigation and rapid earthquake response. We facilitate rapid modeling of the earthquake scenario by systematically defining a suitable parameterization for the regional and fault-specific characteristics. We use a pre-established, efficient algorithm, based on physical relationships between parameters, to assign the illconstrained stress state and strength on the fault using a few trial simulations (Ulrich et al. 2019). This limits the required input parameters to subsurface structure, fault structure, and four parameters governing the stress state and fault conditions. This enables rapid response in delivering physics-driven interpretations that can be integrated synergistically with established data-driven efforts within the first days and weeks after an earthquake.

\subsection{Looking Forward}

The coupled model presented here produces a realistic scenario that agrees with key characteristics of available earthquake and tsunami data. However, future efforts will be directed toward improving the model as new information on fault structure or displacements within the Bay or additional tide gauge measurements become available.

In addition, different earthquake models varying in their fault geometry or in the physical laws governing on- and off-fault behavior can be utilized in further studies of the influence of earthquake characteristics on tsunami generation and impact.

This model provides high resolution synthetics of, e.g., ground deformation in space and time. These results can be readily compared to observational data that are yet to be made available to the scientific community. We provide time series of modeled ground displacements in Appendix 7.2.

Spatial variations of regional stress and fault strength could be constrained in the future by tectonic seismic cycle modeling capable of handling complex fault geometries. Future dynamic earthquake rupture modeling may additionally explore how varying levels of preexisting and coseismic off-fault damage affect the rupture speed specifically and rupture dynamics in general.

Future research should also be directed towards an even more realistic coupling strategy together with an extended sensitivity analysis on the effects of such coupling. This, e.g., requires the integration of nonhydrostatic extensions for the tsunami modeling part (Jeschke et al. 2017) into the coupling framework.

\section{Conclusions}

We present a coupled, physics-based scenario of the 2018 Palu, Sulawesi earthquake and tsunami, which is constrained by rapidly available observations. We demonstrate that coseismic oblique-slip on a dipping strike-slip fault produces a vertical step across the submarine fault segment of $1.5 \mathrm{~m}$ on average in the tsunami source. This is sufficient to produce reasonable tsunami amplitude and inundation elevations. The critical normal-faulting component results from transtension, prevailing in this region, and the fault system geometry.

The fully dynamic earthquake model captures important features, including the timing and speed of the rupture, 3D geometric complexities of the faults, and the influence of seismic waves on the rupture propagation. We find that an early onset of supershear rupture speed, sustained for the duration of the rupture across geometric complexities, is required to match a range of far-field and near-fault observations.

The modelled tsunami amplitudes and inundation elevations agree with observations within the range of 
modeling uncertainties dominated by the available bathymetry and topography data. We conclude that the primary tsunami source may have been coseismically generated vertical displacements. However, in a holistic approach aiming to match high-frequency tsunami features, local effects such as landsliding, non-hydrostatic wave effects, and high resolution topographical features should be included.

A physics-based earthquake and coupled tsunami model is specifically useful to assess tsunami hazard in tectonic settings currently underrepresented in operational hazard assessment. We demonstrate that high-performance computing empowered dynamic rupture modeling produces well-constrained studies integrating source observations and earthquake physics very quickly after an event occurs. In the future, such physics-based earthquake-tsunami response can complement both on-going hazard mitigation and the established urgent response tool set.

\section{Acknowledgements}

We thank Taufiqurrahman for helping us accessing data on Indonesian websites, and for putting us in contact with Indonesian researchers. We thank Dr. T. Yudistira for providing their crustal velocity model of Sulawesi and Dr. Andreas Fichtner for providing us part of the 'Collaborative Seismic Earth Model'. We thank Dr. Marcello de Michele for providing his inferred ground-deformation data and for fruitful discussions. The ALOS-2 original data are copyright JAXA and provided under JAXA RA6 PI projects P3278 and P3360. Dr. Widodo S. Pranowo provided access to very early field survey observations. Furthermore, Dr. Abdul Muhari supported this work by providing 1-min tide gauge data for the Pantoloan tide gauge. We thank two anonymous reviewers and the editor-in-chief Alexander Rabinovich for their constructive comments. Finally, we thank the \#geotweeps twitter community and the participants of the AGU special session about the Palu earthquake and tsunami for stimulating discussions. The work presented in this paper was enabled by the Volkswagen Foundation (project "ASCETE", Grant no. 88479). Computing resources were provided by the Institute of Geophysics of LMU Munich (Oeser et al.
2006), the Leibniz Supercomputing Centre (LRZ, Projects no. h019z, pr63qo and pr45fi on SuperMUC), and the Center for Earth System Research and Sustainability (CEN) at University of Hamburg. T.U., E. H. M. and A.-A. G. acknowledge support by the German Research Foundation (DFG) (projects no. KA 2281/4-1, GA 2465/2-1, GA 2465/3-1), by BaCaTec (Project no. A4) and BayLat, by KONWIHR - the Bavarian Competence Network for Technical and Scientific High Performance Computing (Project NewWave), by KAUST-CRG (GAST, Grant no. ORS-2016-CRG5-3027 and FRAGEN, Grant no. ORS-2017-CRG6 3389.02), by the European Union's Horizon 2020 research and innovation program (ExaHyPE, Grant no. 671698 and ChEESE, grant no. 823844). S. V. acknowledges support by Einstein Stiftung Berlin through Grant EVF-2017358(FU). Part of this research was performed at the Jet Propulsion Laboratory, California Institute of Technology under contract with the National Aeronautics and Space Administration (NASA) by Earth Surface and Interior focus area and NISAR Science Team.

Open Access This article is distributed under the terms of the Creative Commons Attribution 4.0 International License (http:// creativecommons.org/licenses/by/4.0/), which permits unrestricted use, distribution, and reproduction in any medium, provided you give appropriate credit to the original author(s) and the source, provide a link to the Creative Commons license, and indicate if changes were made.

\section{Appendix}

\subsection{Off-Fault Plasticity}

We account for the possibility of off-fault energy dissipation by assuming a Drucker-Prager elastoviscoplastic rheology (Wollherr et al. 2018). The model is parameterized following Ulrich et al. (2019). The internal friction coefficient is set equal to the reference fault friction coefficient (0.6). Similarly, off-fault initial stresses are set equal to the depth-dependent initial stresses prescribed on the fault. The relaxation time $T_{v}$ is set to $0.05 \mathrm{~s}$. Finally, we assume depth-dependent bulk cohesion (see Fig. 17) to account for the hardening of the rock structure with depth. 


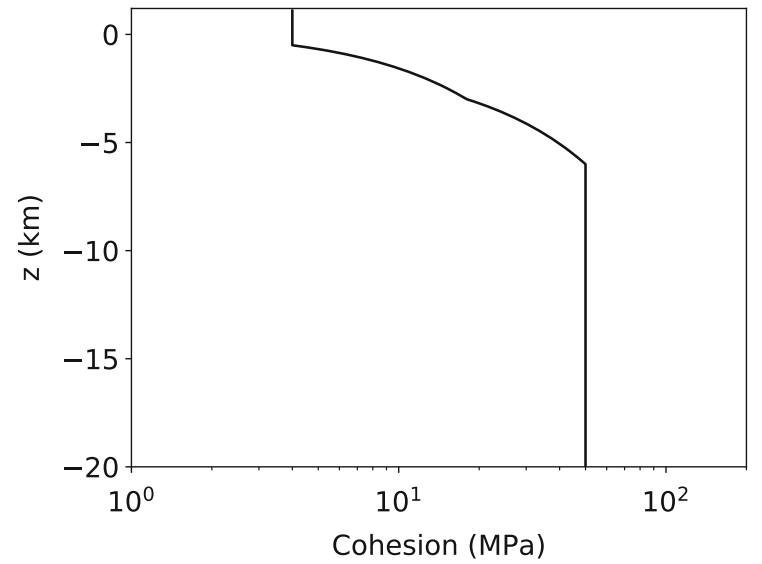

Figure 17

Depth dependence of bulk cohesion in the off-fault plastic yielding criterion

\subsection{Displacement Time Histories}

Many high-rate GNSS stations have recorded the Palu event in the near field (Simons et al. 2018). Nevertheless, these data are not yet available. In Fig. 18, we provide the displacements time histories at a few of these sites (see Fig. 19). We hope future access to this data will provide further constraint on the model.

\subsection{Initial Stress}

In this section, we detail the initial stress parametrization, presented in general terms in Sect. 3.2.

The fault system is loaded by a laterally homogeneous regional stress regime. Assuming an
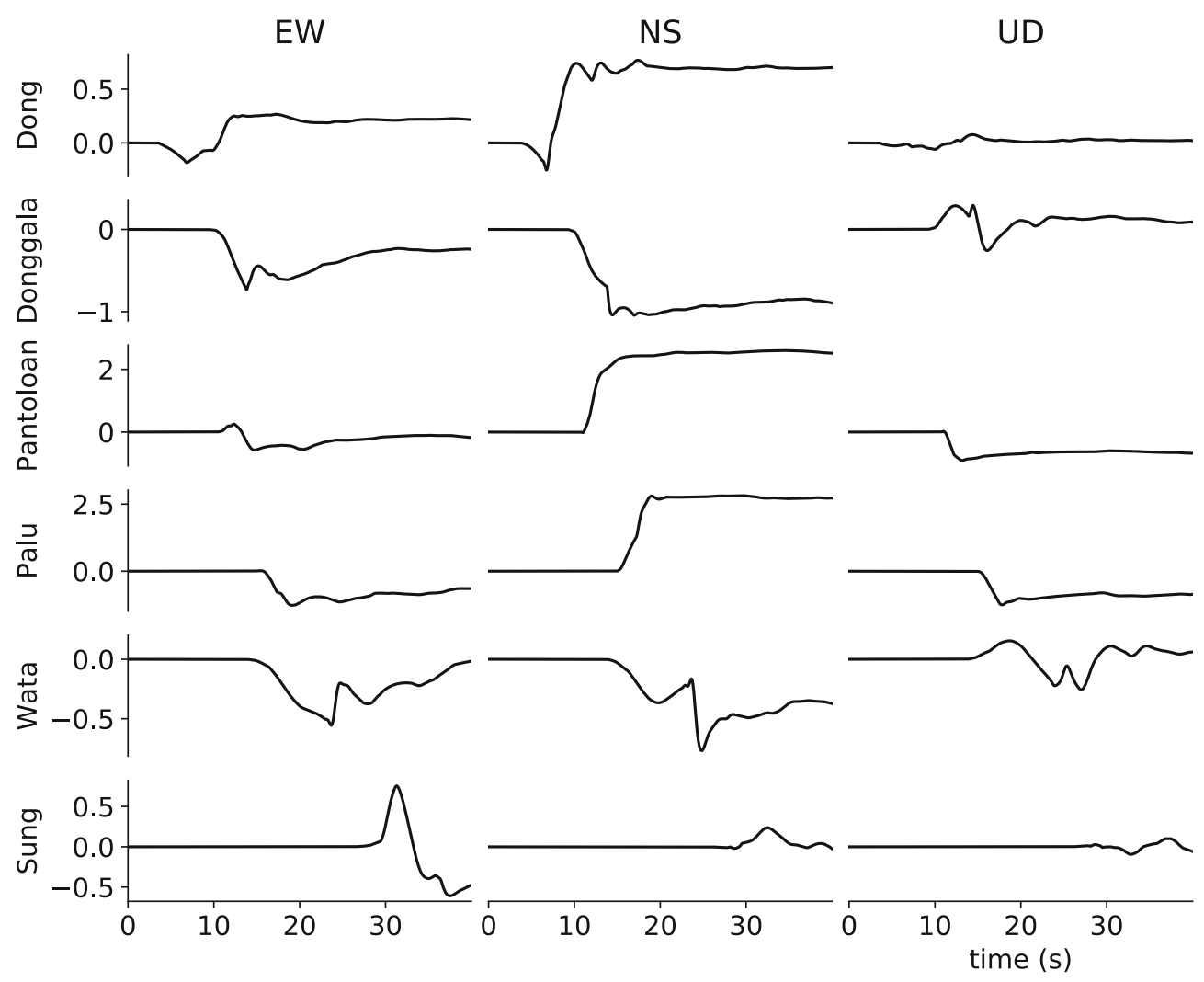

Figure 18

Synthetic unfiltered time-dependent ground displacement in meters at selected locations (see Fig. 19) 
Andersonian stress regime, where $s_{1}>s_{2}>s_{3}>0$ are the principal stresses and $s_{2}$ is vertically oriented, the stress state is fully characterized by four parameters: $\mathrm{SH}_{\max }, v, R_{0}$ and $\gamma . S H_{\max }$ is the azimuth of the maximum horizontal compressive stress; $v$ is a stress shape ratio balancing the principal stress amplitudes; $R_{0}$ is a ratio describing the relative strength of the faults; and $\gamma$ is the fluid pressure ratio.

The World Stress Map (Heidbach et al. 2018) constrains $\mathrm{SH}_{\max }$ to the range of $120 \pm 15^{\circ}$. The stress shape ratio $v=\left(s_{2}-s_{3}\right) /\left(s_{1}-s_{2}\right)$ characterizes the stress regime: $v \approx 0.5$ indicates pure shear, $v>0.5$ indicates transtension and $v<0.5$ indicates transpression. A transtensional regime is suggested by geodetic studies (Walpersdorf et al. 1998; Socquet et al. 2006), fault kinematic analyses from field data (Bellier et al. 2006), and by the USGS focal mechanism of the mainshock, which clearly features a normal faulting component. However, the exact value of $v$ is not constrained.

The fault prestress ratio $R_{0}$ describes the closeness to failure of a virtual, optimally oriented plane according to Mohr-Coulomb theory (Aochi and Madariaga 2003). On this virtual plane, the Coulomb stress is maximized. Optimally oriented planes are critically loaded when $R_{0}=1$. Faults are typically not optimally oriented in reality. In a dynamic rupture scenario, only a small part of the modeled faults need to reach failure in order to nucleate sustained rupture. Other parts of the fault network can fail and slip progressively, even if well below failure before rupture initiation. The propagating rupture front or traveling seismic waves can raise the local shear tractions to match fault strength locally.

We assume fluid pressure $P_{f}$ throughout the crust is proportional to the lithostatic stress: $P_{f}=\gamma \sigma_{c}$, where $\gamma$ is the fluid-pressure ratio and $\sigma_{c}=\rho g z$ is the lithostatic pressure. A fluid pressure of $\gamma=$ $\rho_{\text {water }} / \rho=0.37$ indicates purely hydrostatic pressure. Higher values correspond to overpressurized stress states. Together, $R_{0}$ and $\gamma$ control the average stress drop $d \tau$ in the dynamic rupture model as:

$$
d \tau \sim\left(\mu_{s}-\mu_{d}\right) R_{0}(1-\gamma) \sigma_{c} .
$$

where $\mu_{\mathrm{s}}$ and $\mu_{\mathrm{d}}$ are the static and dynamic fault friction assigned in the model. $d \tau$, is a critical characteristic of the earthquake dynamic rupture model, controlling the average fault slip, rupture speed and earthquake size.

Following Ulrich et al. (2019), we can evaluate different initial stress and strength settings using purely static considerations. By varying the stress parameters within their observational constraints, we compute the distribution of the relative prestress ratio $R$ and of the shear traction orientation resolved on the fault system for each configuration. $R$ is defined as:

$$
R=\left(\tau_{0}-\mu_{s} \sigma_{n}\right) /\left(\left(\mu_{s}-\mu_{d}\right) \sigma_{n}\right),
$$

where $\tau_{0}$ and $\sigma_{n}$ are the initial shear and normal tractions resolved on the fault plane.

We can characterize the spatially variable fault strength in the model by calculating $R$ (Eq. (3)) at every point on each fault (Figs. 20 and 21). By

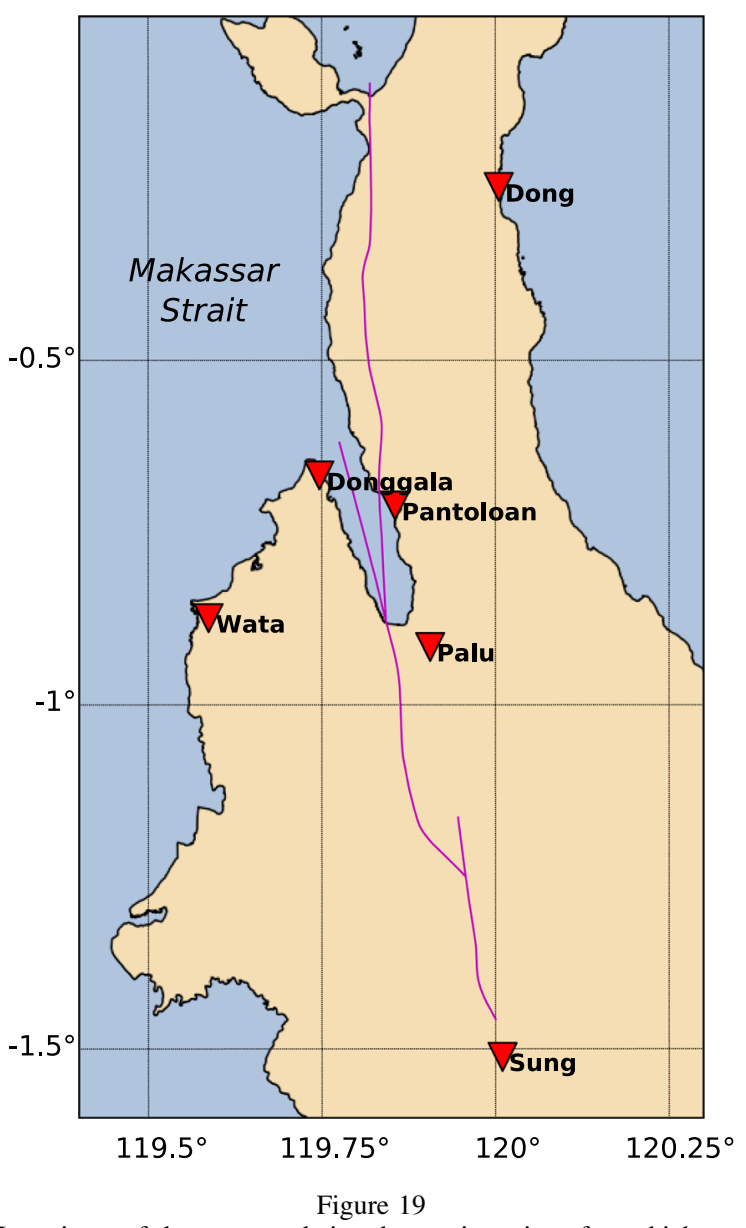

Locations of known geodetic observation sites for which we provide synthetic ground displacement time series (see Fig. 18) 


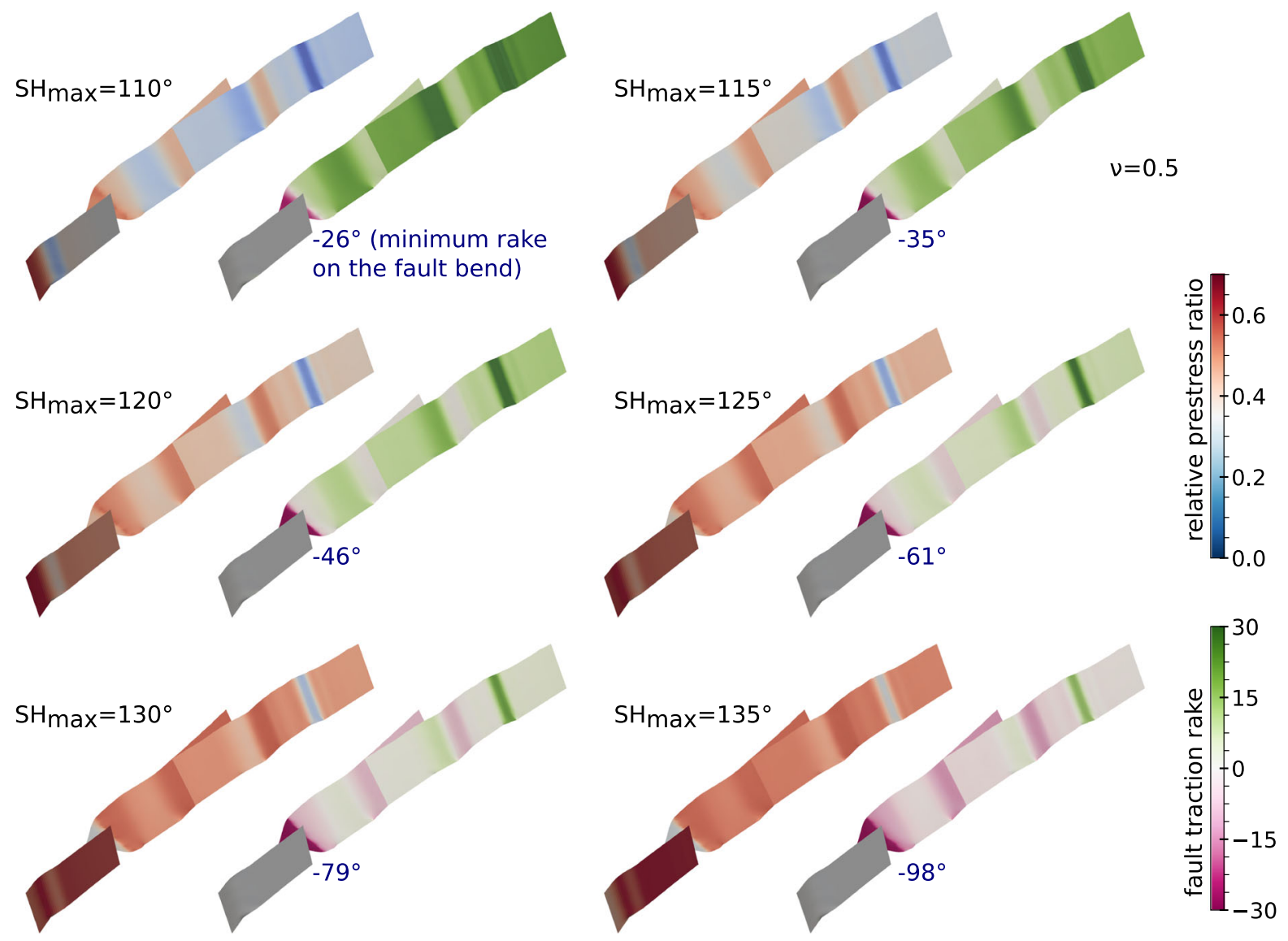

Figure 20

Magnitude and rake of prestress resolved on the fault system for a range of plausible $S H_{\max }$ values, assuming a stress shape ratio $v=0.5$ (pureshear). For each stress state we show the spatial distribution of the pre-stress ratio (left) and the rake angle of the shear traction (right). Here we assume $R_{0}=0.7$ on the optimal plane, which results in $R<R_{0}$ for all faults, since these are not optimally oriented. In blue, we label the (out-of-scale) minimum rake angle on the Palu-Saluki bend

definition, $R$ is always lower or equal to $R_{0}$, since the faults are not necessary optimally oriented.

We then select the stress configuration that maximizes $R$ across the fault system, especially around rupture transition zones to enable triggering, and that represents a shear stress orientation compatible with the inferred ground deformations and the inferred focal mechanisms.

These purely static considerations suggest that a transtensional regime is required to achieve a favourable stress orientation on the fault system. In fact, we see that a biaxial stress regime $(v=0.5)$ does not resolve sufficient shear stress simultaneously on the main north-south striking faults and on the PaluSaluki bend (see Fig. 20). Dynamic rupture experiments confirm that the Saluki fault could not be triggered under such a stress regime. On the other hand, such optimal configuration can be achieved by a transtensional stress state, for instance by choosing $v=0.7$ and $S H_{\max }$ in the range $125^{\circ}-135^{\circ}$ (see Fig. 21). We choose $S H_{\max }=135^{\circ}$, which allows for nucleation with less overstress than lower values and generates ruptures with the expected slip orientations and magnitudes.

The here-assumed fault system does not feature pronounced geometrical barriers apart from the PaluSaluki bend. As a consequence, $R_{0}$ is actually poorly constrained, and trade-offs between $R_{0}$ and $\gamma$ are expected. The preferred, realistic model is characterized by $R_{0}=0.7$ and $\gamma=0.79$. This results in an effective confining stress $(1-\gamma) \sigma_{c}$ that increases with depth by a gradient of $5.5 \mathrm{MPa} / \mathrm{km}$. 


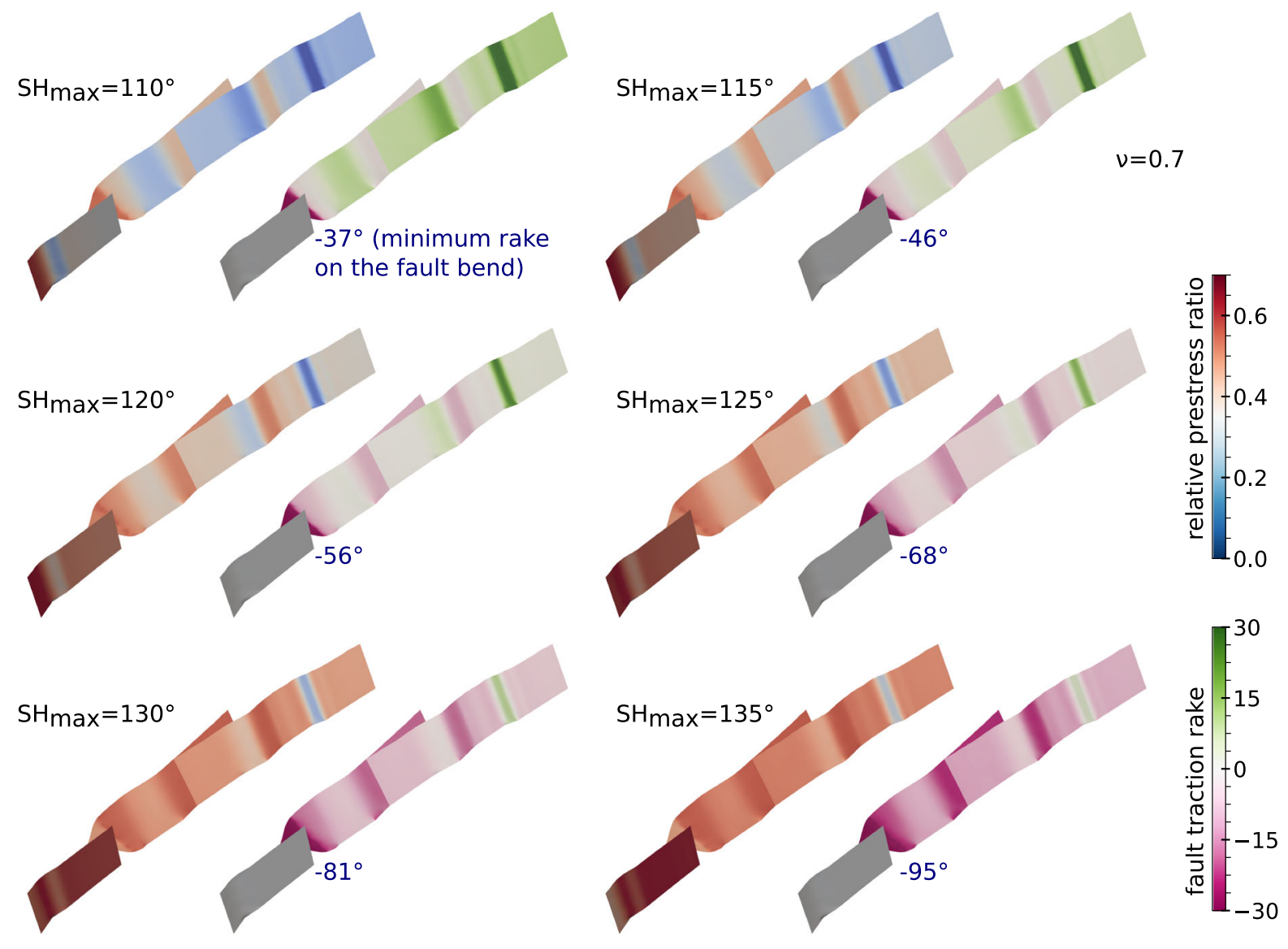

Figure 21

Same as Fig. 20, but assuming a stress shape ratio $v=0.7$ (transtension)

\subsection{Friction Law}

We here use a form of fast-velocity weakening friction proposed in the community benchmark problem TPV104 of the Southern California Earthquake Center (Harris et al. 2018) and as parameterized by Ulrich et al. (2019). Friction drops rapidly from a steady-state, low-velocity friction coefficient, here $f_{0}=0.6$, to a fully weakened friction coefficient, here $f_{w}=0.1$ (see Table 1).

\subsection{Horizontal Displacements as Additional Tsunami Source}

For computing the bathymetry perturbation used as the source for the tsunami model, we apply the method of Tanioka and Satake (1996) to additionally

Table 1

Fault frictional properties assumed in this study

\begin{tabular}{lll}
\hline Direct-effect parameter & $\mathrm{a}$ & 0.01 \\
\hline $\begin{array}{l}\text { Evolution-effect parameter } \\
\text { Reference slip rate }\end{array}$ & $\mathrm{b}$ & 0.014 \\
$\begin{array}{l}\text { Steady-state low-velocity friction } \\
\quad \text { coefficient at slip rate } V_{0}\end{array}$ & $V_{0}$ & $10^{-6} \mathrm{~m} / \mathrm{s}$ \\
$\begin{array}{l}\text { Characteristic slip distance of state } \\
\quad \text { evolution }\end{array}$ & $\mathrm{L}$ & 0.6 \\
$\begin{array}{l}\text { Weakening slip rate } \\
\text { Fully weakened friction coefficient }\end{array}$ & $V_{\mathrm{W}}$ & $0.2 \mathrm{~m}$ \\
Initial slip rate & $f_{\mathrm{W}}$ & $0.1 \mathrm{~m} / \mathrm{s}$ \\
& $V_{\mathrm{ini}}$ & $10^{-16} \mathrm{~m} / \mathrm{s}$ \\
\hline
\end{tabular}

account for horizontal displacements computed in the earthquake model. The final states of the three displacement components $\Delta x, \Delta y$ and $\Delta z$ are given in Figs. 22 and 23. Applying the approach of Tanioka and Satake by using Eq. (1), the displacements are 

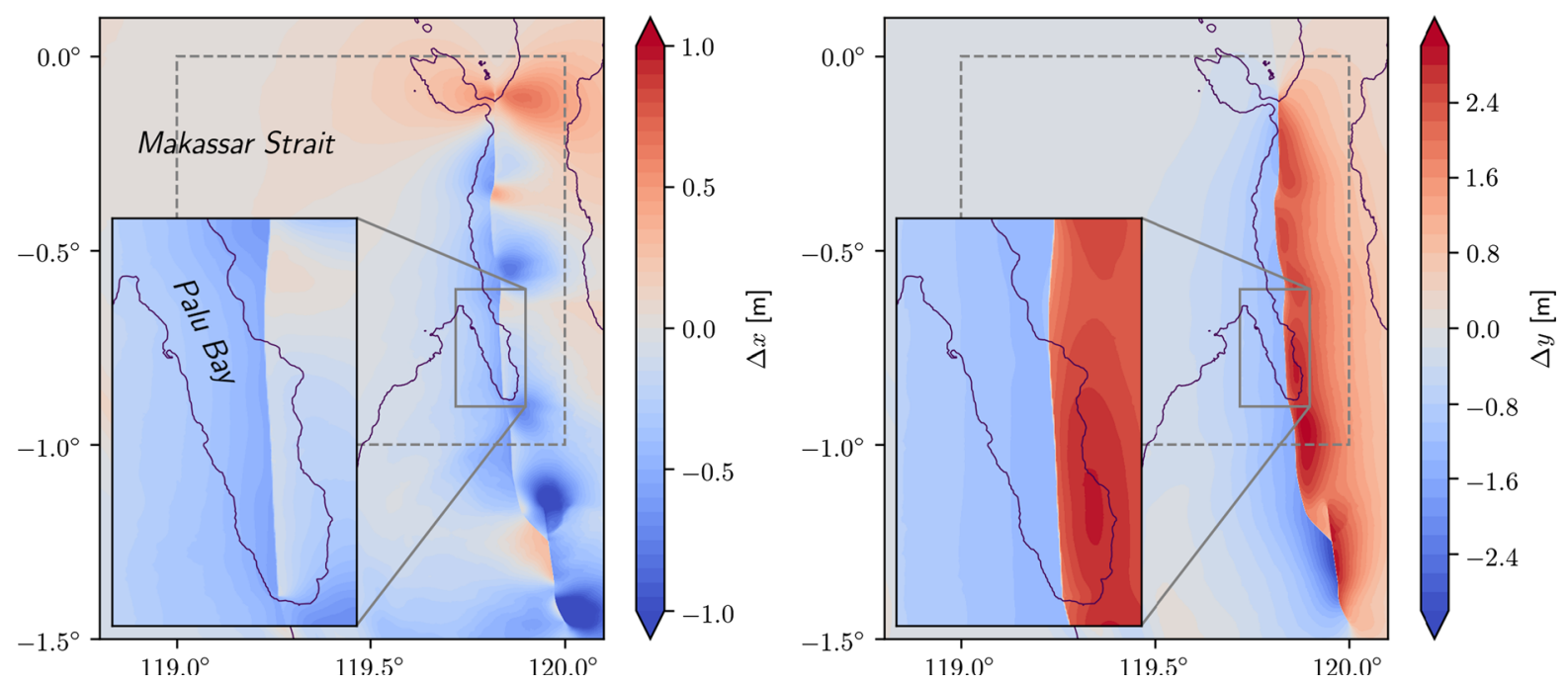

Figure 22

Final horizontal surface displacements ( $\Delta x$ and $\Delta y$ ) as computed by the earthquake model

transformed into the bathymetry perturbation, $\Delta b$ (Fig. 10). The difference between $\Delta z$ and $\Delta b$ locally is up to $0.6 \mathrm{~m}$, as shown in Fig. 24. Although this difference is quite large, and compared to the overall magnitude more than $30 \%$, it is only very local.

We have run the same tsunami scenario, but with the computed seafloor displacement $\Delta z$ as tsunami source. Snapshots of this scenario in Palu Bay can be seen in Fig. 25. Such new scenario differs from the original scenario only by local effects (Fig. 12), especially at points along the coast. The maximum inundation depths at Palu city are mapped for this alternative scenario in Fig. 26. Again, only minor differences appear (compare with Fig. 16). This illustrates that the method by Tanioka and Satake (1996) might be important to capture some local effects of the tsunami, but is not crucial for the general result, which is also confirmed by other studies (Heidarzadeh et al. 2018).

\subsection{Along-Track SAR Measurements}

We here describe measurements of the final coseismic surface displacements in along-track direction from SAR images acquired by the Japan Aerospace Exploration Agency (JAXA) Advanced Land Observation Satellite-2 (ALOS-2) SAR. We measure along-track pixel offsets incoherent cross correlation of ALOS-2 stripmap SAR images acquired along ascending path 126 on 2018/08/17 and 2018/10/12 and ascending path 127 on 2018/08/ 08 and 2018/10/03. We used modules of the InSAR Scientific Computing Environment (ISCE) (Liang and Fielding 2017; Rosen et al. 2012) for ALOS-2 SAR data processing.

\subsection{D Subsurface Structure}

3D heterogeneous media are included in the earthquake model by combining the local model of Awaliah et al. (2018), which is built from ambient noise tomography and covers the model domain down to $40 \mathrm{~km}$ depth, and the Collaborative Seismic Earth Model (Fichtner et al. 2018), which covers the model domain down to $150 \mathrm{~km}$. Figure 27 shows a few cross-sections of the 3D subsurface structure of Awaliah et al. (2018). As this model only defines $V_{s}$, we compute the $\mathrm{P}$-wave speed $V_{p}$ assuming a Poisson's ratio of 0.25 .

$$
V_{p}=V_{s} \sqrt{(3)}
$$

The density $\rho$ is calculated using an empirical relationship (Aochi et al. 2017, and references therein).

$$
\rho=-0.0045 V_{s}^{2}+0.432 V_{s}+1711 \mathrm{~kg} / \mathrm{m}^{3}
$$




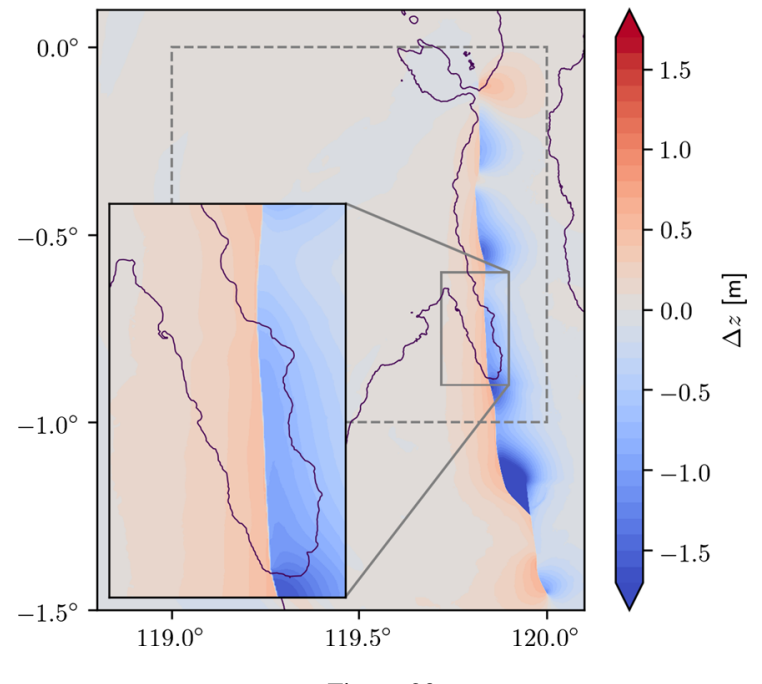

Figure 23

Final vertical surface displacements $(\Delta z)$ as computed by the earthquake model

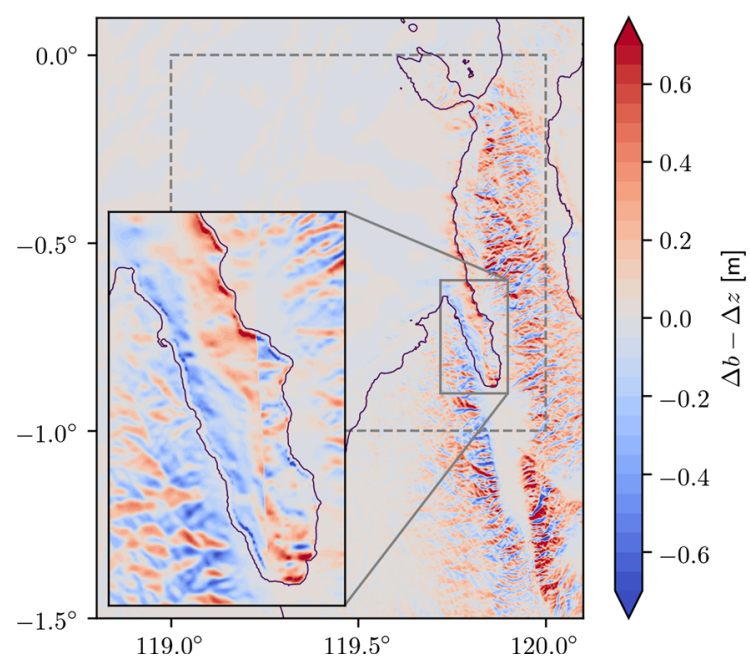

Figure 24

The contribution $\Delta b-\Delta z$ of horizontal displacements to the final bathymetry perturbation, following Tanioka and Satake (1996)

\subsection{Model Validation with Teleseismic Data}

The teleseismic data used in the manuscript for validation of the earthquake model were downloaded from IRIS using Obspy (Beyreuther et al. 2010). The instrument response is removed using the remove_response function of Obspy. Waveform fits are estimated by computing a relative root-mean-square misfit given by:

$$
r R M S=\left(1 / R M S_{o b s}\right) \sqrt{\int_{t_{0}}^{t_{1}}\left(d_{s y n}(t)-d_{o b s}(t)\right)^{2} d t}
$$

where $d_{s y n}$ and $d_{o b s}$ are respectively the synthetic and observed displacement waveforms, $t_{0}$ and $t_{1}$ define the interval over which the misfit is calculated (here we use the same range as the range that we plot in Fig. $4 \mathrm{a}, \mathrm{b}$ ), and $R M S_{o b s}$ is given by:

$$
R M S_{o b s}=\sqrt{\int_{t_{0}}^{t_{1}} d_{o b s}(t)^{2} d t}
$$

\subsection{Reliability of the BATNAS Data Set in Palu Bay Nearshore Areas}

BATNAS (v1.0) (DEMNAS 2018) is to our knowledge the highest resolution data set describing the pre-event bathymetry in the area of interest, with a horizontal resolution of approximately $190 \mathrm{~m}$. This allows for sufficiently accurate representation of bathymetric features. However, the resolution is relatively inaccurate with respect to inundation treatment. High resolution $(8 \mathrm{~m})$ topography (but not bathymetry) is available from DEMNAS (2018). Thus, DEMNAS topography and BATNAS bathymetry could be used conjointly in an effort to improve the local resolution of the modeled inundation. Nevertheless, merging the two data sets is a nontrivial task. To analyze whether this is necessary to support the conclusions of this paper, we here provide a quantitative analysis (Figs. 28, 29).

We randomly pick 8 profiles crossing the Bay (Figs. 30, 31) along which we compare BATNAS and DEMNAS data. Within the range of the observed inundation elevation $(0-10 \mathrm{~m})$, we observe that BATNAS captures slopes rather realistically (e.g., profiles $2,4,8$ ), especially if topography is smooth. At specific locations, however, the topography is clearly smoothed by the BATNAS data set (e.g. profiles $1,6,7)$ and local biases can be expected.

We conclude that the amplitude variation of inundation synthetics around the bay based on BATNAS data, and the qualitative comparison to observations, is relevant as discussed in the main text 


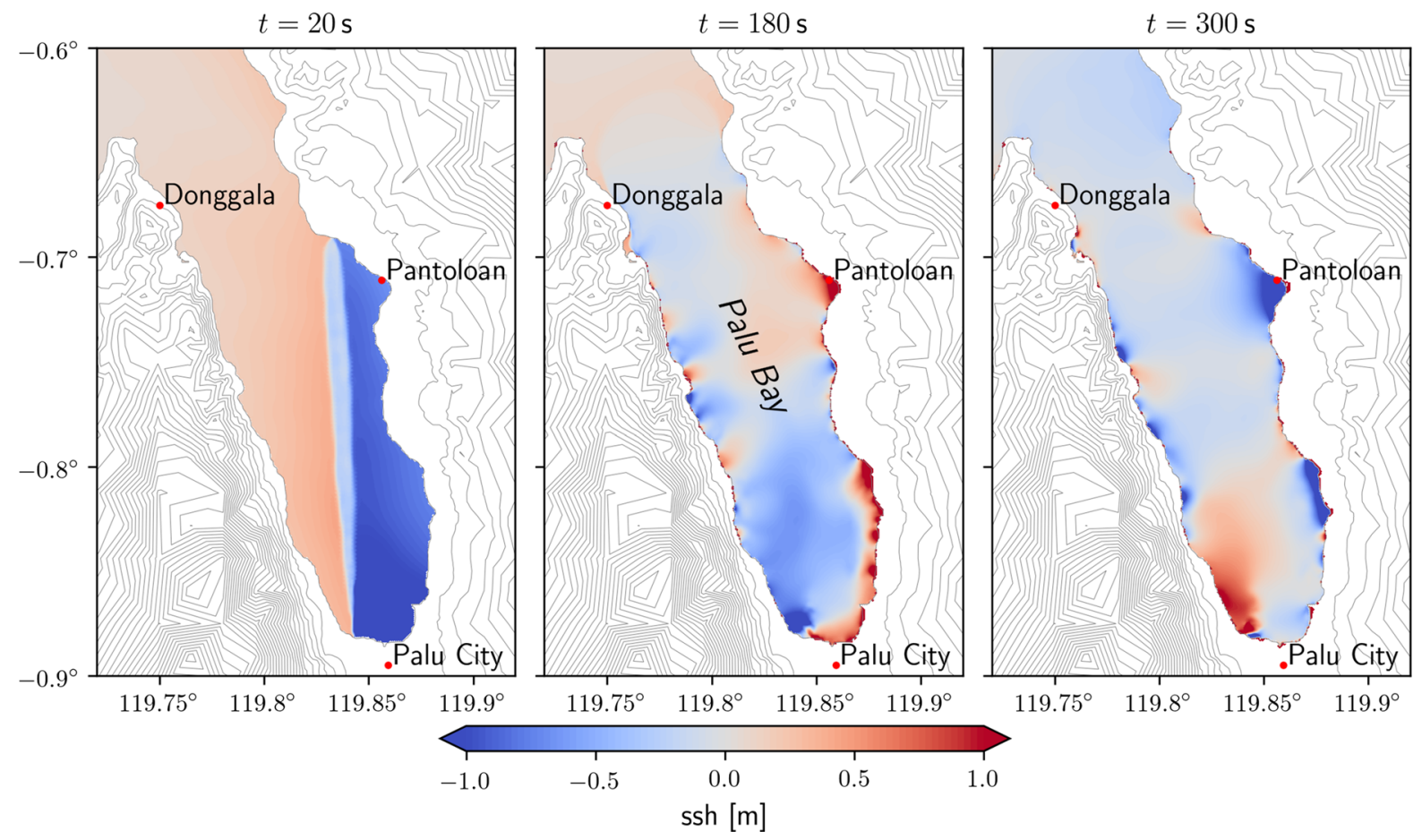

Figure 25

Snapshots at $20 \mathrm{~s}, 180 \mathrm{~s}$, and $300 \mathrm{~s}$ of the tsunami scenario using only the vertical displacement $\Delta z$ from the rupture simulation as the source for the tsunami model

(Sect. 4.2). Despite limited resolution, the qualitative analysis of inundation behavior across the Bay yields valuable insights on the interplay of tsunami waves and (smoothed) nearshore topography.

\subsection{Animations}

Three animations illustrating the earthquake and tsunami scenario are provided. The animations can be downloaded at https://doi.org/10.5281/zenodo. 3233885. The earthquake animations show the absolute slip rate $(\mathrm{m} / \mathrm{s})$ across the fault network during the model earthquake, with (https://zenodo. org/record/3233885/files/movie_Sulawesi_wavefieldcp.mov) and without (https://zenodo.org/record/

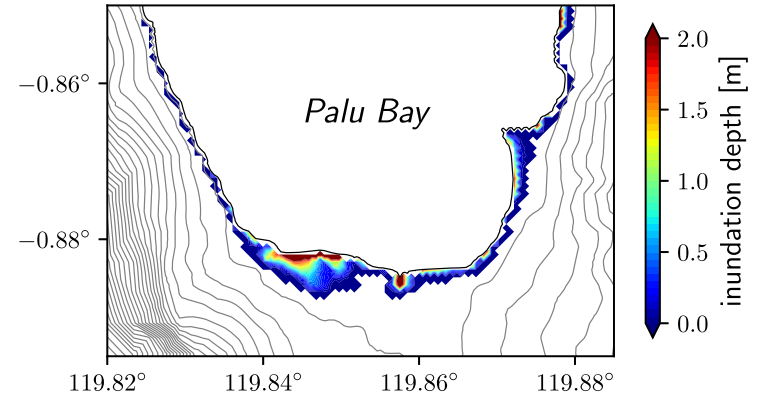

Figure 26

Computed maximum inundation at Palu City using only the vertical displacement $\Delta z$ from the rupture simulation as the source for the tsunami model 


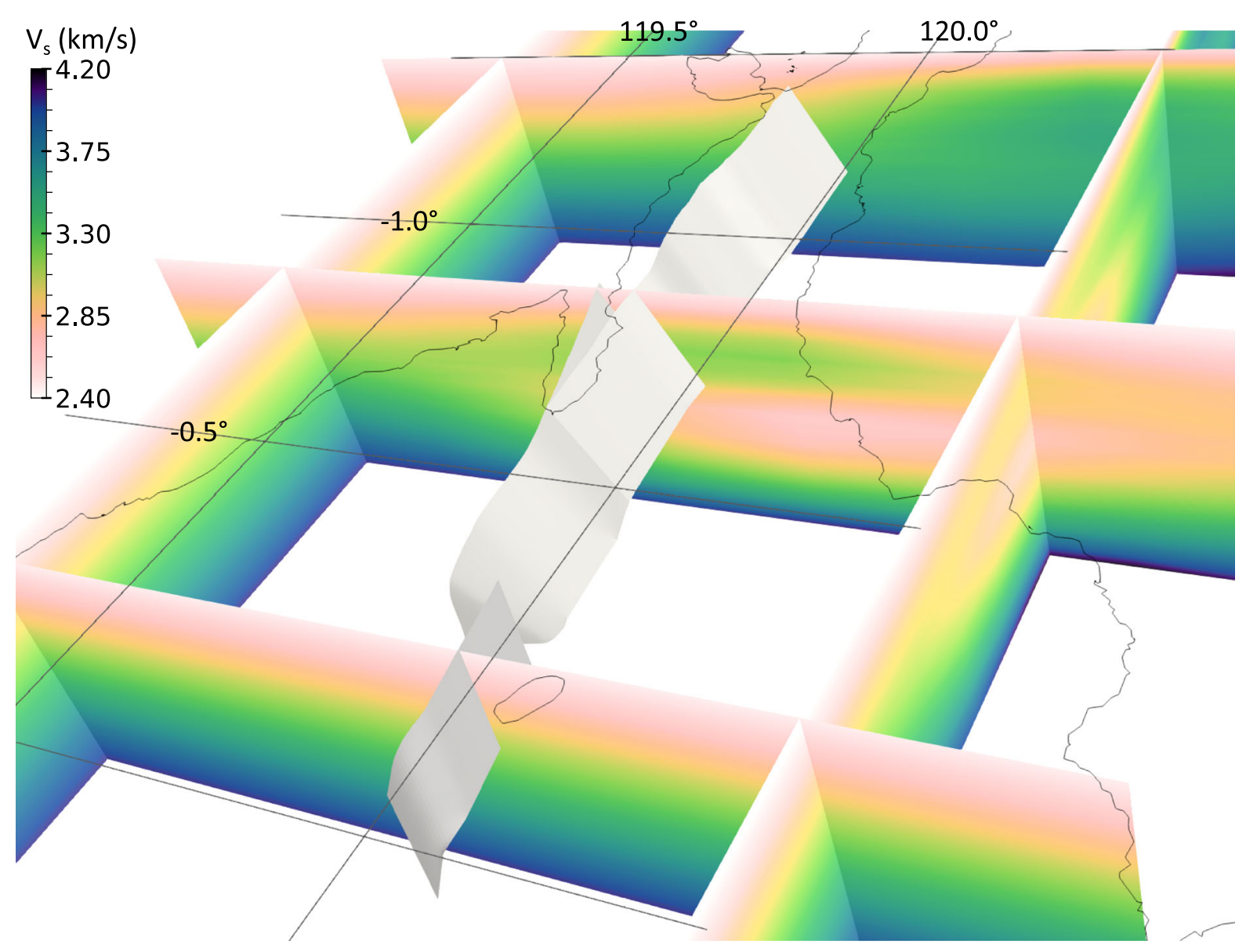

Figure 27

S-wave speeds $\left(V_{s}\right)$ on five cross-sections of the 3D subsurface structure of Awaliah et al. (2018), incorporated into the model

3233885/files/movie_Sulawesi_SR-cp.mov) the seismic wavefield (absolute particle velocity in $\mathrm{m} / \mathrm{s}$ ). The tsunami animation (https://zenodo.org/record/ 3233885/files/SulawesiTanioka.mp4) shows the evolution with time of the sea surface height $(\mathrm{m})$ as predicted by the tsunami scenario.

\subsection{Code and Data Availability}

For the earthquake modeling, we use the opensource software SeisSol (master branch, version tag
201905_Palu), which is available on GitHub (http:// www.github.com/seissol/seissol). The procedure to download, compile, and run the code is described in the documentation (https://seissol.readthedocs.io). All data required to reproduce the earthquake scenario can be downloaded from https://zenodo.org/ record/3234664. We use the following projection: DGN95 / Indonesia TM-3 zone 51.1 (EPSG:23839). 
EW

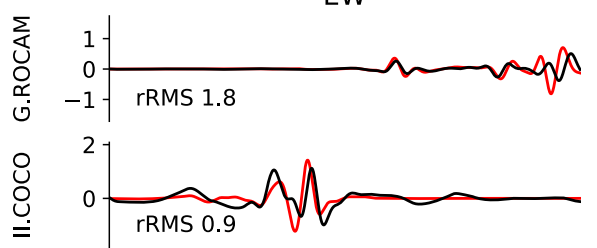

$\stackrel{\vec{z}}{=} \begin{array}{r}0.5 \\ 0.0\end{array}-0.5-{ }_{\text {rRMS } 1.4}$

$-1.0$

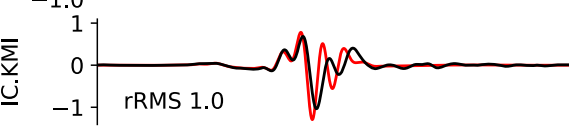

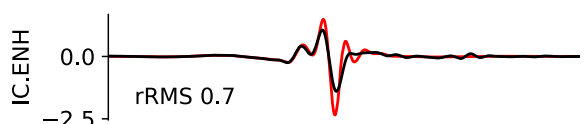

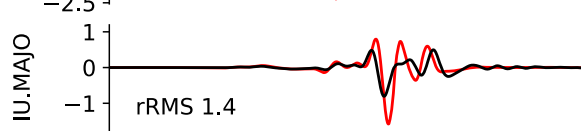

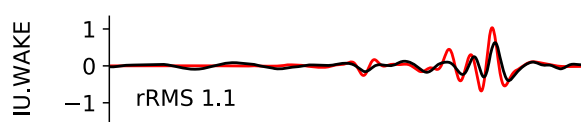
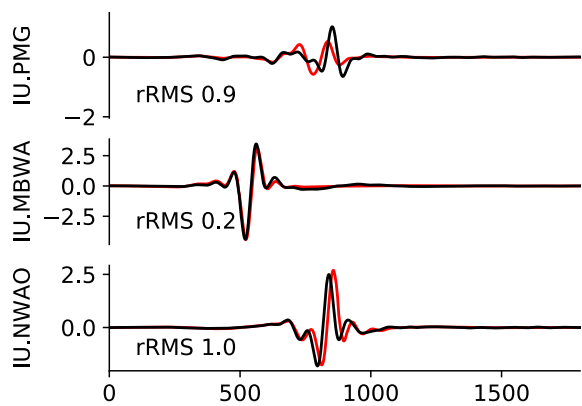

NS

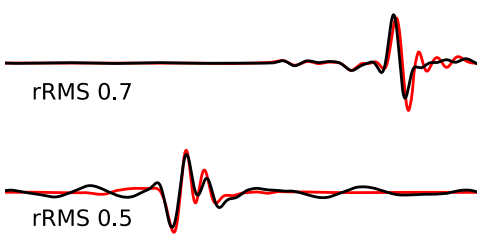

rRMS 1.2
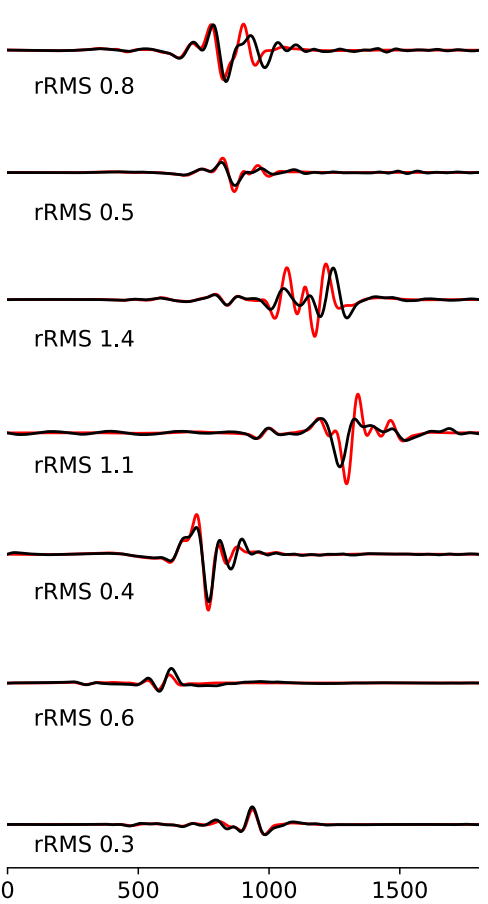

UD
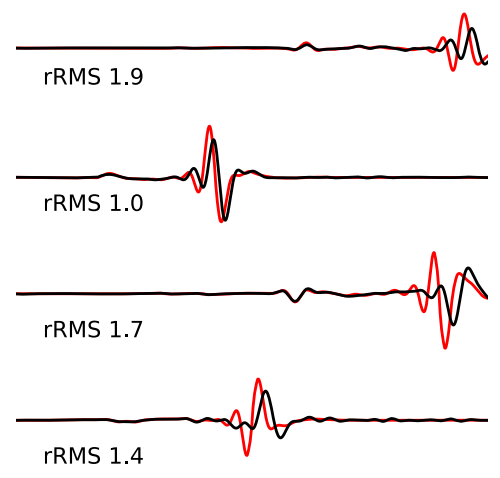

rRMS 1.8
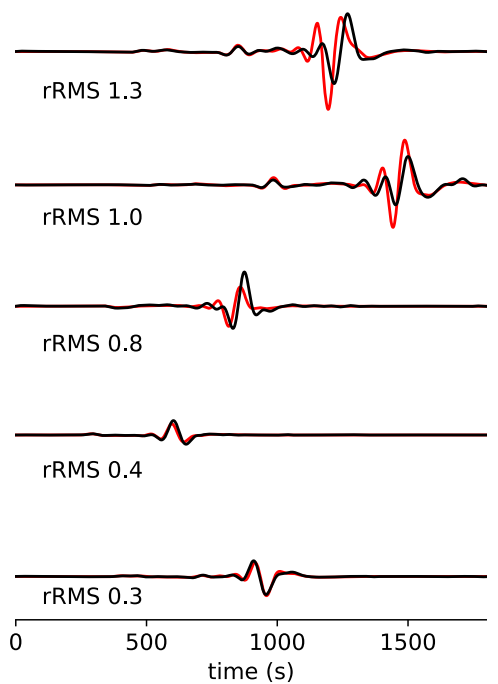

Figure 28

Comparison of modeled (red) and observed (black) teleseismic displacement waveforms at the 10 stations identified by blue triangles in Fig. 5. Full seismograms are dominated by surface waves. For more information, please refer to the caption of Fig. 4 

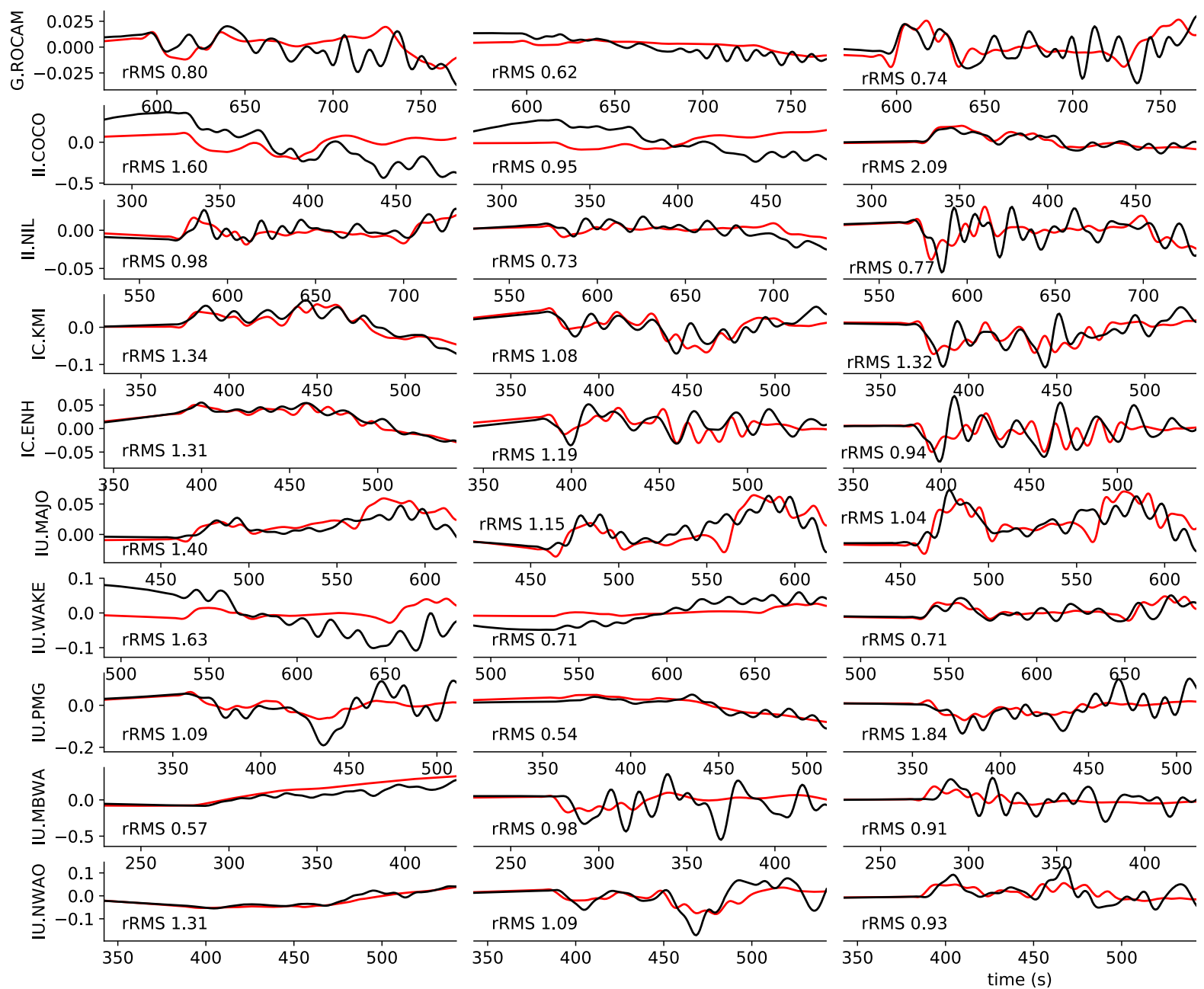

Figure 29

Comparison of modeled (red) and observed (black) teleseismic displacement waveforms at the 10 stations identified by blue triangles in Fig. 5. Zoom in to body wave arrivals. For more information, please refer to the caption of Fig. 4 


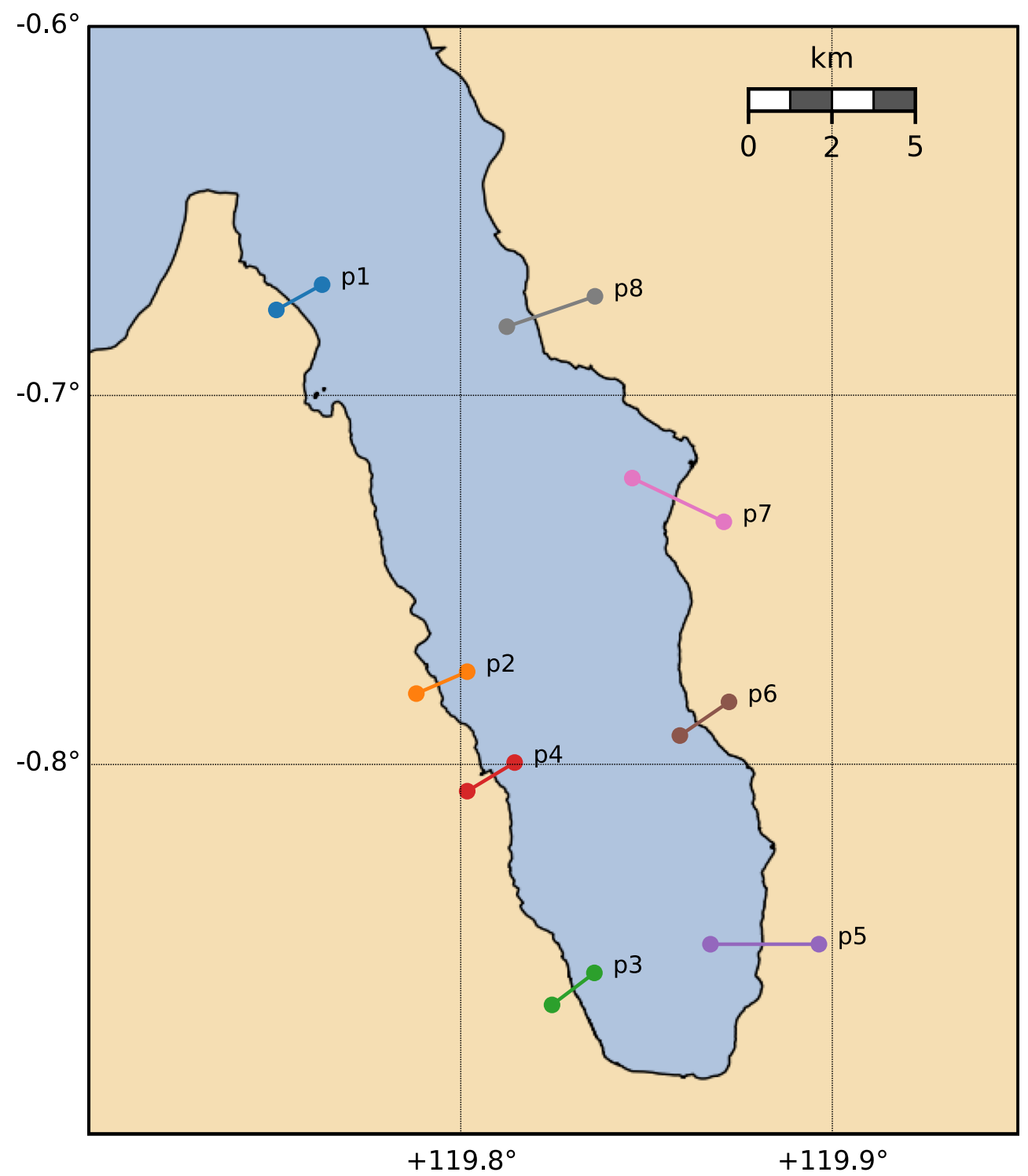

Figure 30

Locations of 8 sections across the shoreline across which the topography of the $8 \mathrm{~m}$ resolution DEMNAS data set and the $190 \mathrm{~m}$ sampled BATNAS bathymetry and topography data set are compared in Fig. 31 

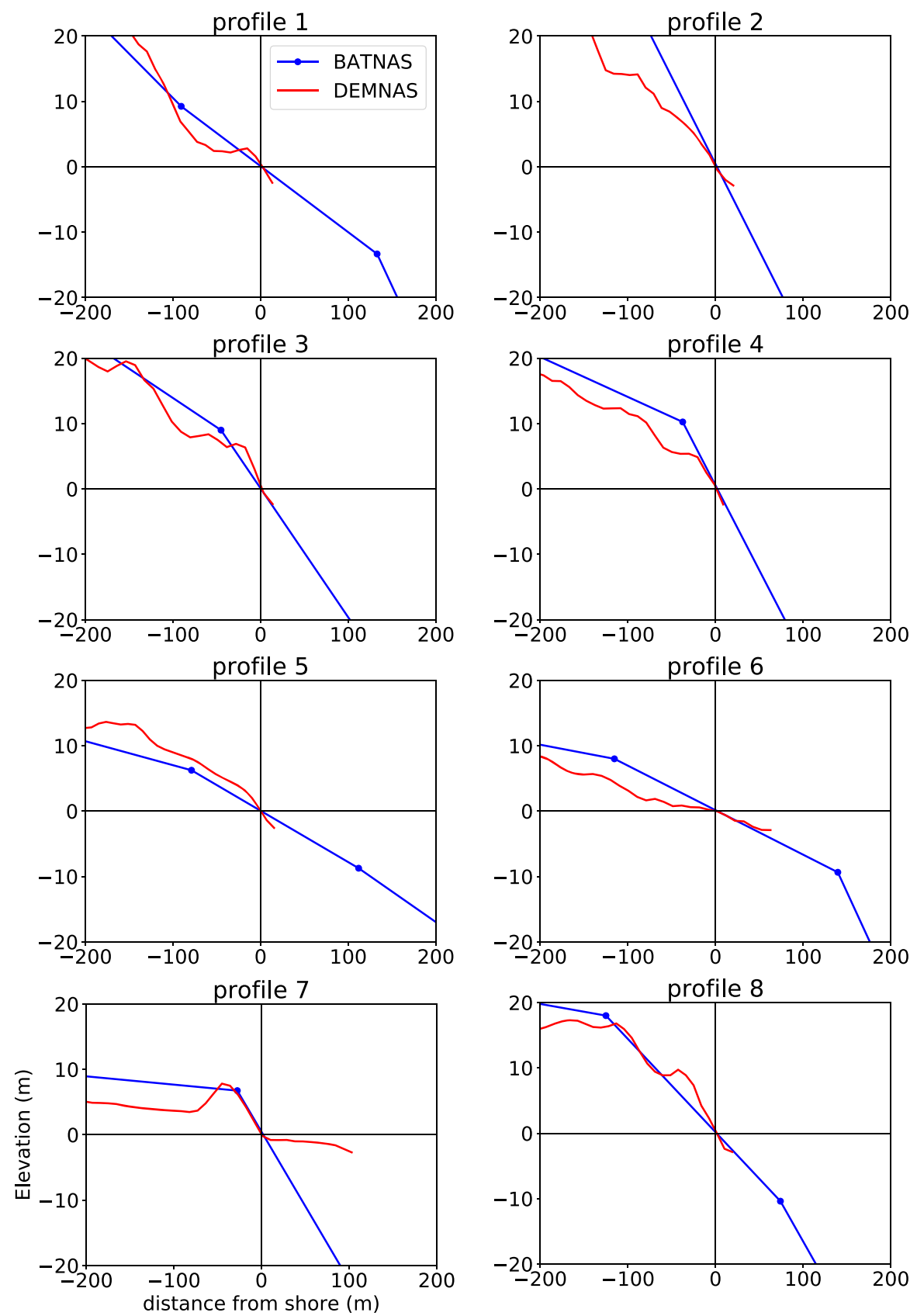

Figure 31

Topography and bathymetry profiles of BATNAS and DEMNAS data sets across the 8 sections of Fig. 30. Profiles are aligned with respect to the shoreline to facilitate comparison 
Publisher's Note Springer Nature remains neutral with regard to jurisdictional claims in published maps and institutional affiliations.

\section{REFERENCES}

Andrews, D. (1976). Rupture velocity of plane strain shear cracks. Journal of Geophysical Research, 81(32), 5679-5687. https:// doi.org/10.1029/JB081i032p05679.

Aochi, H., \& Madariaga, R. (2003). The 1999 Izmit, Turkey, earthquake: Nonplanar fault structure, dynamic rupture process, and strong ground motion. Bulletin of the Seismological Society of America, 93(3), 1249-1266. https://doi.org/10.1785/ 0120020167.

Aochi, H., Douglas, J., \& Ulrich, T. (2017). Stress accumulation in the Marmara Sea estimated through ground-motion simulations from dynamic rupture scenarios: Stress Accumulation in the Marmara Sea. Journal of Geophysical Research: Solid Earth, 122(3), 12219-2235. https://doi.org/10.1002/2016JB013790.

Argus, D. F., Gordon, R. G., \& DeMets, C. (2011). Geologically current motion of 56 plates relative to the no-net-rotation reference frame. Geochemistry, Geophysics, Geosystems. https://doi. org/10.1029/2011GC003751.

Awaliah, W. O., Yudistira, T., \& Nugraha, A. D. (2018). Identification of 3-d shear wave velocity structure beneath sulawesi island using ambient noise tomography method. In 10th ACES international workshop. http://quaketm.bosai.go.jp/ shiqing/ ACES2018/abstracts/aces_abstract_awaliah.pdf. Accessed 7 Aug 2019.

Bao, H., Ampuero, J. P., Meng, L., Fielding, E. J., Liang, C., Milliner, C. W. D., et al. (2019). Early and persistent supershear rupture of the 2018 magnitude 7.5 Palu earthquake. Nature Geoscience, 12, 200-205. https://doi.org/10.1038/s41561-0180297-z.

Bauer, A., Scheipl, F., Küchenhoff, H., \& Gabriel, A. A. (2017). Modeling spatio-temporal earthquake dynamics using generalized functional additive regression. In Proceedings of the 32nd international workshop on statistical modelling, vol. 2, pp. 146-149.

Behrens, J., \& Bader, M. (2009). Efficiency considerations in triangular adaptive mesh refinement. Philosophical Transactions of the Royal Society A: Mathematical, Physical and Engineering, 367(1907), 4577-4589. https://doi.org/10.1098/rsta.2009.0175.

Behrens, J., Rakowsky, N., Hiller, W., Handorf, D., Läuter, M., Päpke, J., et al. (2005). amatos: Parallel adaptive mesh generator for atmospheric and oceanic simulation. Ocean Modelling, 10(1-2), 171-183. https://doi.org/10.1016/j.ocemod.2004.06. 003.

Bellier, O., Sébrier, M., Seward, D., Beaudouin, T., Villeneuve, M., $\&$ Putranto, E. (2006). Fission track and fault kinematics analyses for new insight into the Late Cenozoic tectonic regime changes in West-Central Sulawesi (Indonesia). Tectonophysics, 413(3-4), 201-220. https://doi.org/10.1016/j.tecto.2005.10.036.

Beyreuther, M., Barsch, R., Krischer, L., Megies, T., Behr, Y., \& Wassermann, J. (2010). ObsPy: A Python toolbox for seismology. Seismological Research Letters, 81(3), 530-533. https://doi. org/10.1785/gssrl.81.3.530.
Bird, P. (2003). An updated digital model of plate boundaries. Geochemistry, Geophysics, Geosystems. https://doi.org/10.1029/ $2001 \mathrm{GC} 000252$.

Borrero, J. C., Legg, M. R., \& Synolakis, C. E. (2004). Tsunami sources in the southern California bight. Geophysical Research Letters, 31(L13), 211. https://doi.org/10.1029/2004GL020078.

Breuer, A., Heinecke, A., \& Bader, M. (2016). Petascale local time stepping for the ADER-DG finite element method. In 2016 IEEE international parallel and distributed processing symposium (IPDPS) (pp 854-863). Chicago, IL: IEEE. https://doi.org/10. 1109/IPDPS.2016.109

Breuer, A., Heinecke, A., Rettenberger, S., Bader, M., Gabriel, A. A., \& Pelties, C. (2014). Sustained Petascale performance of seismic simulations with SeisSol on SuperMUC. In Supercomputing. ISC 2014. Lecture Notes in Computer Science (vol. 8488, pp. 1-18). Cham: Springer. https://doi.org/10.1007/978-3-31907518-1_1.

Burridge, R. (1973). Admissible speeds for plane-strain self-similar shear cracks with friction but lacking cohesion. Geophysical Journal International, 35(4), 439-455. https://doi.org/10.1111/j. 1365-246X.1973.tb00608.x.

Carvajal, M., Araya-Cornejo, C., Sepúlveda, I., Melnick, D., \& Haase, J. S. (2018). Nearly instantaneous tsunamis following the Mw 7.5 2018 palu earthquake. Geophysical Research Letters. https://doi.org/10.1029/2019g1082578.

D’Acquisto, M., Dal Zilio, L., van Dinther, Y., Molinari, I., Gerya, T., \& Kissling, E. (2018). Modelling tectonics and seismicity due to slab retreat along the northern apennines thrust belt. In $A G U$ fall meeting 2018. https://agu.confex.com/agu/fm18/meetingapp. cgi/Paper/431867. Accessed 7 Aug 2019.

Dal Zilio, L., van Dinther, Y., Gerya, T., \& Pranger, C. (2018). Seismic behaviour of mountain belts controlled by plate convergence rate. Earth and Planetary Science Letters, 482, 81-92. https://doi.org/10.1016/j.eps1.2017.10.053.

Dal Zilio, L., van Dinther, Y., Gerya, T., \& Avouac, J. (2019). Bimodal seismicity in the himalaya controlled by fault friction and geometry. Nature Communications, 10, 48. https://doi.org/ 10.1038/s41467-018-07874-8.

Daryono, M. R. (2018). Paleoseismologi Tropis Indonesia (Dengan Studi Kasus Di Sesar Sumatra, Sesar Palukoro-Matano, Dan Sesar Lembang). http://docplayer.info/111161004Paleoseismologi-tropis-indonesia-dengan-studi-kasus-di-sesarsumatra-sesar-palukoro-matano-dan-sesar-lembang-disertasi. html. Accessed 7 Aug 2019.

de la Puente, J., Ampuero, J. P., \& Käser, M. (2009). Dynamic rupture modeling on unstructured meshes using a discontinuous Galerkin method. Journal of Geophysical Research: Solid Earth. https://doi.org/10.1029/2008JB006271.

De Michele, M. (2019). Subpixel offsets of copernicus sentinel 2 data, related to the displacement field of the sulawesi earthquake (2018, $M_{w}$ 7.5). https://doi.org/10.5281/zenodo.2573936.

DEMNAS. (2018). Seamless digital elevation model (DEM) dan batimetri nasional. Badan Informasi Geospasial. http://tides.big. go.id/DEMNAS. Accessed 1 Oct 2018.

Di Toro, G., Han, R., Hirose, T., De Paola, N., Nielsen, S., Mizoguchi, K., et al. (2011). Fault lubrication during earthquakes. Nature, 471(7339), 494-498. https://doi.org/10.1038/ nature09838.

Dumbser, M., \& Käser, M. (2006). An arbitrary high-order discontinuous Galerkin method for elastic waves on unstructured meshes-II. The three-dimensional isotropic case. Geophysical 
Journal International, 167(1), 319-336. https://doi.org/10.1111/ j.1365-246X.2006.03120.x.

Dunham, E. M. (2007). Conditions governing the occurrence of supershear ruptures under slip-weakening friction. Journal of Geophysical Research: Solid Earth. https://doi.org/10.1029/ $2006 J B 004717$.

Dunham, E. M., Belanger, D., Cong, L., \& Kozdon, J. E. (2011). Earthquake ruptures with strongly rate-weakening friction and off-fault plasticity, Part 1: Planar faults. Bulletin of the Seismological Society of America, 101(5), 2296-2307. https://doi.org/ 10.1785/0120100075.

Fichtner, A., van Herwaarden, D. P., Afanasiev, M., Simute, S., Krischer, L., Cubuk-Sabuncu, Y., et al. (2018). The collaborative seismic earth model: Generation 1. Geophysical Research Letters, 45(9), 4007-4016. https://doi.org/10.1029/2018GL077338.

Gabriel, A. A., Ampuero, J. P., Dalguer, L. A., \& Mai, P. M. (2012). The transition of dynamic rupture styles in elastic media under velocity-weakening friction. Journal of Geophysical Research: Solid Earth. https://doi.org/10.1029/2012JB009468.

Gabriel, A. A., Ampuero, J. P., Dalguer, L. A., \& Mai, P. M. (2013). Source properties of dynamic rupture pulses with offfault plasticity. Journal of Geophysical Research: Solid Earth, 118(8), 4117-4126. https://doi.org/10.1002/jgrb.50213.

Gabriel, A. A., Behrens, J., Bader, M., van Dinther, Y., Gunawan, T., Madden, E. H., et al. (2018). S21E-0492: Coupled seismic cycle-Earthquake dynamic rupture-Tsunami models. In $A G U$ fall meeting 2018, Washington, D.C. https://agu.confex.com/agu/ fm18/meetingapp.cgi/Paper/453669. Acceseed 7 Aug 2019.

Gallovič, F., Valentová, L., Ampuero, J.-P., \& Gabriel, A.-A. (2019a). Bayesian Dynamic Finite-Fault Inversion: 1. Method and Synthetic Test. Journal of Geophysical Research: Solid Earth. https://doi.org/10.1029/2019JB017510.

Gallovič, F., Valentová, L., Ampuero, J.-P., \& Gabriel, A.-A. (2019b). Bayesian Dynamic Finite-Fault Inversion: 2. Application to the $2016 M_{w} 6.2$ Amatrice, Italy, Earthquake. Journal of Geophysical Research: Solid Earth. https://doi.org/10.1029/ 2019JB017512.

GEBCO. (2015). The GEBCO_2014 Grid, version 20150318.

Geist, E. L., \& Parsons, T. (2005). Triggering of tsunamigenic aftershocks from large strike-slip earthquakes: Analysis of the November $2000 \mathrm{New}$ Ireland earthquake sequence. Geochemistry, Geophysics, Geosystems. https://doi.org/10.1029/ 2005 GC000935.

Harig, S., Chaeroni, Pranowo W. S., \& Behrens, J. (2008). Tsunami simulations on several scales: Comparison of approaches with unstructured meshes and nested grids. Ocean Dynamics, 58, 429-440. https://doi.org/10.1007/s10236-008-0162-5.

Harris, R. A., Barall, M., Andrews, D., Duan, B., Ma, S., Dunham, E., et al. (2011). Verifying a computational method for predicting extreme ground motion. Seismological Research Letters, 82(5), 638-644. https://doi.org/10.1785/gssrl.82.5.638.

Harris, R. A., Barall, M., Aagaard, B., Ma, S., Roten, D., Olsen, K., et al. (2018). A suite of exercises for verifying dynamic earthquake rupture codes. Seismological Research Letters, 89(3), 1146-1162. https://doi.org/10.1785/0220170222.

Heidarzadeh, M., Muhari, A., \& Wijanarto, A. B. (2018). Insights on the source of the 28 september 2018 sulawesi tsunami, Indonesia based on spectral analyses and numerical simulations. Pure and Applied Geophysics. https://doi.org/10.1007/s00024018-2065-9.
Heidbach, O., Rajabi, M., Cui, X., Fuchs, K., Müller, B., Reinecker, J., et al. (2018). The World Stress Map database release 2016: Crustal stress pattern across scales. Tectonophysics, 744 , 484-498. https://doi.org/10.1016/J.TECTO.2018.07.007.

Heinecke, A., Breuer, A., Rettenberger, S., Bader, M., Gabriel, A. A., Pelties, C., et al. (2014). Petascale high order dynamic rupture earthquake simulations on heterogeneous supercomputers. In SC14: International conference for high performance computing, networking, atorage and analysis (pp. 3-14). IEEE. https://doi. org/10.1109/SC.2014.6.

IPGP. (2018). http://geoscope.ipgp.fr/index.php/en/catalog/ earthquake-description?seis=us1000h3p4. Accessed 1 Oct 2018.

Jeschke, A., Pedersen, G. K., Vater, S., \& Behrens, J. (2017). Depth-averaged non-hydrostatic extension for shallow water equations with quadratic vertical pressure profile: Equivalence to Boussinesq-type equations. International Journal for Numerical Methods in Fluids, 84(10), 569-583. https://doi.org/10.1002/fld. 4361.

Kolecka, N., \& Kozak, J. (2014). Assessment of the accuracy of SRTM C- and X-Band high mountain elevation data: A case study of the polish tatra mountains. Pure and Applied Geophysics, 171(6), 897-912. https://doi.org/10.1007/s00024-0130695-5.

Krischer, L., Hutko, A. R., van Driel, M., Stähler, S., Bahavar, M., Trabant, C., et al. (2017). On-demand custom broadband synthetic seismograms. Seismological Research Letters, 88(4), 1127-1140. https://doi.org/10.1785/0220160210.

Legg, M. R., \& Borrero, J. C. (2001). Tsunami potential of major restraining bends along submarine strike-slip faults. In Proceedings of the international tsunami symposium 2001. NOAA/ PMEL, 1, pp. 331-342.

Legg, M. R., Borrero, J. C., \& Synolakis, C. E. (2003). Tsunami hazards from strike-slip earthquakes. American Geophysical Union, Fall Meeting 2003, abstract id OS21D-06. http://adsabs. harvard.edu/abs/2003AGUFMOS21D..06L. Accessed 7 Aug 2019.

Liang, C., \& Fielding, E. J. (2017). Interferometry with ALOS-2 full-aperture ScanSAR data. IEEE Transactions on Geoscience and Remote Sensing, 55(5), 2739-2750.

Liang, Q., \& Marche, F. (2009). Numerical resolution of wellbalanced shallow water equations with complex source terms. Advances in Water Resources, 32, 873-884. https://doi.org/10. 1016/j.advwatres.2009.02.010.

Liu, P. L. F., Barranco, I., Fritz, H. M., Haase, J. S., Prasetya, G. S., Qiu, Q., et al. (2018). What we do and don't know about the 2018 Palu Tsunami-A future plan. In AGU fall meeting 2018. https:// agu.confex.com/agu/fm18/meetingapp.cgi/Paper/476669. Accessed 7 Aug 2019.

Lotto, G. C., Dunham, E. M., Jeppson, T. N., \& Tobin, H. J. (2017a). The effect of compliant prisms on subduction zone earthquakes and tsunamis. Earth and Planetary Science Letters, 458, 213-222. https://doi.org/10.1016/j.epsl.2016.10.050.

Lotto, G. C., Nava, G., \& Dunham, E. M. (2017b). Should tsunami simulations include a nonzero initial horizontal velocity? Earth, Planets and Space, 69(1), 117. https://doi.org/10.1186/s40623017-0701-8.

Lotto, G. C., Jeppson, T. N., \& Dunham, E. M. (2018). Fully coupled simulations of megathrust earthquakes and tsunamis in the Japan trench, Nankai Trough, and Cascadia Subduction Zone. Pure and Applied Geophysics, 1, 1-33. https://doi.org/10.1007/ s00024-018-1990-y. 
Løvholt, F., Hasan, H., Lorito, S., Romano, F., Brizuela, B., Piatanesi, A., et al. (2018). Multiple source sensitivity study to model the 28 September Sulawesi tsunami - landslide and strike slip sources. In AGU fall meeting 2018, Washington, DC. https:// agu.confex.com/agu/fm18/meetingapp.cgi/Paper/476627. Accessed 7 Aug 2019.

Maeda, T., \& Furumura, T. (2013). FDM simulation of seismic waves, ocean acoustic waves, and tsunamis based on tsunamicoupled equations of motion. Pure and Applied Geophysics, 170(1-2), 109-127. https://doi.org/10.1007/s00024-011-0430-z.

Mai, P. M. (2019). Supershear tsunami disaster. Nature Geoscience, 12, 150-151. https://doi.org/10.1038/s41561-019-03088.

Mai, P. M., Schorlemmer, D., Page, M., Ampuero, J. P., Asano, K., Causse, M., et al. (2016). The earthquake-source inversion validation (SIV) project. Seismological Research Letters, 87(3), 690-708. https://doi.org/10.1785/0220150231.

Mansinha, L., \& Smylie, D. E. (1971). The displacement fields of inclined faults. Bulletin of the Seismological Society of America, 61(5), 1433-1440.

McAdoo, B. G., Richardson, N., \& Borrero, J. (2007). Inundation distances and run-up measurements from ASTER, QuickBird and SRTM data, Aceh coast, Indonesia. International Journal of Remote Sensing, 28(13-14), 2961-2975. https://doi.org/10.1080/ 01431160601091795.

Muhari, A., Imamura, F., Arikawa, T., Hakim, A. R., \& Afriyanto, B. (2018) Solving the puzzle of the september 2018 Palu, Indonesia, tsunami mystery: clues from the tsunami waveform and the initial field survey data. Journal of Disaster Research 13(Scientific Communication), sc20181108. https://doi.org/10. 20965/jdr.2018.sc20181108.

Oeser, J., Bunge, H. P., \& Mohr, M. (2006). Cluster design in the earth sciences: Tethys. International conference on high performance computing and communications (pp. 31-40). Berlin: Springer.

Okada, Y. (1985). Surface deformation due to shear and tensile faults in a half-space. Bulletin of the Seismological Society of America, 75(4), 1135.

Okal, E. A., Fritz, H. M., Synolakis, C. E., Borrero, J. C., Weiss, R., Lynett, P. J., et al. (2010). Field survey of the Samoa Tsunami of 29 September 2009. Seismological Research Letters, 81(4), 577-591. https://doi.org/10.1785/gssrl.81.4.577.

Okuwaki, R., Yagi, Y., \& Shimizu, K. (2018). rokuwaki/2018paluindonesia: v2.0. https://doi.org/10.5281/zenodo.1469007.

Omira, R., Dogan, G. G., Hidayat, R., Husrin, S., Prasetya, G., Annunziato, A., et al. (2019). The september 28th, 2018, tsunami In Palu-Sulawesi, Indonesia: a post-event field survey. Pure and Applied Geophysics, 176(4), 1379-1395. https://doi.org/10.1007/ s00024-019-02145-z.

Pelinovsky, E., Yuliadi, D., Prasetya, G., \& Hidayat, R. (1997). The 1996 Sulawesi Tsunami. Natural Hazards, 16(1), 29-38. https:// doi.org/10.1023/A:1007904610680.

Pelties, C., Puente, J., Ampuero, J. P., Brietzke, G. B., \& Käser, M. (2012). Three-dimensional dynamic rupture simulation with a high-order discontinuous Galerkin method on unstructured tetrahedral meshes. Journal of Geophysical Research: Solid Earth. https://doi.org/10.1029/2011JB008857.

Pelties, C., Gabriel, A. A., \& Ampuero, J. P. (2013). Verification of an ADER-DG method for complex dynamic rupture problems. Geoscientific Model Development Discussions, 6, 5981-6034. https://doi.org/10.5194/gmdd-6-5981-2013.
Pelties, C., Gabriel, A. A., \& Ampuero, J. P. (2014). Verification of an ADER-DG method for complex dynamic rupture problems. Geoscientific Model Development, 7(3), 847-866. https://doi.org/ 10.5194/gmd-7-847-2014.

Peyrat, S., Olsen, K., \& Madariaga, R. (2001). Dynamic modeling of the 1992 Landers earthquake. Journal of Geophysical Research: Solid Earth, 106(B11), 26,467-26,482. https://doi.org/ 10.1029/2001JB000205.

Power, W., Clark, K., King, D. N., Borrero, J., Howarth, J., Lane, E. M., et al. (2017). Tsunami runup and tide-gauge observations from the 14 november 2016 M7.8 Kaikōura earthquake, New Zealand. Pure and Applied Geophysics, 174(7), 2457-2473. https://doi.org/10.1007/s00024-017-1566-2.

Prasetya, G. S., De Lange, W. P., \& Healy, T. R. (2001). The Makassar Strait Tsunamigenic region, Indonesia. Natural Hazards, 24(3), 295-307. https://doi.org/10.1023/A: 1012297413280.

Preuss, S., Herrendörfer, R., Gerya, T., Ampuero, J., \& van Dinther, Y. (2019). Seismic and aseismic fault growth lead to different fault orientations. Journal of Geophysical Research: Solid Earth. https://doi.org/10.1029/2019JB017324.

Pribadi, S., Nugraha, J., Susanto, E., Chandra, Gunawan I., Haryono, T., \& Hery, I. (2018). Laporan pendahuluan gempabumi dan tsunami donggala-palu 2018 (Preliminary report on the Donggala-Palu 2018 earthquake and tsunami). Pers. comm.

Quantum GIS. (2013). Development team. Quantum GIS geographic information system. Open Source geospatial foundation project.

Rettenberger, S., Meister, O., Bader, M., \& Gabriel, A. A. (2016). Asagi: A parallel server for adaptive geoinformation. In Proceedings of the Exascale applications and software conference 2016, ACM, New York, NY, USA, EASC '16, pp. 2:1-2:9. https://doi.org/10.1145/2938615.2938618

Rosen, P. A., Gurrola, E., Sacco, G. F., \& Zebker, H. (2012). The insar scientific computing environment. In Synthetic aperture radar, 2012. EUSAR. 9th European conference on, VDE, pp. 730-733.

Ryan, K. J., Geist, E. L., Barall, M., \& Oglesby, D. D. (2015). Dynamic models of an earthquake and tsunami offshore Ventura, California. Geophysical Research Letters, 42(16), 6599-6606. https://doi.org/10.1002/2015GL064507.

Saito, T., \& Furumura, T. (2009). Three-dimensional simulation of tsunami generation and propagation: Application to intraplate events. Journal of Geophysical Research, 114(B2), B02,307. https://doi.org/10.1029/2007JB005523.

Sassa, S., \& Takagawa, T. (2019). Liquefied gravity flow-induced tsunami: first evidence and comparison from the 2018 Indonesia sulawesi earthquake and tsunami disasters. Landslides, 16(1), 195-200. https://doi.org/10.1007/s10346-018-1114-x.

SeisSol GitHub (2019). https://github.com/SeisSol/SeisSol. Accessed 7 Aug 2019.

SeisSol website (2019). https://www.seissol.org. Accessed 7 Aug 2019.

Sepulveda, I., Haase, J. S., Liu, P. L. F., Xu, X., Carvajal, M. (2018). On the contribution of co-seismic displacements to the 2018 Palu tsunami. In AGU Fall Meeting 2018. https://agu. confex.com/agu/fm18/meetingapp.cgi/Paper/476717. Accessed 7 Aug 2019.

Shimizu, K., Yagi, Y., Okuwaki, R., \& Fukahata, Y. (2019). Development of an inversion method to extract information on 
fault geometry from teleseismic data. https://doi.org/10.31223/ osf.io/q58t7.

Simons, W. J., Riva, R., Pietrzak, J., et al. (2018). Tsunami potential of the 2018 Sulawesi earthquake from GNSS constrained source mechanism. In AGU Fall Meeting 2018, Washington, D.C. https://agu.confex.com/agu/fm18/meetingapp. cgi/Paper/476730. Accessed 7 Aug 2019.

Socquet, A., Simons, W., Vigny, C., McCaffrey, R., Subarya, C., Sarsito, D., et al. (2006). Microblock rotations and fault coupling in SE Asia triple junction (Sulawesi, Indonesia) from GPS and earthquake slip vector data. Journal of Geophysical Research: Solid Earth. https://doi.org/10.1029/2005JB003963.

Socquet, A., Hollingsworth, J., Pathier, E., \& Bouchon, M. (2019). Evidence of supershear during the 2018 magnitude 7.5 Palu earthquake from space geodesy. Nature Geoscience, 12, 192-199. https://doi.org/10.1038/s41561-018-0296-0.

Song, X., Zhang, Y., Shan, X., Liu, Y., Gong, W., \& Qu, C. (2019). Geodetic observations of the $2018 \mathrm{Mw} 7.5$ Sulawesi earthquake and its implications for the kinematics of the Palu fault. Geophysical Research Letters, 46(8), 4212-4220. https://doi.org/10. 1029/2019GL082045.

Synolakis, C. E., Bernard, E. N., Titov, V. V., Kânoğlu, U., \& González, F. I. (2007). Standards, criteria, and procedures for NOAA evaluation of tsunami numerical models. Tech. Rep. NOAA Technical Memorandum OAR PMEL-135, NOAA/OAR/ PMEL.

Tanioka, Y., \& Satake, K. (1996). Tsunami generation by horizontal displacement of ocean bottom. Geophysical Research Letters, 23(8), 861-864. https://doi.org/10.1029/96GL00736.

Tanioka, Y., Yudhicara, Kususose T., Kathiroli, S., Nishimura, Y., Iwasaki, S. I., \& Satake, K. (2006). Rupture process of the 2004 great Sumatra-Andaman earthquake estimated from tsunami waveforms. Earth, Planets and Space, 58(2), 203-209. https:// doi.org/10.1186/BF03353379.

Ulrich, T., Gabriel, A. A., Ampuero, J. P., \& Xu, W. (2019). Dynamic viability of the $2016 \mathrm{Mw} 7.8$ Kaikōura earthquake cascade on weak crustal faults. Nature Communications, 10(1), 1213. https://doi.org/10.1038/s41467-019-09125-w.

Uphoff, C., Rettenberger, S., Bader, M., Madden, E., Ulrich, T., Wollherr, S., \& Gabriel, A. A. (2017). Extreme scale multiphysics simulations of the tsunamigenic 2004 sumatra megathrust earthquake. In Proceedings of the international conference for high performance computing, networking, storage and analysis, SC 2017. https://doi.org/10.1145/3126908.3126948

USGS. (2018a). https://earthquake.usgs.gov/earthquakes/ eventpage/us1000h3p4/moment-tensor. Accessed 7 Aug 2019.

USGS. (2018b). https://earthquake.usgs.gov/earthquakes/ eventpage/us1000h3p4/finite-fault. Accessed 7 Aug 2019.

Valkaniotis, S., Ganas, A., Tsironi, V., \& Barberopoulou, A. (2018). A preliminary report on the M7.5 Palu 2018 earthquake co-seismic ruptures and landslides using image correlation techniques on optical satellite data. https://doi.org/10.5281/ zenodo.1467128, report submitted to EMSC.

Vallée, M., Charléty, J., Ferreira, A. M. G., Delouis, B., \& Vergoz, J. (2011). SCARDEC: a new technique for the rapid determination of seismic moment magnitude, focal mechanism and source time functions for large earthquakes using body-wave deconvolution. Geophysical Journal International, 184(1), 338-358. https://doi.org/10.1111/j.1365-246X.2010.04836.x.

van Dinther, Y., Gerya, T., Dalguer, L., Mai, P., Morra, G., \& Giardini, D. (2013). The seismic cycle at subduction thrusts:
Insights from seismo-thermo-mechanical models. Journal Geophysical Research, 118, 6183-6202. https://doi.org/10.1002/ 2013JB010380.

van Dinther, Y., Mai, P. M., Dalguer, L. A., \& Gerya, T. V. (2014). Modeling the seismic cycle in subduction zones: The role and spatiotemporal occurrence of off-megathrust events. Geophysical Research Letters, 41(4), 1194-1201. https://doi.org/10.1002/ 2013 GL058886.

van Dongeren, A., Vatvani, D., \& van Ormondt, M. (2018). Simulation of 2018 tsunami along the coastal areas in the palu bay. In AGU fall meeting 2018. https://agu.confex.com/agu/fm18/ meetingapp.cgi/Session/66627. Accessed 7 Aug 2019.

van Zelst, I., Wollherr, S., Gabriel, A. A., Madden, E., \& van Dinther, Y. (2019). Modelling coupled subduction and earthquake dynamics. https://doi.org/10.31223/osf.io/f6ng5.

Vater, S., \& Behrens, J. (2014). Well-balanced inundation modeling for shallow-water flows with Discontinuous Galerkin schemes. In J. Fuhrmann, M. Ohlberger, M., \& Rohde, C. (Eds). Finite volumes for complex applications VII-elliptic, parabolic and hyperbolic problems, Springer Proceedings in mathematics \& statistics, Vol. 78, pp. 965-973. https://doi.org/10.1007/978-3319-05591-6_98.

Vater, S., Beisiegel, N., \& Behrens, J. (2015). A limiter-based wellbalanced discontinuous galerkin method for shallow-water flows with wetting and drying: One-dimensional case. Advances in Water Resources, 85, 1-13. https://doi.org/10.1016/j.advwatres. 2015.08.008.

Vater, S., Beisiegel, N., \& Behrens, J. (2017). Comparison of wetting and drying between a RKDG2 method and classical FV based second-order hydrostatic reconstruction. In C. Cancès, \& P. Omnes (Eds.), Finite volumes for complex applications VIIIhyperbolic, elliptic and parabolic problems (pp. 237-245). Springer. https://doi.org/10.1007/978-3-319-57394-6_26.

Vater, S., Beisiegel, N., \& Behrens, J. (2019). A limiter-based wellbalanced discontinuous Galerkin method for shallow-water flows with wetting and drying: Triangular grids. International Journal for Numerical Methods in Fluids. https://doi.org/10.1002/fld. 4762.

Vigny, C., Perfettini, H., Walpersdorf, A., Lemoine, A., Simons, W., van Loon, D., et al. (2002). Migration of seismicity and earthquake interactions monitored by GPS in SE Asia triple junction: Sulawesi, Indonesia. Journal of Geophysical Research: Solid Earth, 107(B10), ETG-7. https://doi.org/10.1029/ 2001JB000377.

Walpersdorf, A., Rangin, C., \& Vigny, C. (1998). GPS compared to long-term geologic motion of the north arm of Sulawesi. Earth and Planetary Science Letters, 159(1), 47-55. https://doi.org/10. 1016/S0012-821X(98)00056-9.

Watkinson, I. M., \& Hall, R. (2017). Fault systems of the eastern Indonesian triple junction: Evaluation of Quaternary activity and implications for seismic hazards. Geological Society, London, Special Publications, 441(1), 71-120. https://doi.org/10.1144/ SP441.8.

Weatherall, P., Marks, K. M., Jakobsson, M., Schmitt, T., Tani, S., Arndt, J. E., et al. (2015). A new digital bathymetric model of the world's oceans. Earth and Space Science, 2(8), 331-345. https:// doi.org/10.1002/2015EA000107.

Widiyanto, W., Santoso, P. B., Hsiao, S. C., \& Imananta, R. T. (2019). Post-event Field Survey of 28 September 2018 Sulawesi Earthquake and Tsunami. Natural Hazards and Earth System 
Sciences Discussions, 1, 1-23. https://doi.org/10.5194/nhess2019-91.

Wollherr, S., Gabriel, A. A., \& Uphoff, C. (2018). Off-fault plasticity in three-dimensional dynamic rupture simulations using a modal Discontinuous Galerkin method on unstructured meshes: implementation, verification and application. Geophysical Journal International, 214(3), 1556-1584. https://doi.org/10.1093/ gji/ggy 213 .

Wollherr, S., Gabriel, A. A., \& Mai, P. M. (2019). Landers 1992 "reloaded": Integrative dynamic earthquake rupture modeling.
Journal of Geophysical Research: Solid Earth. https://doi.org/10. 1029/2018JB016355.

Yalciner, A. C., Hidayat, R., Husrin, S., Prasetya, G., Annunziato, A., Doğan, G. G., et al. (2018). The 28th September 2018 Palu earthquake and tsunami ITST 07-11 November 2018 post tsunami field survey report (short). Report, Middle East Technical University (and others), Ankara, Turkey. http://itic.ioc-unesco. org/images/stories/itst_tsunami_survey/itst_palu/ITST-Nov-711-Short-Survey-Report-due-on-November-23-2018.pdf. Accessed 7 Aug 2019.

(Received February 20, 2019, revised July 25, 2019, accepted July 27, 2019, Published online August 22, 2019) 